\title{
(ख)
}

AUTARQUIA ASSOCIADA À UNIVERSIDADE DE SÃO PAULO

\section{ANÁLISE DAS DIFERENÇAS BIOQUÍMICAS NOS TECIDOS E LESÕES TIREOIDIANAS POR IMAGEAMENTO ESPECTRAL OBTIDOS POR ESPECTROSCOPIA NO INFRAVERMELHO (FTIR)}

Thiago Martini Pereira

\author{
Tese apresentada como parte dos \\ requisitos para obtenção do Grau de \\ Doutor em Ciências na Área de Tecnologia \\ Nuclear - Materiais \\ Orientadora: \\ Profa. Dra. Denise Maria Zezell
}


INSTITUTO DE PESQUISAS ENERGÉTICAS E NUCLEARES

Autarquia associada à Universidade de São Paulo

\title{
ANÁLISE DAS DIFERENÇAS BIOQUÍMICAS NOS TECIDOS E LESÕES TIREOIDIANAS POR IMAGEAMENTO ESPECTRAL OBTIDOS POR ESPECTROSCOPIA NO INFRAVERMELHO (FTIR)
}

Thiago Martini Pereira

\author{
Tese apresentada como parte dos \\ requisitos para obtenção do Grau de \\ Doutor em Ciências na Área de Tecnologia \\ Nuclear - Materiais \\ Orientadora: \\ Profa. Dra. Denise Maria Zezell
}

\footnotetext{
Versão Original

Versão Original disponível no IPEN
}

São Paulo

2013 


\section{Dedicatória}

Aos meus pais, José Roberto e Maristela, por todo incentivo dado desde o começo da minha jornada acadêmica e por todos os ensinamentos de vida. 0

Ao meu irmão Matheus, pela amizade e companheirismo desde os tempos de criança. 


\section{Agradecimentas Especiais}

À minha orientadora Prof. Dra. Denise Maria Zezell, pela oportunidade de realizar este trabalho assim como por seu companheirismo e compreensão nos momentos difíceis enfrentados durante a realização desta tese.

Ao Prof. Dr. Max Diem, pela valiosa contribuição e orientação para o presente trabalho assim como pelas boas discussões sobre os resultados apresentados nesta tese.

À minha querida companheira Débora Picanço Aureliano, que sempre me apoiou carinhosamente nos momentos mais difíceis deste trabalho assim como na revisão finado texto e as longas discussões que ajudaram muito no desenvolvimento deste trabalho.

Agradeço carinhosamente a minha madrinha e super Tia Marilene pela a super ajuda na revisão desta tese além dos grandes ensinamentos de vida. 


\section{Agradecimentas}

À Universidade de São Paulo, e ao Instituto de Pesquisas Energéticas e Nucleares (IPEN - CNEN/SP).

Aos professores do Centro de Lasers e Aplicações (CLA) do IPEN por participarem desta etapa tão significativa de minha vida.

A todos os funcionários do Centro de Lasers e aplicações assim como os seguranças, pela presteza e tranquilidade com que sempre me atenderam.

Agradeço a Profa. Dra. Maria Lucia Zaidan Dagli por abrir as portas do laboratório e contribuir para realização deste trabalho.

Agradeço especialmente a amiga Profa. Dra. Patrícia da Ana pela grandiosa contribuição no desenvolvimento desta tese.

Agradeço especialmente ao Prof. Dr. Luciano Bachmann pelas frutíferas discussões que contribuirão para o desenvolvimento deste trabalho.

Agradeço ao Prof. Dr. Herculano Martinho pelas sugestões dadas no meu Seminário de área assim como na minha qualificação.

Agradeço especialmente também as grandes amizades que fiz durante meu estagio em Boston, Dr. Benjamin Bird e Dr. Milos Miljkovic pela grandiosa contribuiçao na discussão dos resultados deste trabalho.

Agradeço a Msc. Carolina Benetti pela valiosa ajuda na revisão desta tese.

Aos colegas do Centro de Lasers e Aplicações Carolina, Cassio, José Quinto, Moisés, Maíra, Viviane, Paulo, Marcelo, Leticia, Leandro, Thiago, Horacio, Patricia, Tania, Antonio, Danilo, Eliane, Alessandra, Claudio, Silvia, Renato,llka, Caetano, Camila. que sempre terão minha profunda admiração, gratidão e amizade. 
Ao CNPq pela concessão da bolsa de Doutorado (143166/2009-3), pelo projeto Universal (478865/2004-4) e Instituto Nacional de Fotônica (573.916/2008-0) que financiou a infraestrutura de informática e os microarrays.

À CAPES pelo projeto Procad (0349/05-4) que financiou o material de consumo assim como a bolsa sanduiche Capes/PSDE (9036-11-3) que me permitiu a colaboração frutífera com o Prof Dr Max Diem na Universidade Northeastern.

À FAPESP por meio do projeto CEPID - Centro de Pesquisa em Óptica e Fotônica (05/51689-2), pelo financiamento desta pesquisa.

A todos que, direta ou indiretamente, contribuíram para que este trabalho fosse realizado com sucesso. 
"A coisa mais bela que o homem pode experimentar é o mistério. É essa emoção fundamental que está na raiz de toda ciência e toda arte."

Albert Einsten 


\section{Sumário}

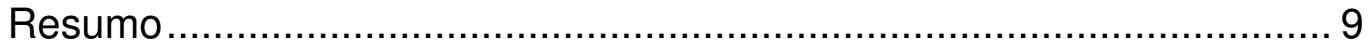

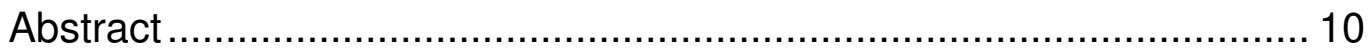

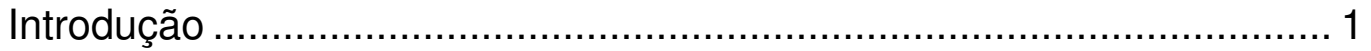

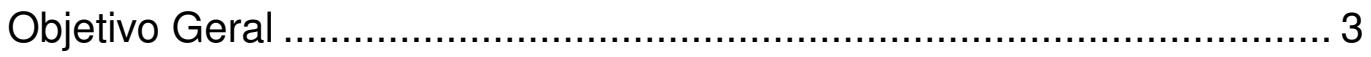

Objetivos Específicos .............................................................. 3

1. Revisão da Literatura ............................................................ 4

1.1 Espectroscopia no infravermelho $(\mathrm{IR}) \ldots \ldots \ldots \ldots \ldots \ldots \ldots \ldots \ldots \ldots \ldots \ldots \ldots$

1.1.1 Teoria da espectroscopia no Infravermelho ....................... 5

1.1.2 Instrumentação - Transformada de Fourier no Infravermelho -

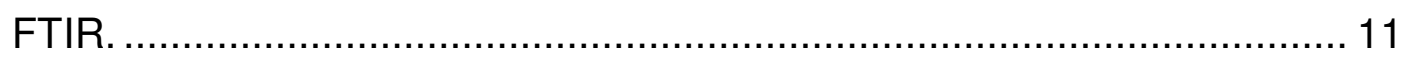

1.1.3 Espectroscopia no infravermelho de tecidos biológicos ......... 12

1.2 Distorções do espectro de absorção na região do Infravermelho em

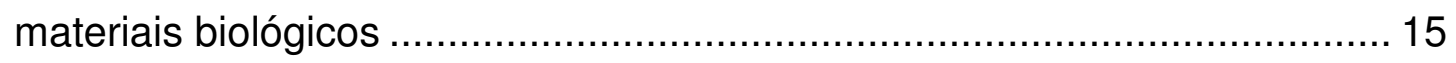

1.3 Pré-processamento dos dados de microespectroscopia FTIR .....20

1.3.1 Testes de qualidade ............................................... 21

1.3.2 Redução de ruído pela técnica NAPC -Noise Adjusted Principal Component ............................................................ 21

1.3.3 Correção de contribuições dispersivas. ........................... 24

1.4 Estatística multivariada aplicada a Espectroscopia ...................27

1.4.1 Análise por componentes principais................................ 28

1.4.2 Análise de Agrupamento ................................................ 31

1.5 Histologia da glândula da tireóide ...................................... 34

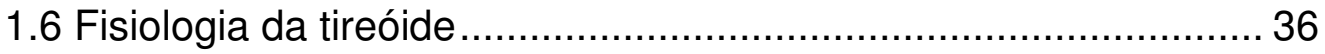

1.6.1 Formação dos hormônios.......................................... 37

1.6.2 Tiroglobulina ...................................................... 41

1.7 Neoplasia benignas da tireoide.......................................... 42 
1.7.1 Bocio $^{[5]}$

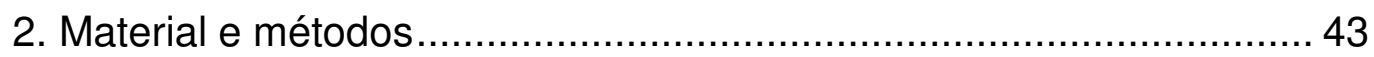

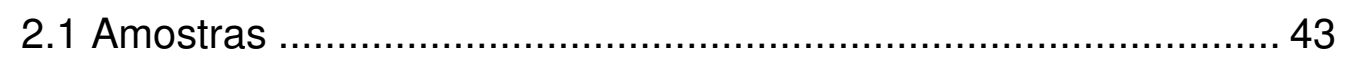

2.2 Aquisição dos espectros dos tecidos tireoidianos......................... 46

2.3 Pré - processamento dos espectros dos tecidos tireoidianos ....... 47

2.3.1 Remoção de pixels que não contêm amostra e/ou têm grande contribuição do espalhamento

2.3.2 Remoção de ruídos utilizando a técnica de NAPC (noise adjust principal components) 50

2.3.3 Restrição da região espectral entre $778-1800 \mathrm{~cm}^{-1}$ 51

2.3.4 Cálculos da segunda derivada utilizando o filtro Savitzky-Golay

2.3.5 Correção do espalhamento dos espectros utilizando a correção da fase 52

2.3.6 Normalização vetorial na região de $778 \mathrm{~cm}^{-1}-1800 \mathrm{~cm}^{-1} \ldots \ldots .52$

2.3.7 Imagens com pseudocores utilizando a técnica de agrupamento hierárquico (HCA) …...................................................... 53

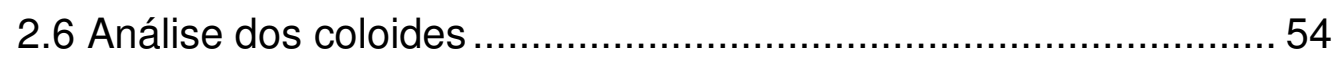

2.7 Hormônios tireoidianos sintéticos ................................................ 54

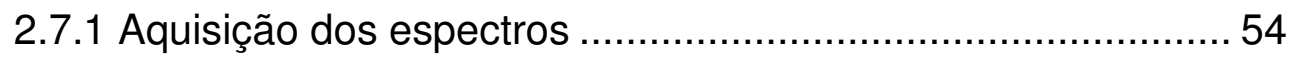

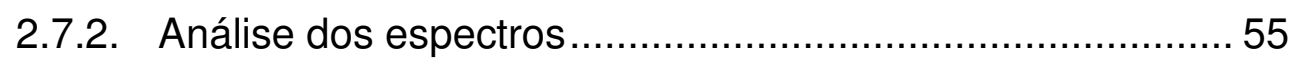

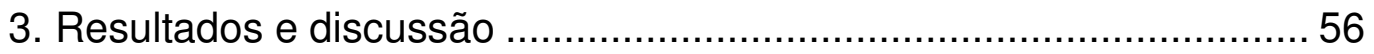

3.1 Dados espectrais dos hormônios tireoidianos ………………...... 56

3.2 Dados espectrais dos tecidos normais ........................................ 60

3.3 Dados espectrais dos tecidos com bócio nodular......................... 67

3.4 Dados espectrais dos Coloides. ……………………............... 73

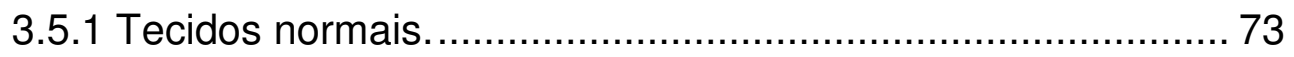


3.5.2 Bócio Nodular.

3.5.4 Comparação entre colóides normais e com bócio nodular

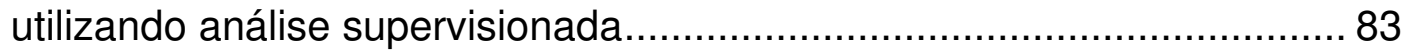

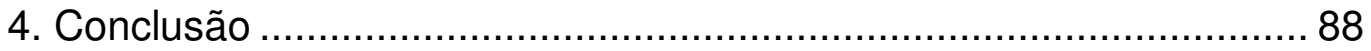

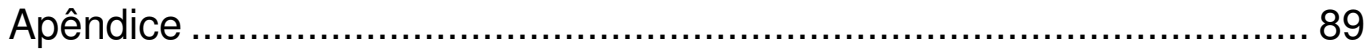

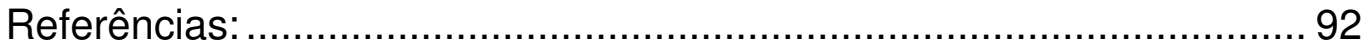

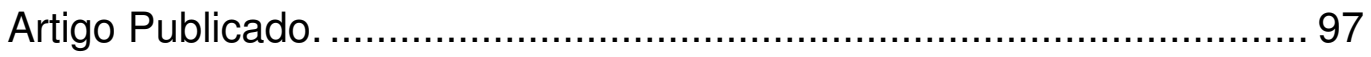




\title{
ANÁLISE DAS DIFERENÇAS BIOQUÍMICAS NOS TECIDOS E LESÕES TIREOIDIANAS POR IMAGEAMENTO ESPECTRAL NO INFRAVERMELHO (FTIR)
}

\author{
Thiago Martini Pereira
}

\section{RESUMO}

A tireoide é uma das principais glândulas do nosso sistema endócrino e responsável pela produção dos hormônios Triodotirosina (T3) e Tetraiodotironina (T4) que são responsáveis pelo controle metabólico basal. A tireoide pode ser acometida por neoplasias benignas e malignas que pode levar a uma produção anormal de hormônios e levando a sérios problemas de saúde. O diagnóstico de algumas destas neoplasias por citologia ainda não possuem altas taxas de sensibilidade e especificidade para os casos com padrão folicular, portanto o desenvolvimento de novos métodos que se baseiam na analise de características bioquímicas dos tecidos tireoidianos se faz necessário. O presente trabalho caracterizou tecidos tireoidianos normais e com bócio nodular por meio da espectroscopia no infravermelho. As imagens espectrais foram adquiridas com alta resolução e aliadas a um grande processamento das mesmas utilizando métodos de estatística multivariada se obteve diferenças bioquímicas dos tecidos. Nos resultados obtidos no presente trabalho, a maior diferença observada está na região da amida I que está relacionada a estrutura secundária da tiroglobulina devido ao processo de incorporação de iodo. Outras observações que foram feitas são diferenças em glicosilaçao do tipo N. A partir dos resultados obtidos nesta tese conclui-se que a técnica de imageamento por microespectroscopia no infravermelho é capaz de observar diferenças bioquímicas importantes entre tecidos tireoidianos sadios e com bócio, apresentando grande potencial para o desenvolvimento no futuro de novas metodologias, baseadas em espectroscopia vibracional. 


\section{ANALYSIS OF BIOCHEMICAL DIFFERENCES IN NORMAL AND LESIONED THYROID TISSUE BY INFRARED SPECTRAL IMAGING (FTIR)}

\section{Thiago Martini Pereira}

\section{ABSTRACT}

The thyroid is one of the major glands of endocrine system; it is responsible for the production triodothyronine(T3) and thyroxine (T4) hormones, which are responsible for metabolic basal control. The thyroid can be affected by benign and malignant lesions, that leads to increased hormone levels (hyperthyroidism) or reduce their production (hypothyroidism). This abnormal hormones production by the thyroid gland can lead to serious health problems. The present cytological diagnosis for these tumors do not present high level of sensitivity and specificity, thus the development of new methods based on the analysis of biochemical characteristics of the thyroid tissue is required. This study used the infrared spectroscopy to characterize normal thyroid tissue or tissue with nodular goiter. The spectral images were obtained with high resolution, and multivariate statistics analysis were used to observe biochemical tissues differences. The most remarkable difference observed was at the amide I region, which is related to the secondary structure of thyroglobulin, due to the process of incorporation of iodine. It was also observed differences in the $\mathrm{N}$ glycosylation. From the results of this study, it was possible conclude that the technique of infrared microspectroscopy and imaging is able to observe important biochemical differences between healthy thyroid tissue and goiter. 


\section{INTRODUÇÃO}

A glândula tireoide é uma das mais importantes do sistema endócrino. Ela secreta principalmente dois hormônios: Triodotirosina (T3) e Tetraiodotironina (T4), que são necessários para diversos processos fisiológicos tais como a homeostase e o controle da temperatura corpórea ${ }^{[1-3]}$. Ela está em constante estado de adaptação devido a diversos estados fisiológicos tais como: gravidez, lactação, puberdade ou em certos casos de estresse psicológico. Nestas situações, a tireoide se torna maior e mais ativa, seus folículos crescem e as células epiteliais tornam-se mais colunares ${ }^{[4,5]}$.

Histologicamente, a glândula tireoide consiste em uma fina camada de células epiteliais denominadas células foliculares, cuja principal função é produzir uma iodoglicoproteína, a tiroglobulina, que é precursora dos hormônios T3 e T4 ${ }^{[6]}$. Essa proteína é armazenada dentro dos folículos tireoidianos, em estruturas chamadas de colóides, até ser utilizada pelo organismo $^{[2]}$.

A síntese dos hormônios é um processo extremamente complexo e pode ser dividido em quatro etapas. As duas primeiras ocorrem dentro das células foliculares, são a síntese protéica e a glicosilação; as duas últimas são a iodinação e a conjunção, que ocorrem dentro dos colóides ${ }^{[1,2]}$.

A complexa ação dos hormônios tireoidianos pode ser abruptamente interrompida se a glândula for afetada por alguma neoplasia benigna ou maligna, e como consequência, a glândula começa a produzir uma grande quantidade de hormônio (hipertireoidismo) ou produzir uma baixa quantidade de hormônio (hipotireoidismo) ${ }^{[5]}$. Essa produção anormal de hormônios pela tireoide pode levar a sérios problemas de saúde, tais como, retardo do crescimento, doenças vasculares, disfunções pulmonares e renais, alterações no sistema neuromuscular, dentre outros ${ }^{[1]}$.

Existem diversos métodos para o diagnóstico da neoplasia da tireoide, sendo o exame de ultrassonográfica amplamente utilizado. O uso desta técnica 
representou um importante passo no diagnostico de nódulos de tireoide, tendo sido observado um aumentado de até $30 \%$ na prevalência de algumas neoplasias. [7], Entretanto a técnica de ultrassonografia é inespecífica na caracterização do nódulo, sendo necessária a realização de uma punção aspirativa por agulha fina (PAAF).

A PAAF é considerada o padrão ouro para o diagnóstico do nódulo de tireoide, entretanto esse método apresenta uma taxa de falso negativo de até $37 \%$ quando ultrasom não é utilizado ${ }^{[8]}$ para alguns tipos de neoplasias, tornando o diagnóstico difícil em alguns casos. Uma das razões para a alta taxa de falso negativo do método se deve ao inadequado posicionamento da agulha no momento da punção, que leva a remoção de uma pequena quantidade de células, tornando difícil a análise citologica desse material pelo patologista ${ }^{[9]}$. Entretanto, acredita-se que qualquer material residual da punção (por exemplo, colóides) contém informações bioquímicas valiosas, que podem levar a um diagnóstico correto.

O desenvolvimento de novos métodos de diagnóstico que consigam extrair informações bioquímicas do material residual da punção, assim como das células foliculares é de grande importância para a melhoria do diagnóstico. Neste contexto, a espectroscopia no infravermelho vem sendo utilizada para diagnósticos de diversas neoplasias tais como na mama ${ }^{[10-12]}$, no pulmão ${ }^{[13,14]}$, no intestino ${ }^{[15,16]}$ e na próstata ${ }^{[17]}$. O uso de técnicas espectroscopicas em diagnósticos, levou ao desenvolvimento da técnica chamada SHP (spectral histopathology), que consiste na combinação de micro espectroscopia vibracional com técnicas de análise multivariada ${ }^{[18]}$. A SHP é uma abordagem diferente, pois utiliza diferenças bioquímicas para o diagnóstico e/ou caracterização dos tecidos e células, enquanto histologia normal utiliza a luz visível e inspeção visual para detectar diferenças morfológicas do tecido. Portanto SHP tem a capacidade de detectar neoplasias em estágios muito iniciais, possibilitando maiores chances de cura e tratamentos menos agressivos. 


\section{OBJETIVO GERAL}

- Avaliar a potencialidade da técnica de imageamento por microespectroscopia FTIR na caracterização e diferenciação de tecido da glândula tireoide.

\section{OBJETIVOS ESPECÍFICOS}

- Desenvolvimento de uma metodologia para processamento dos mapas espectrais.

- Caracterização dos padrões bioquímicos encontrados no tecido tireoidiano normal e com bócio nodular.

- Obtenção de espectros dos hormônios tireoidianos assim como dos precursores dos hormônios.

- Analisar mudanças conformacionais da proteína e diferenças de glicosilação na proteína tiroglobulina.

- Avaliação da possibilidade da utilização de métodos supervisionados para futuro desenvolvimento de método de diagnóstico. 


\section{REVISÃO DA LITERATURA}

\subsection{Espectroscopia no infravermelho (IR) ${ }^{[19,20]}$}

A luz infravermelha foi descoberta por um cientista chamado Sir Willian Herschel por volta do ano de 1800. Ele estava fazendo experimentos com prisma de vidro, decompondo a luz visível e verificando o calor que cada um dos comprimentos de onda possuía, quando observou que ao passar da cor vermelha a quantidade de calor aumentava. Com isto, ele concluiu que existiam ondas eletromagnéticas que não eram perceptíveis aos nossos olhos. A continuidade deste trabalho pioneiro foi realizada por seus filhos Sir Willian e John Tendal por volta de 1840 a 1855. Esses trabalhos deram início as primeiras medidas de absorção na região do infravermelho. Ao final do século XIX a comunidade científica tinha apenas uma visão geral de que as bandas de absorção ou emissão estavam relacionadas com efeitos de ressonância envolvendo cargas dentro das moléculas.

Entretanto, nas primeiras décadas do século $X X$, com o grande progresso da teoria quântica, permitiu-se uma compreensão alternativa e mais aprofundada dos espectros moleculares. Esse progresso no novo campo da física colminou na década de 30 no desenvolvimento da equação de Schroedinger. Esta permitiu a obtenção de equações de onda para diversos modelos que confirmavam os dados experimentais de espectros de absorbância e de emissão na região do infravermelho médio. O sucesso na análise de espectros vibracionais e rotacionais, devido à recém formulada mecânica quântica, resultou na publicação de um livro abrangente sobre 0 tema intitulado "Molecular Spectra and Molecular Structure: infrared and raman spectra of polyatomic molecules".

Na década de 40 houve uma evolução na eletrônica permitindo avanços significativos em instrumentação que possibilitaram a aquisição mais fácil de espectros no infravermelho. Entretanto, o maior e mais importante avanço no desenvolvimento da instrumentação ocorreu na década de $70 \mathrm{com}$ a 
incorporação de computadores aos equipamentos. Isso permitiu a construção de espectrofotômetros baseados em interferometria, nos quais os dados de frequência são recuperados por meio da transformada de Fourier. Esses sistemas levaram a construção de espectrofotômetros menores e com maior resolução além de muito mais rápida aquisição de dados.

\subsubsection{Teoria da Espectroscopia no Infravermelho}

As interações entre uma onda eletromagnética e dipolos elétricos presentes nas moléculas podem ser descritas pela física clássica. Num modelo simples para moléculas diatômicas podem-se supor esferas rígidas ligadas por uma mola de constante elastica $k$. A lei de Hooke descreve a força de uma mola pela seguinte equação:

$$
F=-k x
$$

Equação 1

Onde: $\boldsymbol{k}$ é a constante elástica da mola, $\boldsymbol{x}$ é o deslocamento das massas a partir do ponto de equilíbrio.

$$
x=r-r_{e}
$$

Equação 2

Onde: $\boldsymbol{r}_{\boldsymbol{e}}$ é a posição de equilíbrio, $\boldsymbol{r}$ é a posição.

Suponhamos que temos dois átomos diferentes tendo massas $m_{1}$ e $m_{2}$. Logo, devido à interação entre as cargas de cada átomo, ocorrerá atração entre estes gerando um deslocamento relativo entre as cargas positivas e negativas o que leva a um momento de dipolo.

A definição de momento de dipolo é dado pelo produto da magnitude da carga elétrica de cada molécula e a distância entre os centros -de cargas negativas e positivas. O momento de dipolo é apresentado por um vetor $\vec{p}$, e ilustrado na figura abaixo. 


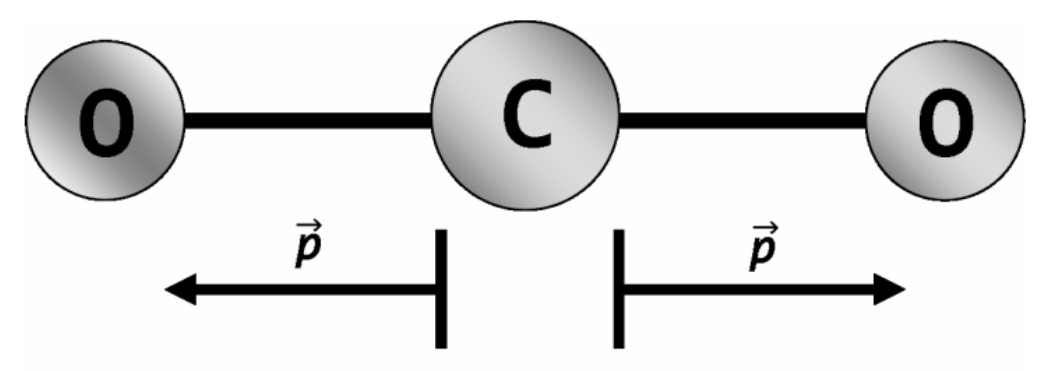

Figura 1: Diagrama esquemático de um momento de dipolo. ${ }^{[21]}$

Quando este momento de dipolo interage com campos elétricos oscilantes provenientes de uma onda eletromagnética poderá ocorrer deslocamento de massa de um átomo em relação ao outro. Entretanto, somente quando a frequência de oscilação do campo elétrico da radiação incidente coincidir com uma freqüência natural de vibração desta molécula haverá ressonância. Neste caso, a molécula vai absorver a radiação incidente e como conseqüência um aumento de vibração da molécula ocorrerá.

Para calcular os modos normais de vibração de uma molécula, consideramos que uma força de restauração de mola $\vec{F}$ é igual à força dada pela $2^{\underline{a}}$ lei de Newton. Então, temos uma equação diferencial de $2^{\underline{a}}$ ordem na qual a solução geral é dada por:

$$
v=\frac{1}{2 \pi} \sqrt{\frac{f}{\mu}}
$$

Equação 3

Onde: $\mu$ é massa reduzida, f é a frequência de oscilação e $v$ é oscilação em torno do ponto de equilíbrio.

A Equação 3 é a descrição clássica de um espectro vibracional de uma molécula diatômica simples. Portanto, quando se aplica este modelo para um conjunto de sistemas massa mola acoplados, haverá outros modos vibracionais resultantes do acoplamento de moléculas mais complexas. Uma observação importante a ser considerada é que rotações livres são possíveis somente no estado gasoso, enquanto vibrações acontecem em todos os estados da matéria. 
Esse modelo acima apresentado explica diversos aspectos da absorção tais como a necessidade de ter uma variação do momento de dipolo para haver acoplamento inclusive em moléculas poliatômicas. Apesar das contribuições dos modos rotacionais para o espectro estarem bem esclarecidas, a teoria clássica não explica as linhas discretas. Isto implica que a molécula só pode rotacionar em certos modos e não livremente.

Outro aspecto limitante da teoria clássica é o fato de que a energia potencial tende ao infinito com o aumento da distância entre os átomos, portanto não seria possível a quebra de uma ligação química. A Figura 2 mostra o perfil de energia de uma molécula diatômica como um oscilador harmônico.

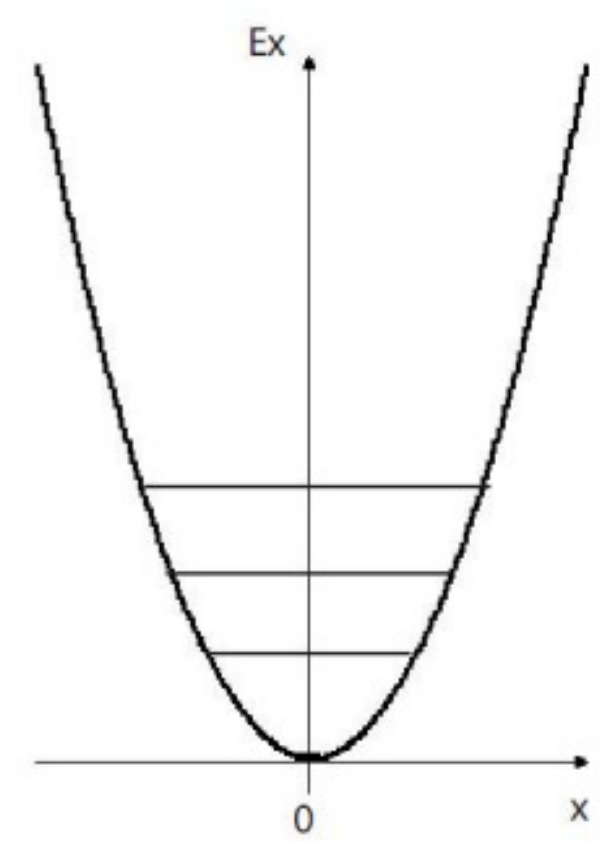

Figura 2: Perfil de energia de uma molécula diatômica como de um oscilador harmônico.

Com limitações da teoria clássica para explicação de todos os processos vibracionais e rotacionais das moléculas, a compreensão teórica só foi possível através da mecânica quântica.

No início do século XIX diversos cientistas passaram afirmavar que a matéria não interage de maneira contínua com a radiação eletromagnética 
conforme era suposto até então. Os trabalhos de diversos cientistas, dentre eles, Planck, Einstein e Bohr, indicaram de formas diferentes que a energia da radiação eletromagnética não era de forma contínua, mas sim quantizada. Planck no seu trabalho pioneiro determinou uma constante, que recebeu seu nome, a qual relaciona a energia do fóton com a frequência da onda eletromagnética.

$$
\varepsilon=h \vartheta
$$

Equação 4

Onde $h$ é a constante de Planck e $\vartheta$ é a frequência da onda associada ao fóton.

Planck, por meio da Equação 4 relacionou, pelas primeira vez, uma grandeza proveniente da física clássica com outra da física moderna. Balmer, ao observar as linhas monocromáticas do espectro de emissão do hidrogênio, verificou a existência de níveis de energia vibracionais e rotacionais que poderiam ser apresentados em forma de níveis de energia quantizados.

Portanto, as transições entre os níveis são obtidas pela diferença de energias entre dois níveis de energia da molécula, resultando na conclusão de que a freqüência de absorção poderia ser calculada a partir da seguinte equação.

$$
\vartheta=\frac{E_{1}-E_{2}}{h}
$$

Equação 5

A frequência de uma banda do espectro de absorção é a mesma do espectro de emissão desde que não ocorram outros processos de transferência de energia não radiante. Esses processos são mostrados por meio de diagramas de níveis de energia que estão apresentados na Figura 3. Cada nível de energia é representado por uma linha horizontal e neste exemplo foram mostrados somente 3 níveis vibracionais da molécula (V) e 4 níveis rotacionais. 


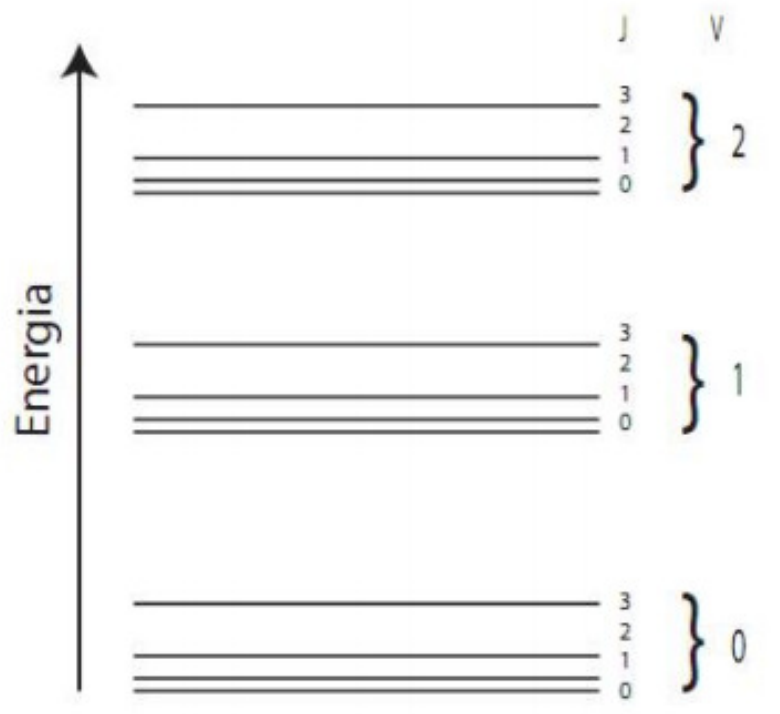

Figura 3: Diagrama de níveis de energia de uma molécula diatômica qualquer ${ }^{[22]}$.

O cálculo dos níveis de energia de qualquer molécula é feito por meio da resolução da equação de Schroedinger. Todavia, para o cálculo dos níveis de energia precisa-se de um modelo de energia potencial da molécula. Na teoria clássica, a função para descrever a energia potencial é obtida considerando a vibração da molécula como se fosse descrita por um oscilador harmônico. Entretanto, esta função de energia potencial tem limitações conforme foi descrito anteriormente.

Em 1929, uma nova expressão matemática formulada por Morse passa a tratar a energia potencial como um oscilador anarmônico, conforme mostrado na figura abaixo. 


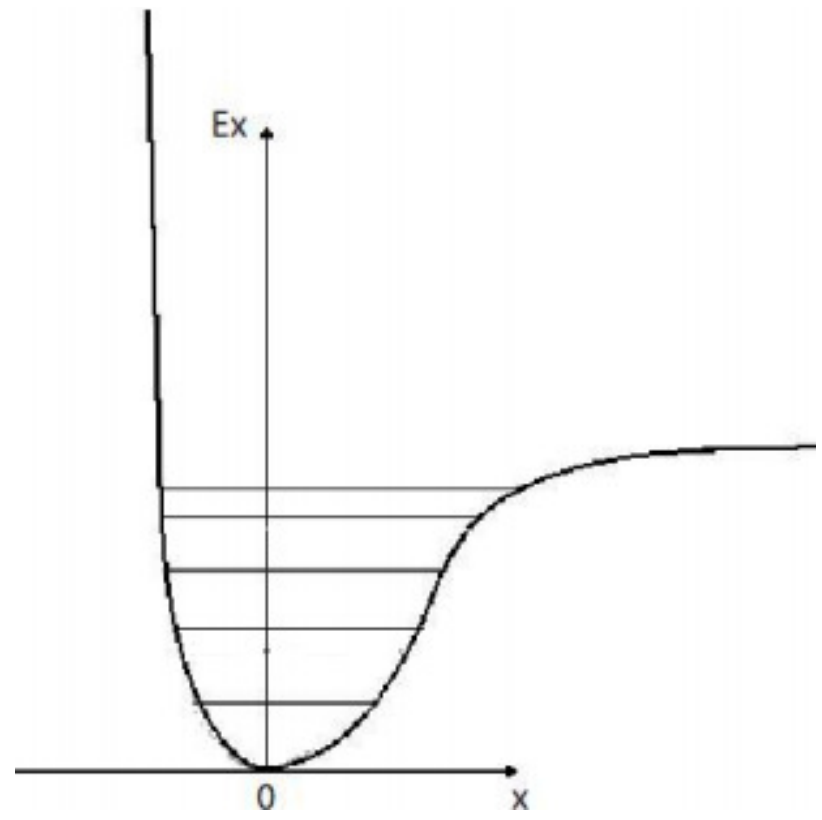

Figura 4: Função energia potencial anarmônica ${ }^{[22]}$.

Os níveis de energia para um oscilador anarmônico passam a ser:

$$
E_{v}=h v_{e}(V+1 / 2)-\left(\left(h v_{e}\right)^{2} / 4 D\right)(V+1 / 2)^{2}
$$

Equação 6

Onde: a energia é função de um número inteiro $V, v_{e}$ é a frequência da onda eletromagnética e $D$ é a energia de dissociação.

As moléculas absorverão energia quando a diferença entre estes dois níveis consecutivos tiver a mesma energia do fóton incidente. A regra de seleção diz que a molécula só pode absorver energia correspondente a hv se tiver uma variação no momento de dipolo. Este valor corresponde a posição espectral de máxima intensidade da banda no espectro. Entretanto, também pode ocorrer o chamado overtone, onde a absorção ocorre em uma energia 2hv. No espectro, esta absorção é representada por uma banda com menor intensidade e localizada em um número de onda de aproximadamente metade do inicial. Esta segunda banda apresenta menor intensidade, pois a probabilidade de ocorrer a transição 2 hv é menor do que a hv. 
1.1.2 Instrumentação - espectroscopia no infravermelho por transformada de Fourier.

A espectroscopia no infravermelho por transformada de Fourier utiliza o fato de que um padrão de interferência, obtido através de um interferômetro de Michelson, possa ser utilizado para construir um espectro de frequências através da transformada de Fourier.

A Figura 5 mostra um diagrama de um sistema FTIR. Um interferograma é a intensidade do sinal obtido em função de uma diferença de caminho ótico gerado por uma diferença de distância entre um dos espelhos do interferometro e seu divisor de feixe. O valor zero deste interferograma é definido quando as distâncias entre os espelhos e o divisor de feixe são iguais.

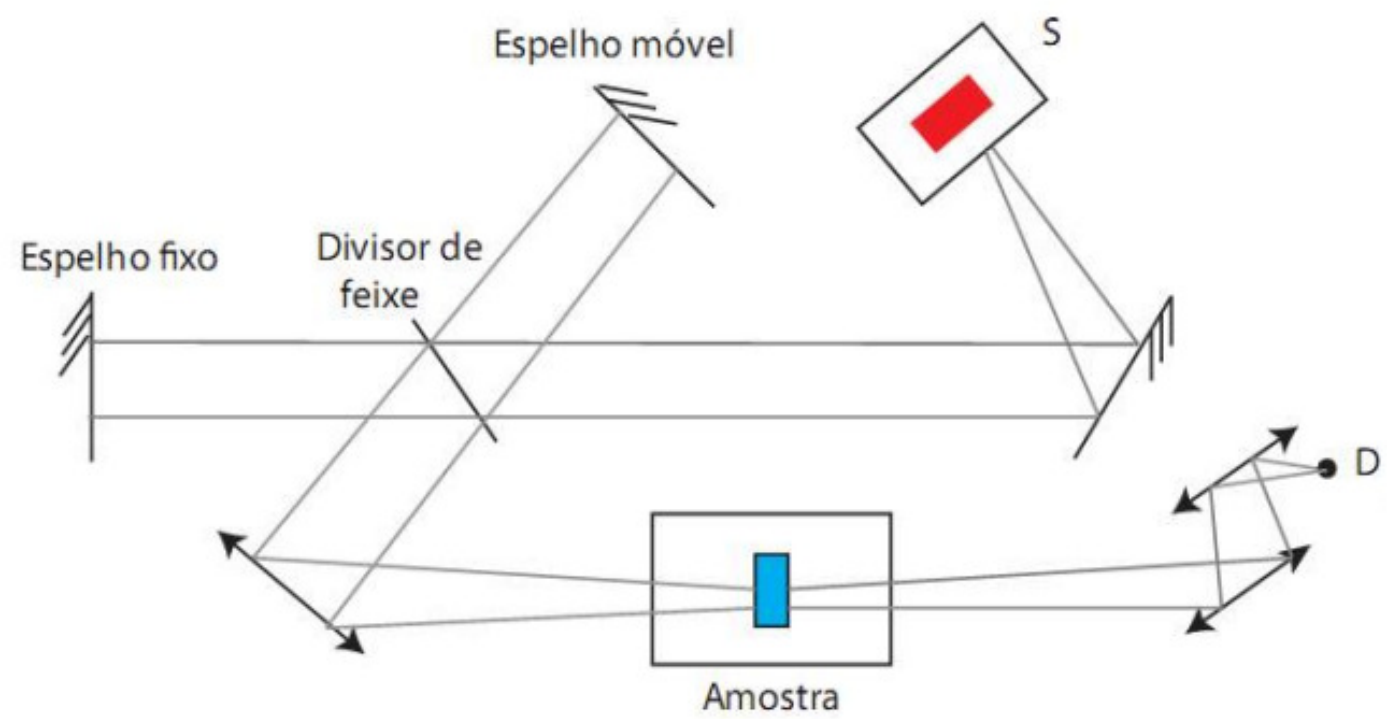

Figura 5: Diagrama de funcionamento de um sistema FTIR. Onde S é a fonte de luz, D detector $^{[22]}$.

A partir do interferograma, se calcula a transformada de Fourier para se obter os espectros de absorção (frequências). A transformada é dada pelas seguintes relações. 


$$
\begin{aligned}
& I(\delta)=\int_{0}^{\infty} B(\bar{v}) \cos (2 \pi \bar{v} \delta) d \bar{v} \\
& B(\bar{v})=\int_{0}^{\infty} I(\delta) \cos (2 \pi \bar{v} \delta) d \delta
\end{aligned}
$$

Equação 7

Onde: $I(\delta)$ é a Intensidade no detector, $B(\bar{v})$ é a densidade espectral de potência para um determinado número de onda $\bar{v}$.

As equações acima são conhecidas como par da transformada de Fourier. A primeira demonstra a variação da densidade espectral $I(\delta)$ de potência em função da diferença de caminho ótico. A segunda demonstra a variação da intensidade em função da diferença de caminho ótico que é o espectro, sendo que uma pode ser convertida na outra por meio da transformada de Fourier.

Essa técnica de obtenção de espectros na região de IR permite aquisição de dados rápida, pois se mede todos os comprimentos de onda que passam pelo cominho ótico de uma única vez. Entretanto, isso só foi possível com o avanço dos recursos computacionais que levou ao desenvolvimento de algoritmos para realizar o processamento dos interferogramas de maneira ágil permitindo sua utilização em larga escala.

Devido à velocidade de se obter um espectro foi possível a obtenção de espectros com alta razão sinal ruído fazendo-se a média de diversos interferogramas antes de realizar a transformada de Fourier.

\subsubsection{Espectroscopia no infravermelho de tecidos biológicos}

A complexidade dos tecidos biológicos leva a uma difícil interpretação dos espectros de absorção na região do infravermelho. Um entendimento detalhado dos constituintes dos tecidos que tenham modos vibracionais ativos no IR é o primeiro passo para a compreensão de um espectro proveniente de uma amostra biológica. Podemos pensar, numa primeira abordagem, que o espectro pode ser estimado como uma soma de espectros de carboidratos, 
lipídios, proteínas, ácido desoxirribonucléico (DNA) e ácido ribonucléico (RNA) um vez que todos podem estar presentes num amostra biológica. Esses constituintes individualmente possuem diversas bandas de absorção na região de 400-4000 $\mathrm{cm}^{-1}$ logo podem existem várias bandas sobrepostas principalmente na região entre $900-1800 \mathrm{~cm}^{-1}$

Existem trabalhos na literatura ${ }^{[23]}$ que tentam verificar as bandas de todos os uns dos constituintes dos tecidos biológicos. Estudos adicionais foram feitos utilizando fontes radiação synchrotrons ${ }^{[24]}$ com objetivo de aumentar a resolução espectral dos dados. A tabela 1 mostra as principais bandas de tecidos biológicos reportadas na literatura. 
Tabela 1: Principais bandas de absorção de biomoléculas na região do infravermelho médio ${ }^{[23]}$.

\begin{tabular}{|c|c|c|}
\hline Pico de absorção $\left(\mathrm{cm}^{-1}\right)$ & Modo vibracional & Constituinte biológico \\
\hline 3290 & Amida A N-H estiramento & Proteínas \\
\hline 3050 & Amida B N - H flexão & Proteína \\
\hline $2960-2930$ & $\mathrm{CH}_{3}$ estiramento antissimétrico & Lipídios e proteínas \\
\hline $2925-2920$ & $\mathrm{CH}_{2}$ estiramento antissimétrico & Lipídios e proteínas \\
\hline $2874-2870$ & $\mathrm{CH}_{3}$ estiramento simétrico & Lipídios e proteínas \\
\hline $2855-2850$ & $\mathrm{CH}_{2}$ estiramento simétrico & Lipídios e proteínas \\
\hline 1735 & Ester $\mathrm{C}=\mathrm{O}$ estiramento & Lipídios \\
\hline 1717 & purina $\mathrm{C}=\mathrm{O}$ estiramento & Ácidos nucléicos \\
\hline 1666 & pirimidina $\mathrm{C}=\mathrm{O}$ estiramento & Ácidos nucléicos \\
\hline $1655-1650$ & Amida I $\mathrm{C}=\mathrm{O}$ estiramento & Proteína ( $\alpha$-hélice) \\
\hline $1640-1630$ & Amida I $\mathrm{C}=\mathrm{O}$ estiramento & Proteína (folha- $\beta$ ) \\
\hline $1468^{[25]}$ & Vibração anel fenólico & lodotirosina - tiroglobulina \\
\hline 1580 & COO`estiramento antissimétrico & Proteínas \\
\hline $1560-1500$ & Amida II N-H flexão & Proteínas \\
\hline $1470-1405$ & $\mathrm{CH}_{2}$ flexão & Lipídios e proteínas \\
\hline 1400 & COO estiramento simétrico & proteínas \\
\hline $1380-1250$ & $\mathrm{CH}_{3}$ flexão & Lipídios e proteínas \\
\hline 1280 & Amida III e colágeno & proteínas \\
\hline $1245-1220$ & $\mathrm{PO}_{2}^{-}$estiramento antissimétrico & Ácidos nucléicos, Lipídios \\
\hline 1240 & Amida III e colágeno & proteínas \\
\hline 1204 & Amida III e colágeno & proteínas \\
\hline $1155-1150$ & $\mathrm{C}=\mathrm{O}$ estiramento & carboidrato \\
\hline $1085-1075$ & $\mathrm{C}=\mathrm{C}$ estiramento & carboidrato \\
\hline $1028-1020$ & $\mathrm{C}-\mathrm{O}-\mathrm{H}$ deformação & carboidrato \\
\hline 1080 & $\mathrm{PO}_{2}{ }^{-}$estiramento simétrico & Ácidos nucléicos, Lipídios \\
\hline
\end{tabular}




\subsection{Distorções do espectro de absorção na região do infravermelho em materiais biológicos ${ }^{[26]}$}

Quando se obtém um espectro de absorção toma-se como premissa que majoritariamente só o efeito de absorção terá contribuído no espectro de modo que todas as outras contribuições possam ser desprezadas. Entretanto, esta premissa só é válida quando se tem uma amostra homogênea opticamente, ou seja, as propriedades ópticas são constantes em função do número de onda e ao longo da amostra. Essas contribuições não ligadas à absorção nos espectros são definidas como contribuições dispersivas.

Os materiais biológicos possuem uma grande heterogeneidade no índice de refração, por exemplo, o núcleo de uma célula (que mede por volta 12 mícrons) apresenta uma grande quantidade de aminoácidos que forma a longa cadeia de DNA que é envolvido por um citoplasma que apresenta características bioquímicas completamente diferentes. Portanto as características ópticas entre estas duas regiões são completamente distintas. Essa heterogeneidade optica das células aliada à insuficiente resolução espacial das imagens obtidas por microespectroscopia FTIR proporcionam a aquisição de espectros no IR que geram grandes contribuições não ligadas à absorção.

Este efeito não se limita somente a medidas em células isoladas, mas também em tecidos biológicos. Por exemplo, ocorre nos espectros na região do infravermelho provenientes de tecidos tireoidianos que possuem uma monocamada de células epiteliais as quais envolvem uma substância gelatinosa chamada coloide. Logo, têm-se também grandes diferenças ópticas levando a aquisição de espectros com grandes contribuições dispersivas.

Como resultados destas contribuições dispersivas, observam-se bandas assimétricas com valores de absorbância negativos ao lado de alto número de onda acompanhado de um deslocamento do pico para número de onda menor. Diante disto, a problemática a ser pensada é: Quais as contribuições 
dispersivas e não relacionadas à absorção que estão contribuindo para os espectros?

Para começar a responder essa pergunta, vamos pensar que além da contribuição da absorção temos também uma contribuição que não pode ser excluída devido à reflexão. A propriedade física que relaciona absorção e reflexão é o índice de refração que é dado pelas seguintes equações:

$$
\begin{array}{cr}
n=R-i \kappa & \text { Equação } 8 \\
n=R-i \frac{2 \cdot 3 \varepsilon \cdot \lambda \cdot C}{4 \pi} & \text { Equação 9 }
\end{array}
$$

Onde: $n$ é o índice de refração, $R$ é contribuição da reflexão, $\kappa$ é a contribuição da absorção, $\varepsilon$ é coeficiente de extinção molar, $C$ é a concentração da amostra em mol L ${ }^{-1}$ e $\lambda$ é o número de onda.

Há diferenças nos parâmetros $n(\lambda)$ (parte referente à reflexão) e $\kappa(\lambda)$ (parte referente à absorção) em todos os números de onda. Essas discrepâncias se acentuam para valores de $\lambda$ próximos ao pico máximo de absorção, o que resultam em distorções nas bandas devido a diferentes contribuições de reflexão e absorção ao longo da banda.

Há um conjunto de relações matemáticas que relacionam o espectro de absorção com o espectro de reflexão. Estas relações são chamadas de transformações de Kramers-Kronig ${ }^{[27]}$ e é dado por:

$$
\begin{aligned}
& n(\omega)=\frac{1}{\pi} \int_{-\infty}^{\infty} \frac{\varepsilon(\omega)}{\omega-\omega_{0}} d \omega \\
& \varepsilon(\omega)=-\frac{1}{\pi} \int_{-\infty}^{\infty} \frac{n(\omega)}{\omega-\omega_{0}} d \omega
\end{aligned}
$$

Onde: $\omega$ é a frequência angular e $\omega_{0}$ é frequência de absorção máxima. 
Esse conjunto de relações só pode ser utilizado quando se tem um espectro de reflexão puro ou espectro de absorção puro. Entretanto, em tecidos biológicos não conseguimos obter estes espectros puros devidos a fatores já explicados. Para exemplificar isso, a Figura 6 mostra um espectro de absorção puro e reflexão pura assim como um espectro distorcido proveniente de um tecido humano.

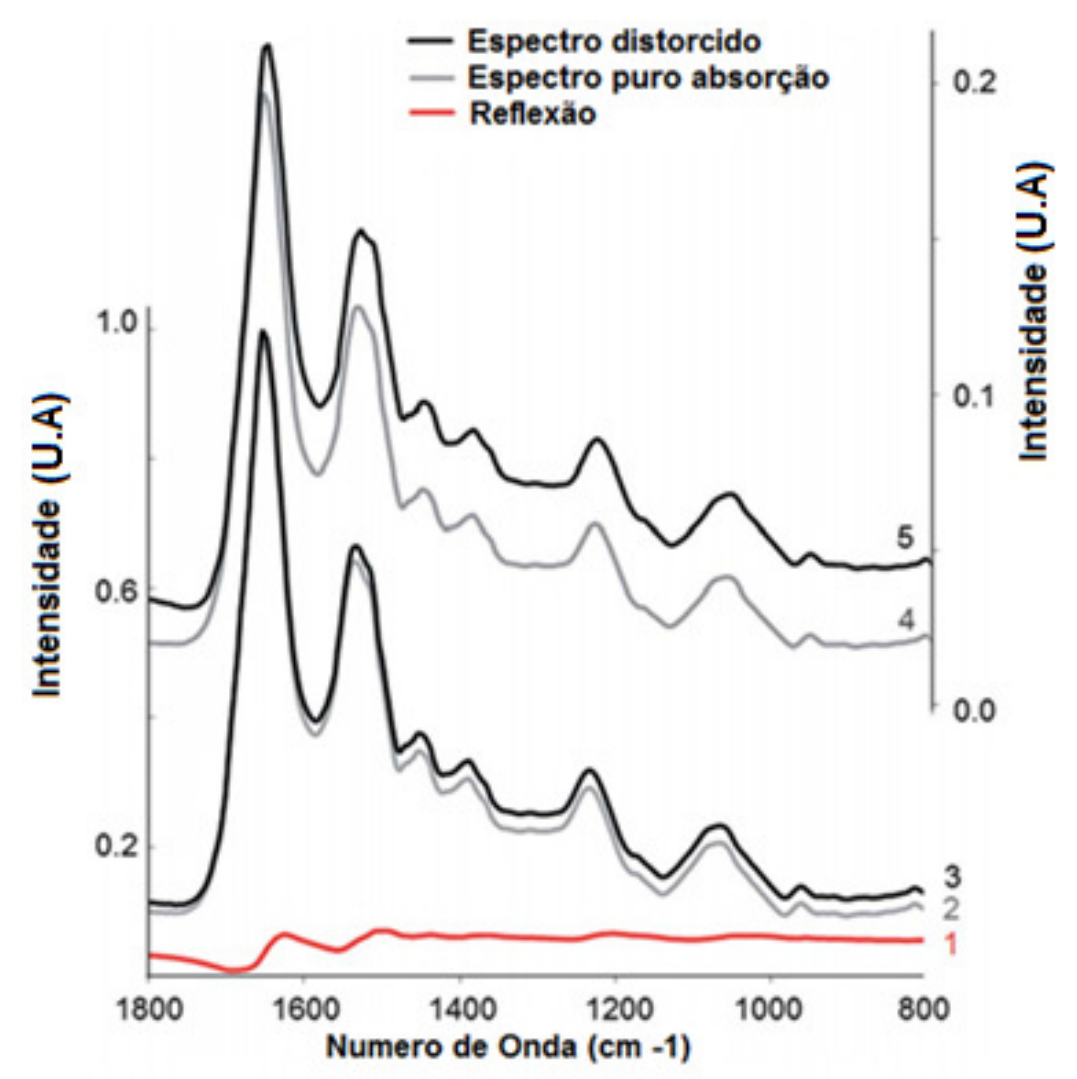

Figura 6: Espectro de absorção puro, reflexão pura e o espectro distorcido de um tecido humano ${ }^{[26]}$.

Outra contribuição dispersiva é devido a erros instrumentais. Os sistemas FTIR tomam como premissa que o interferograma coletado é perfeitamente simétrico, portanto a transformada de Fourier para se obter 0 espectro de frequência é feita por meio da transforma de Fourier de cossenos (equação 7). Porém, na prática, o interferograma não é totalmente simétrico devido a erros como: diferenças em tempos de aquisição gerando dados no interferograma não igualmente espaçado e resposta não linear do detector. Os 
interferogramas que são transformados utilizando-se somente a forma de cossenos introduzizem erros nos espectros. Este não terá somente efeitos de absorção, mas também contribuições devido a esses erros.

Para se corrigir isto matematicamente, os sistemas FTIR modernos utilizam um algoritmo chamado de correção de fase. Isso nada mais é do que encontrar um valor constante, $t^{\prime}$ no espaço de tempo, e introduzir na transformada de Fourier. Com isso se "introduz" matematicamente uma fase para corrigir o erro.

Outro motivo que gera grandes contribuições dispersivas ao espectro de absorção é a interface amostra atmosfera. As medidas de FTIR envolvendo material biológico muitas vezes são realizadas sem utilização de portaamostras ou sanduíches de janelas de $\mathrm{CaF}_{2}$. Essa interface ar amostra tem grande descontinuidade em termos de índice de refração, portanto gera forte reflexão contribuindo no espectro de adquirido.

Além das razões já descritas relacionadas à contribuição dispersiva, o espalhamento Mie é apontado como a maior contribuição não associada à absorção e pode tornar, muitas vezes, difícil a análise dos espectros destas amostras. O espalhamento Mie ocorre quando uma partícula esférica ou aproximadamente esférica e dielétrica interage com uma onda eletromagnética cujo comprimento de onda é similar ao diâmetro da partícula. Isto ocorre muito em tecidos biológicos e células, pois os núcleos das células do corpo humano têm tamanho entre 10 e $22 \mu \mathrm{m}$ que são similares aos comprimentos de onda na região do infravermelho médio. A equação que descreve a probabilidade de ocorrer o espalhamento Mie em função do número de onda é dado por:

$$
Q_{s c a}=2-(4 / \rho) \sin \rho+\left(4 / \rho^{2}\right)(1-\cos \rho)
$$

Equação 12

Onde: $\boldsymbol{\rho}=\mathbf{2 \pi \boldsymbol { d }}\left(\boldsymbol{\eta}_{12}-1\right) / \lambda ; Q_{s c a}$ é a probabilidade de ocorrer o espalhamento, $d$ é odiametro, $n_{12}$ é a razão entre índice de refração e $\lambda$ comprimento de onda 
A Figura 7 mostra a probabilidade de ocorrer espalhamento Mie de algumas partículas com diversos diâmetros.

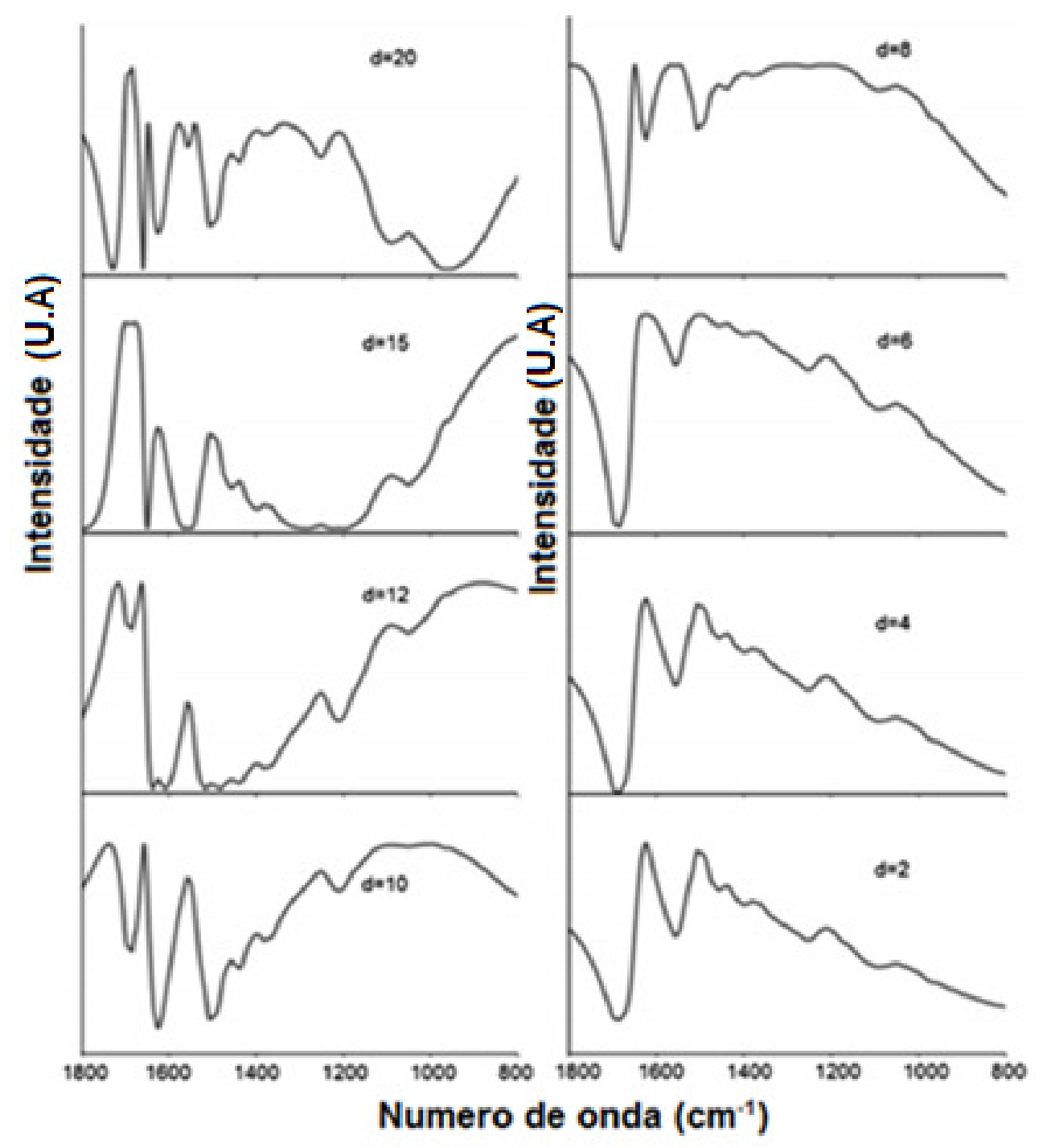

Figura 7: Espectros simulados de espalhamento Mie para esferas de diversos tamanhos $^{[26]}$.

Muitos trabalhos na literatura, desde 2005, ${ }^{[26,28,29]}$ mostram o efeito do espalhamento Mie nos espectros coletados de células. Entretanto uma explicação detalhada foi dada somente no ano de 2009 por Bassan et al. ${ }^{[30,31]}$.

Esses são os principais motivos para contribuições dispersivas que vemos nos espectros de absorção em tecidos biológicos. Essas contribuições, principalmente relativas ao espalhamento Mie, foram um dos grandes 
obstáculos para o desenvolvimento de técnica de microespectroscopia FTIR para fins de diagnóstico. Foram desenvolvidos métodos matemáticos e técnicas de medidas de forma a atenuar esse problema permitindo o desenvolvimento da técnica nessa área. $\mathrm{O}$ método matemático utilizado neste trabalho para remoção dessas contribuições dispersivas está explicado na sessão 1.3 .2

\subsection{Pré-processamento dos dados de microespectroscopia}

FTIR

Com o avanço tecnológico foi possível o desenvolvimento de sensores de detecção de radiação IR cada vez mais sensíveis. Isso permitiu o desenvolvimento de sistemas de espectroscopia no IR que podem ser acoplados a um microscópio permitindo a construção de imagens espectrais. Cada pixel da imagem gerada é um espectro no IR. Os sistemas atuais permitem construção de imagens com resolução espacial de em torno de $6 \mu \mathrm{m}$, podendo ter numa área de $1 \mathrm{~mm}^{2}$ aproximadamente 12 mil espectros gerando 200 megabytes de dados.

Devido a grande quantidade de dados gerados se faz necessário o desenvolvimento de rotinas de processamento pelos seguintes motivos:

1. A remoção de espectros da imagem com baixa razão sinal ruído e/ou com grande contribuições de espalhamento.

2. Remoção de ruídos, vapor d’água residual e espalhamento Mie.

Essa etapa é necessária, pois os métodos de estatística multivariada utilizados para extrairmos informações bioquímicas dos espectros se baseiam em cálculos de variância, portanto deve-se remover diferenças espectrais devido à fatores não relacionados a diferenças bioquímicas.

Nas próximas subseções será explicado como cada um desses algoritmos funciona. 


\subsubsection{Testes de qualidade}

Cada mapa espectral possui centenas de milhares de espectros tornando quase não factível a inspeção visual para verificar quais espectros apresentam boa qualidade ou não. Por isso, a seleção dos espectros "bons" é feita por meio de alguns cálculos feitos em cada espectro. Essas medidas são as seguintes: área sob a curva, razão entre áreas, intensidade e razão de intensidade. A partir da medida calculada, o usuário seleciona um valor que servirá de ponto de corte. Por exemplo, espectros que têm área sobre a curva na região entre $900-1800 \mathrm{~cm}^{-1}$ menores que um determinado valor são excluídos, pois têm um sinal fraco ou a amostra possui uma espessura muito fina.

Os testes de qualidade são determinados para cada tipo de amostra biológica e a determinação dos pontos de corte é feita de forma totalmente empírica.

1.3.2 Redução de ruído pela técnica NAPC -Noise Adjusted Principal Component ${ }^{[32]}$

A técnica de redução de ruído chamada de Noise Adjusted Principal Component - NAPC se baseia nas propriedades matemáticas do método estatístico definido como Análise por Componentes Principais (PCA). Essa é uma técnica na qual todas as variáveis iniciais de um sistema, neste caso números de onda, são reconstruídas em novas coordenadas ( chamadas de PCs), por meio de uma matriz de transformação, de tal forma que se pode representar a variância total em menor número de variáveis. A variável PC1 possui a maior variância e a PC2 possui a segunda maior variância e assim sucessivamente.

Pensando em termos de sinal amostrado num equipamento, todo o dado $D$ coletado possui um sinal $s$ e um ruído $N$ conforme a equação abaixo.

$$
D=S+N
$$


Se tivermos um conjunto de dados coletados temos uma variância Var. Portanto temos:

$$
\operatorname{Var}(D)=\operatorname{Var}(S)+\operatorname{Var}(N)+2 * \operatorname{Cov}(S, N)
$$

Equação 14

O sinal $(\boldsymbol{S})$ e o ruído $(\boldsymbol{N})$ não estão correlacionados, portanto a covariância $(\operatorname{Cov}(S, N))$ será zero.

Assumindo que o dado coletado possui maior sinal do que ruído, pode-se concluir que a variância devido ao sinal é também maior que a relativa ao ruído. Portanto, as variáveis PCs também podem ser analisadas da seguinte maneira: PC1 possui a maior razão sinal ruído, PC2 possui $2^{\circ}$ maior e assim por diante.

Portanto a redução do ruído por NAPC se baseia em duas idéias:

1. Reconstruir os espectros utilizando somente os $N$-primeiros PCs de forma a aumentar a razão sinal ruído. O número de PCs para a reconstrução dos espectros é uma escolha a ser feita pelo analisador.

2. Renormalizar a matriz de transformação de tal forma que números de onda que possuem baixa razão sinal ruído tenham menor contribuição na reconstrução dos dados.

Matematicamente, isso é feito da seguinte maneira. Primeiro monta-se duas matrizes ( $M D, M N$ ) com os seguintes dados: a matriz MD contém espectros da região que contém amostra (sinal + ruido) e a matriz MN são espectros coletados da região que não contém amostra, portanto qualquer sinal gerado será devido a ruído.

Os passos do algoritmo NAPC são: 
1. Calculam-se as matrizes de covariância $\left(\sum_{\mathrm{D}}, \Sigma_{\mathrm{N}}\right)$ das matrizes MD e MN respectivamente.

2. Calculam-se os autovalores $\left(\Delta_{n}\right)$ e autovetores ortonormalizados $(E)$ da matriz de covariância $\Sigma_{N}$ de tal forma que:

$$
E^{T} \Sigma_{n} E=\Delta_{n} \quad \text { Equação } 15
$$

Calcula-se a matriz de renormalização $F=E \Delta_{n}{ }^{-1 / 2}$ de tal forma que:

$$
F^{T} \Sigma_{n} F=I
$$

Equação 16

Onde: I é a matriz identidade.

3. Calcula-se a matriz de covariância dos dados retirando o ruído da seguinte forma:

$$
\Sigma_{a d j}=F^{T} \Sigma_{d} F
$$

Equação 17

4. Calculam-se os autovetores, G, a partir da matriz $\Sigma_{a d j}$. De tal forma que:

$$
G^{T} \Sigma_{a d j} G=\Delta_{a d j}
$$

Equação 18

Pega-se a matriz MD (conjunto de espectros com sinal) e subtrai a média em cada número de onda. Tendo uma matriz $D_{\mathrm{mm}}$ logo teremos uma distribuição em cada número de onda a qual a média é zero.

5. Calcula-se a matriz dos dados transformados que será utilizada para reduzir o ruído. Isso é feito utilizando a seguinte equação:

$$
\text { NAPCtransform }=H^{\prime} D_{m m}
$$

Equação 19

Pega-se e altera a matriz $\boldsymbol{H}$ e remove-se as componentes acima de certo PCs. Esse parâmetro é definido pelo usuário.

6. Os espectros com maior razão sinal ruído são dados por: 
A figura 8 mostra o espectro antes e depois da remoção de ruído NAPC utilizando os 20 primeiros PCs.

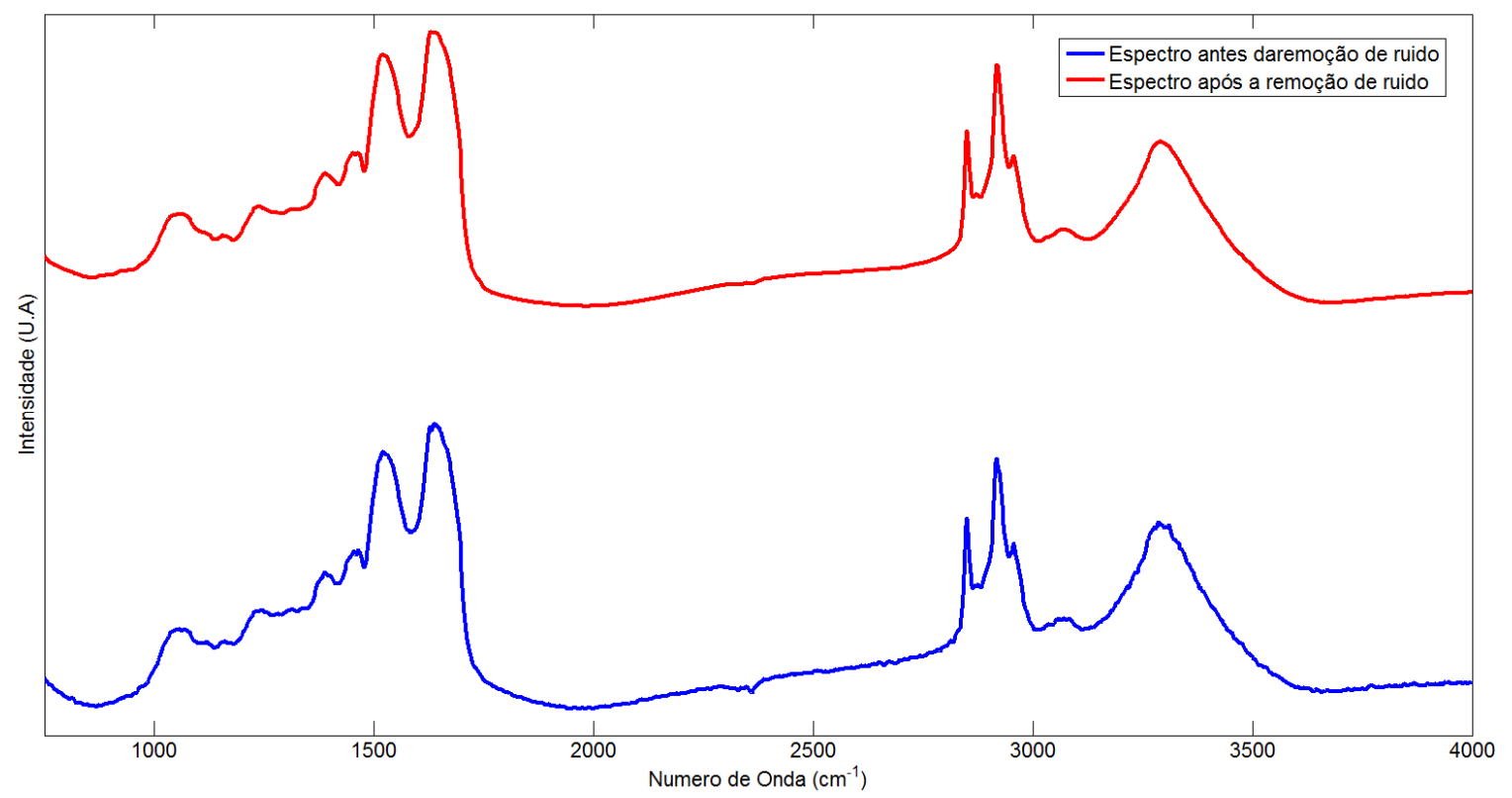

Figura 8: Espectro de infravermelho antes e depois da redução de ruído utilizando a técnica de NAPC.

\subsubsection{Correção de contribuições dispersivas.}

Os espectros de absorção coletados de materiais biológicos possuem grandes contribuições não relacionadas ao fenômeno da absorção. Essas contribuições adicionam grandes diferenças nos espectros que dificultam a aplicação de técnicas de estatística multivariada para separação e diferenciação de acordo com diferenças bioquímicas. Nesses espectros a maior contribuição não relacionada à absorção é o espalhamento Mie. Isso ocorre pelo fato de que a morfologia dos tecidos e células favorece esse fenômeno. Tendo em vista o problema exposto na sessão 1.2 se faz necessária a remoção ou atenuação das contribuições não relacionadas à 
absorção. Existem dois métodos descritos na literatura para a redução do espalhamento Mie.

O primeiro método foi proposto em 2010 por Bassan et al.. ${ }^{[33]}$ e tem como premissa a necessidade de ter previamente o espectro de absorção puro (sem contribuição de espalhamento) e um espectro de espalhamento Mie. Este algoritmo usa o espectro puro de absorção de um conjunto de proteínas e por meio das transformações de Kramers-kronig se obtém o espectro de reflexão puro. Esses, devido ao espalhamento Mie, são calculados a partir de 1000 curvas de $\boldsymbol{Q}_{\text {sca }}$ (equação 12) e se constrói uma base ortonormal utilizando PCA. Para corrigir os espectros, o algoritmo utiliza extended multiplicative signal correction para achar a melhor combinação de curvas de $\boldsymbol{Q}_{\text {sca }}$ para subtrair do espectro a ser corrigido. A cada interação do algoritmo o espectro corrigido é utilizado como espectro de reflexão puro em vez do espectro medido. Após $\mathrm{N}$-interações o espectro terá poucas ou nenhuma contribuição de espalhamento Mie. Isso é testado observando-se a similaridade entre o espectro corrigido após $\mathrm{N}$ interações e espectro puro de um conjunto de proteínas. A figura 9 mostra um diagrama de funcionamento desse algoritmo.

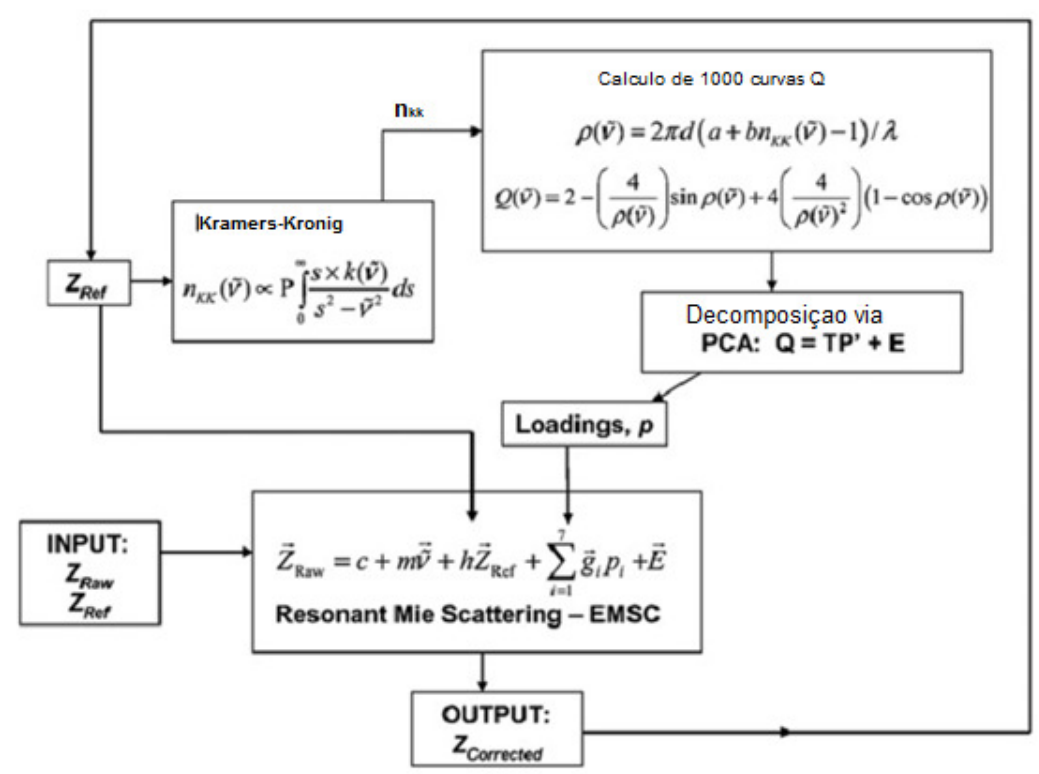

Figura 9: Diagrama esquemático de funcionamento de algoritmo proposto por Bassan et al. $^{20]}$ 
Este algoritmo acima descrito tem várias limitações. Dentre elas podemos citar:

- Ele só corrige contribuição relacionada ao espalhamento Mie.

- Não é rápido computacionalmente. Para corrigir 10 mil espectros podese levar algumas horas.

- Necessita de um espectro puro de referência que é difícil de obter devido à especificidade de cada tecido biológico.

O segundo método para a correção das contribuições dispersivas foi desenvolvido por Milijkovic et al.. A teoria por trás desse método é simples e se propõem a correção das distorções do espectro da seguinte forma:

1. Aplica-se uma transformada de Fourier no espectro;

2. Adiciona-se uma fase $(\varphi)$ resultando em mudanças na parte imaginária e real;

3. Aplica-se a transformada de Fourier inversa para recuperar o espectro.

A equação 21 descreve como é adicionado a fase nos espectros.

$$
\left(\begin{array}{l}
R E^{\prime} \\
I M^{\prime}
\end{array}\right)=\left(\begin{array}{cc}
\cos (\varphi) & \sin (\varphi) \\
-\sin (\varphi) & \cos (\varphi)
\end{array}\right)\left(\begin{array}{l}
R E \\
I M
\end{array}\right)
$$

Equação 21

A fase que tem que ser aplicada em cada espectro não é conhecida. Portanto um método interativo deve ser montado para encontrar a melhor fase. Algumas premissas foram feitas para se descobrir a melhor fase. Calculam-se 16 possibilidades igualmente espaçadas entre 0 e $\frac{\pi}{2}$. A fase que melhor corrige o espectro é determinada segundo um critério. Os autores propõem diversas metodologias, tais como, maior intensidade na região da amida I ou maior freqüência da banda de amida I. A Figura 10 mostra os espectros com diferentes fases aplicadas. O espectro azul é a melhor fase encontrada enquanto o espectro vermelho é o espectro sem correção alguma. 


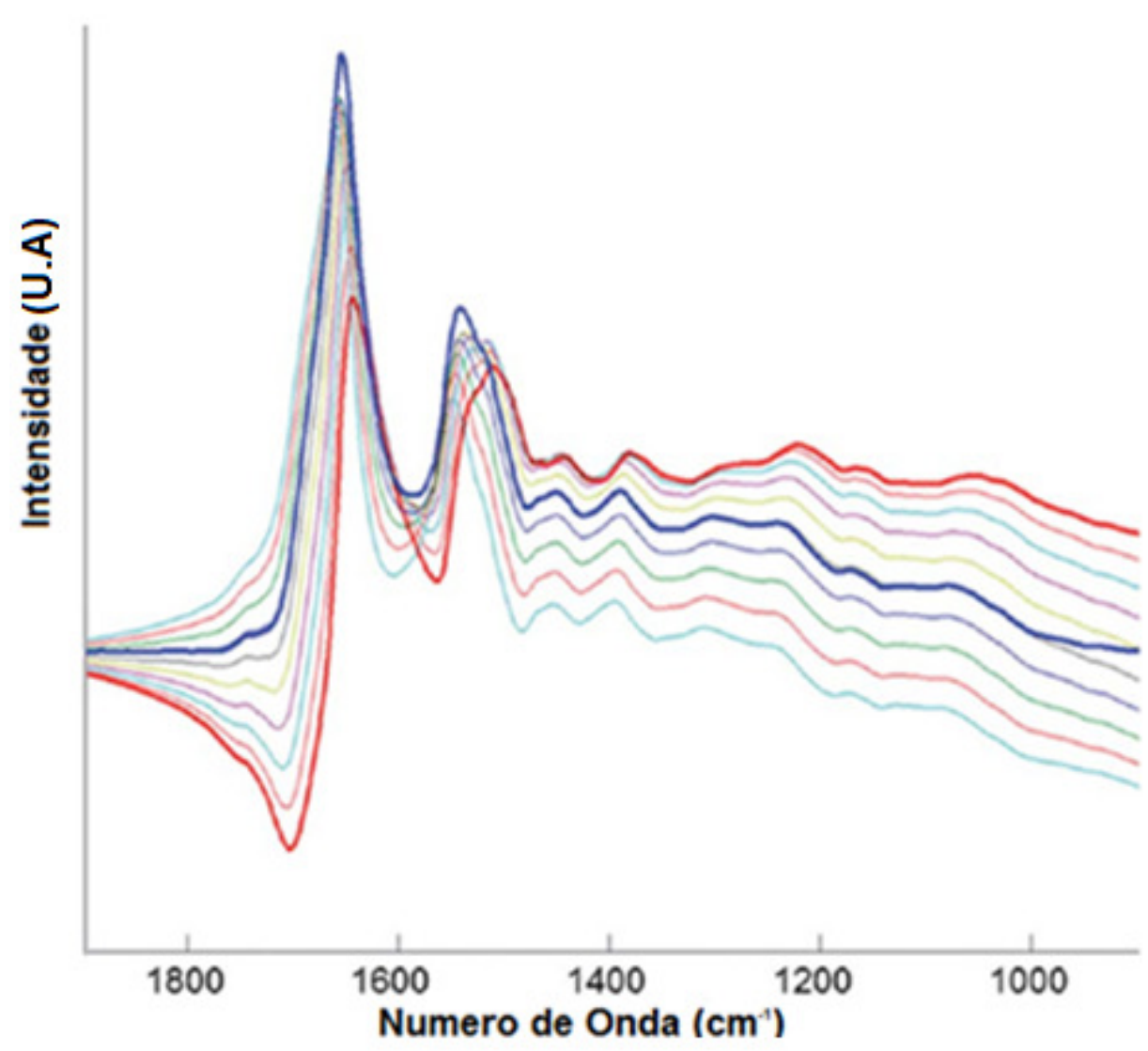

Figura 10: Espectros não corrigidos e corridos utilizando o algoritmo proposto por Milijkovic et al. ${ }^{[26]}$.

\subsection{Estatística multivariada aplicada a espectroscopia}

O avanço dos sistemas de espectroscopia micro-Raman e micro-FTIR permitiram a aquisição de grande quantidade de espectros de uma amostra. 0 sistema utilizado no presente trabalho é capaz de adquirir aproximadamente 12 mil espectros por $1 \mathrm{~mm}^{2}$ gerando em torno de 200 megabytes de dados. Os sistemas Raman podem adquirir uma quantidade de dados ainda maior devido à utilização de região com menor comprimento de onda possibilitando e a aquisição de imagens com maior resolução espacial.

Apesar da grande quantidade de dados coletados, a diferença entre um tecido sadio e um anormal pode estar relacionada a uma pequena diferença nos espectros em somente alguns números de onda, portanto sendo extremamente difícil notar a "olho nu". 
Para se detectar e conseguir observar essas diferenças bioquímicas, (espectrais), diversos métodos de estatística multivariada vêm sendo aplicados em espectroscopia vibracional para se encontrar padrões espectrais de tecidos biológicos. Nas próximas subseções serão explicados os métodos estatísticos que foram utilizados no presente trabalho e como se obtêm informações espectrais a partir de um conjunto de dados por meio destas técnicas estatísticas.

\subsubsection{Análise por componentes principais ${ }^{[34-36]}$}

A análise de componentes principais comumente chamada pela sua sigla PCA que vem do inglês Principal Component Analysis, se baseia numa transformação linear das $\mathrm{N}$-variáveis originais do sistema criando novas $\mathrm{P}$ variáveis. Dessa forma a variância de todas as $n$-variáveis iniciais pode ser representada por novas p-variáveis, de tal forma que toda informação seja representada por um número muito menor de variáveis $(n<<p)$. Esse procedimento reduz o número de variáveis para análise com pouca perda das informações contidas nos dados. A demonstração matemática detalhada deste processo está explicada no apêndice I.

No nosso caso, as variáveis originais do sistema são os valores de absorbância obtidos nos espectros, e as novas variáveis, chamadas de PCs, são construídas por meio de uma combinação linear explicitada na equação18.

$$
P C_{d}=\sum_{n=1}^{n} \mathbf{p}_{\mathrm{d}, \mathrm{n}} \cdot \boldsymbol{A}_{n}
$$

Equação 22

Onde: $\mathrm{PC}_{\mathrm{d}}$ são as novas variáveis, $\mathrm{p}_{\mathrm{d}, \mathrm{n}}$ são os pesos dados a cada número de onda, $A_{n}$ os valores de absorbância.

Em termos de variância o $\mathrm{PC}_{1}$ possui a maior variância e $\mathrm{PC}_{2}$ possui a segunda maior variância e assim por diante. Por conta dessa característica podemos calcular a porcentagem da variância total acumulada entre $0 \mathrm{PC}_{1}$ até $\mathrm{PC}_{\mathrm{n}}$. por meio desse cálculo, podemos selecionar quantos PCs vamos usar 
para discriminar dois grupos. Por exemplo, do $\mathrm{PC}_{1}$ até $0 \mathrm{PC}_{3}$ de um conjunto de dados tem-se mais de $95 \%$ da variância original, portanto serão utilizadas somente essas 3 primeiras variáveis para discriminação entre os grupos.

Os valores $P_{d, n}$ são os pesos que são atribuidos a cada variável inicial. Esses valores de $P$ nos fornecem informações importantes a respeito dos dados. Por exemplo: o maior valor de $P_{1, z}$ nos informa que a variável $A_{z}$ possui a maior variância das variáveis iniciais e $P_{2, z z}$ nos informa que a variável $A_{z z}$ possui a $2^{\text {a }}$ maior variância do banco de dados e assim por diante. Através dessa análise, pode-se descobrir quais os números de onda são mais importantes para a diferenciação entre dois grupos.

Os valores $P_{d, n}$ podem ser grafitados em função do número de onda e esses gráficos são chamados de loading plots.

Podemos através dos gráficos loading plots extrair diversas informações espectrais. Para explicar melhor isso, um conjunto de espectros construídos a partir de uma soma de gaussianas foi analisado por PCA. Na figura abaixo se tem a média de 2 grupos com 100 espectros cada, todos gerados por soma de várias funções gaussianas.

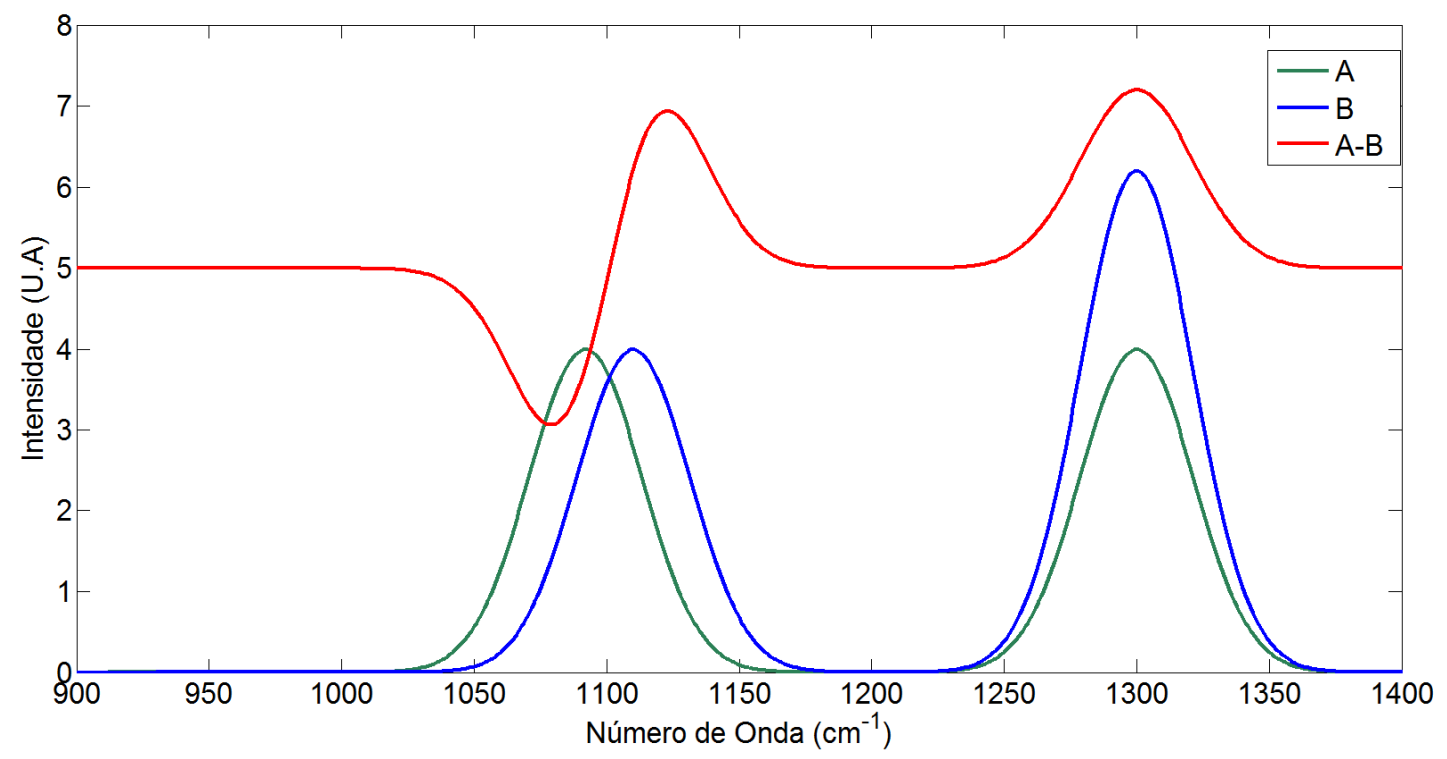

Figura 11: Espectros sintéticos médios gerados com soma de gaussianas. 
Nos espectro da Figura 11 nota-se que na região de $1000 \mathrm{~cm}^{-1}$ tem-se um shift de banda enquanto que na região de $1330 \mathrm{~cm}^{-1}$ tem-se somente uma diferença na intensidade de absorção da banda. A linha vermelha da Figura 11 representa a diferença entre os espectros.

$\mathrm{Na}$ figura 12, estão mostrados os loading plots referentes aos componentes $\mathrm{PC}_{1}, \mathrm{PC}_{2}$, e $\mathrm{PC}_{3}$, respectivamente. Essas 3 variáveis representam mais de $99 \%$ da variância total do deste conjunto de dados.

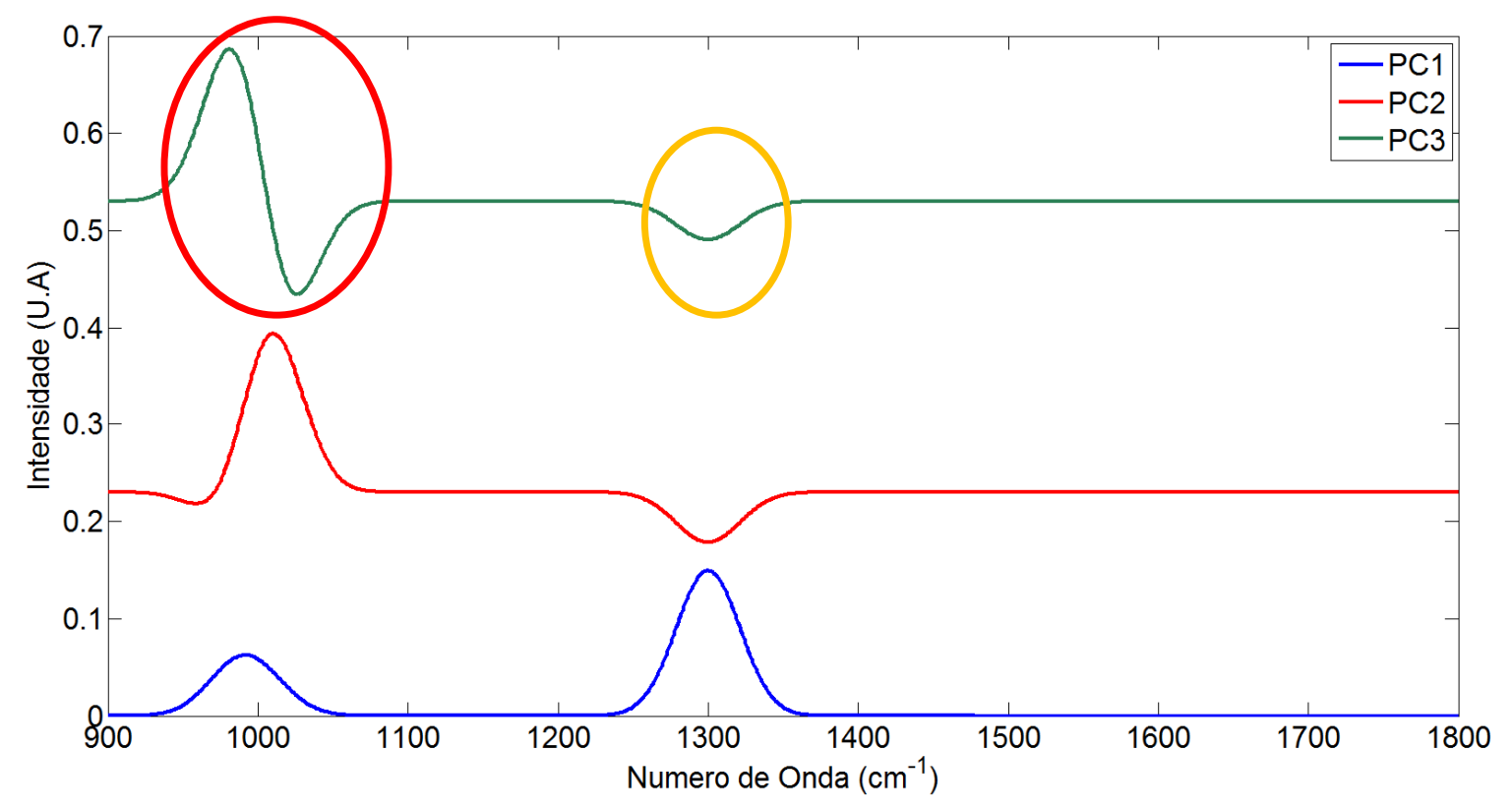

Figura 12: Loading plots dos dados sintéticos construídos na Figura 11.

Analisando os loading plots (figura 12), observa-se que o PC1 (linha azul) representa a média dos espectros dos grupos A e B. Nos loading plots das variáveis $\mathrm{PC} 2$ e PC3, observa-se as diferenças espectrais entre os grupos. Pode-se notar que a diferença é devida a um shift da banda ou diferença na absorção. Quando se tem um shift de banda, isso aparece no loading plot como função do tipo assimétrica (círculo vermelho). Quando a diferença for devida à absorção, observa-se por uma função simétrica (círculo Amarelo).

No exemplo simples acima é fácil observar essas diferenças espectrais entre os grupos utilizando os loading plots, entretanto, quando se analisam espectros de materiais biológicos, a interpretação torna-se mais complexa. 
Há diversas razões para isso. A primeira se deve ao fato de que o espectro desse tipo de material possui várias bandas de absorção sobrepostas, então a interpretação desses sinais do loading plots fica mais complicada. Outra razão é o fato de que a análise de PCA é baseada em variância da base de dados, portanto qualquer efeito que distorça as bandas dos espectros, tais como espalhamento Mie, ruído, ou bandas de vapor da água, gera ruído nos loading plots impossibilitando a sua análise.

\subsubsection{Análise de agrupamento ${ }^{[36,37]}$}

A análise de agrupamento, comumente chamada de análise de cluster, tem como objetivo agrupar espectros de acordo com suas semelhanças de tal forma que as diferenças dentro do grupo sejam muito menores que as diferenças entre grupos.

Para agrupar um conjunto de espectros precisa-se primeiro estabelecer qual será o método para calcular a similaridade entre cada um dos espectros. Em espectroscopia [13, 38-41], o método mais utilizado para o cálculo das similaridades entres os espectros é distância euclidiana. A distância euclidiana entre o espectro $j$ e o $i$ é definida da seguinte forma.

$$
D\left(e_{k i}, e_{k j}\right)=\left[\sum_{k=1}^{p}\left(e_{k i}-e_{k i}\right)^{2}\right]^{\frac{1}{2}}
$$

Equação 23

Onde: p é o número de pontos de absorbância.

A distância euclidiana é na realidade a soma de todas as diferenças de cada absorbância do espectro. Com o cálculo das distâncias efetuado, montase uma matriz com dimensão nxn (n é número de espectros) a qual recebe 0 nome de matriz de similaridade.

A partir da matriz de similaridade calculada tem que definir qual vai ser a técnica de agrupamento. Há dois tipos: a Hierárquica e não hierárquica. A do tipo hierárquico é o agrupamento ao qual não se impõe nenhuma restrição ao número de grupos. Esse tipo de agrupamento é utilizado para se observarem padrões bioquímicos dentre espectros de um conjunto de pacientes. 
A outra técnica de agrupamento chama-se não hierárquica a qual se define previamente pelo número de grupos. Este tipo é utilizado quando se tem alguma informação a priori dos dados. Por exemplo, um mapa espectral de um tecido, já se sabe previamente o tipo de tecido que aquela amostra possui.

Com o cálculo de matriz de similaridade realizado, tem-se que definir qual o algoritmo de agrupamento que será utilizado. Existem diversos algoritmos de agrupamento. O mais utilizado em espectroscopia é o método de "Wards".

Este método tem como característica minimizar a distância euclidiana dentro de cada grupo e maximizar essa distância entre os grupos. A forma mais comum de observar os dados de um agrupamento é por meio de dendogramas.

Para melhor exemplificar qual tipo de informação que se pode extrair do dendograma de uma análise de agrupamento foram criados grupos de espectros. A média de cada um dos grupos está na figura 13

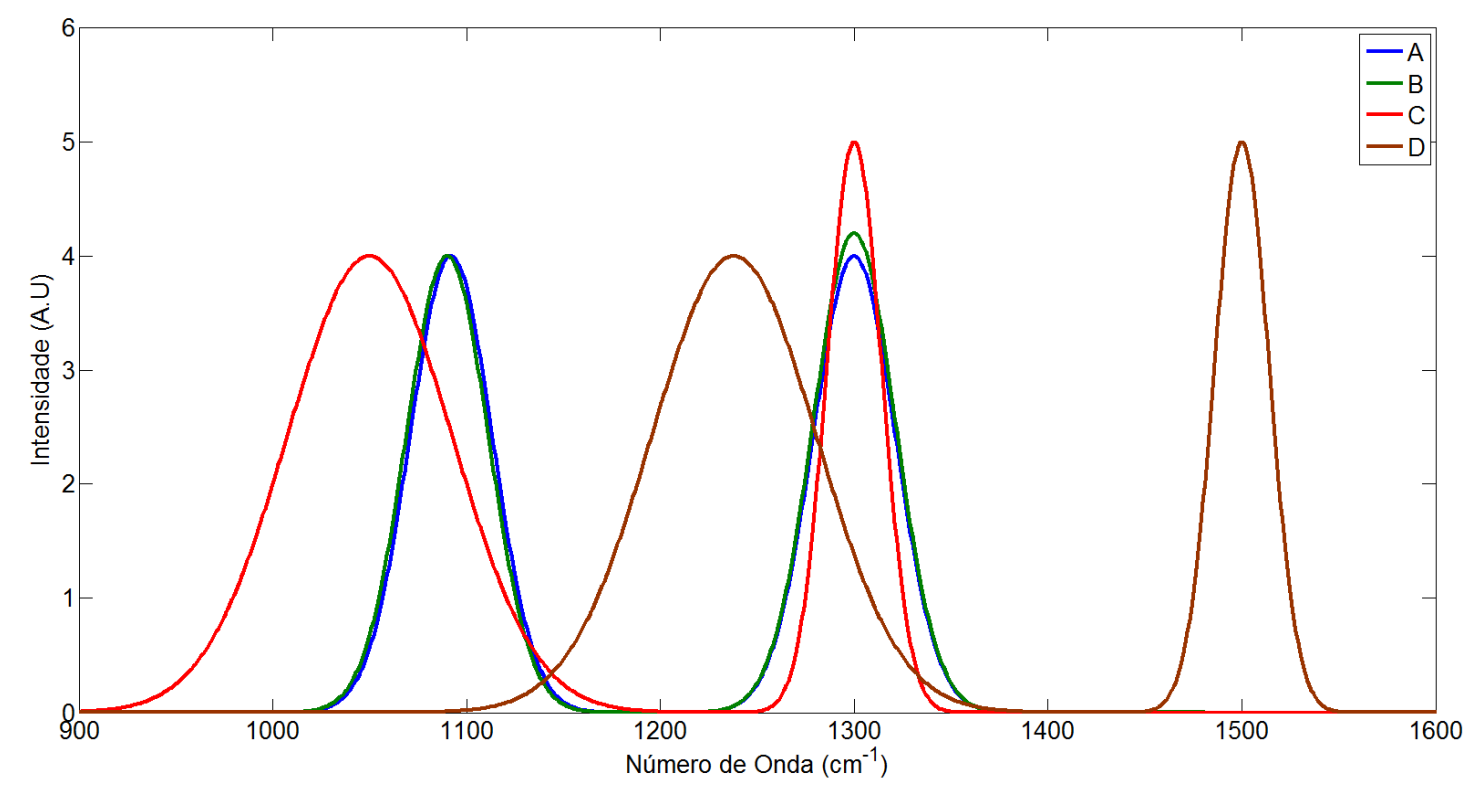

Figura 13: Espectros sintéticos médio gerados com soma de gaussianas.

O dendograma referente aos dados sintéticos gerados a partir dos espectros da Figura 13 é: 


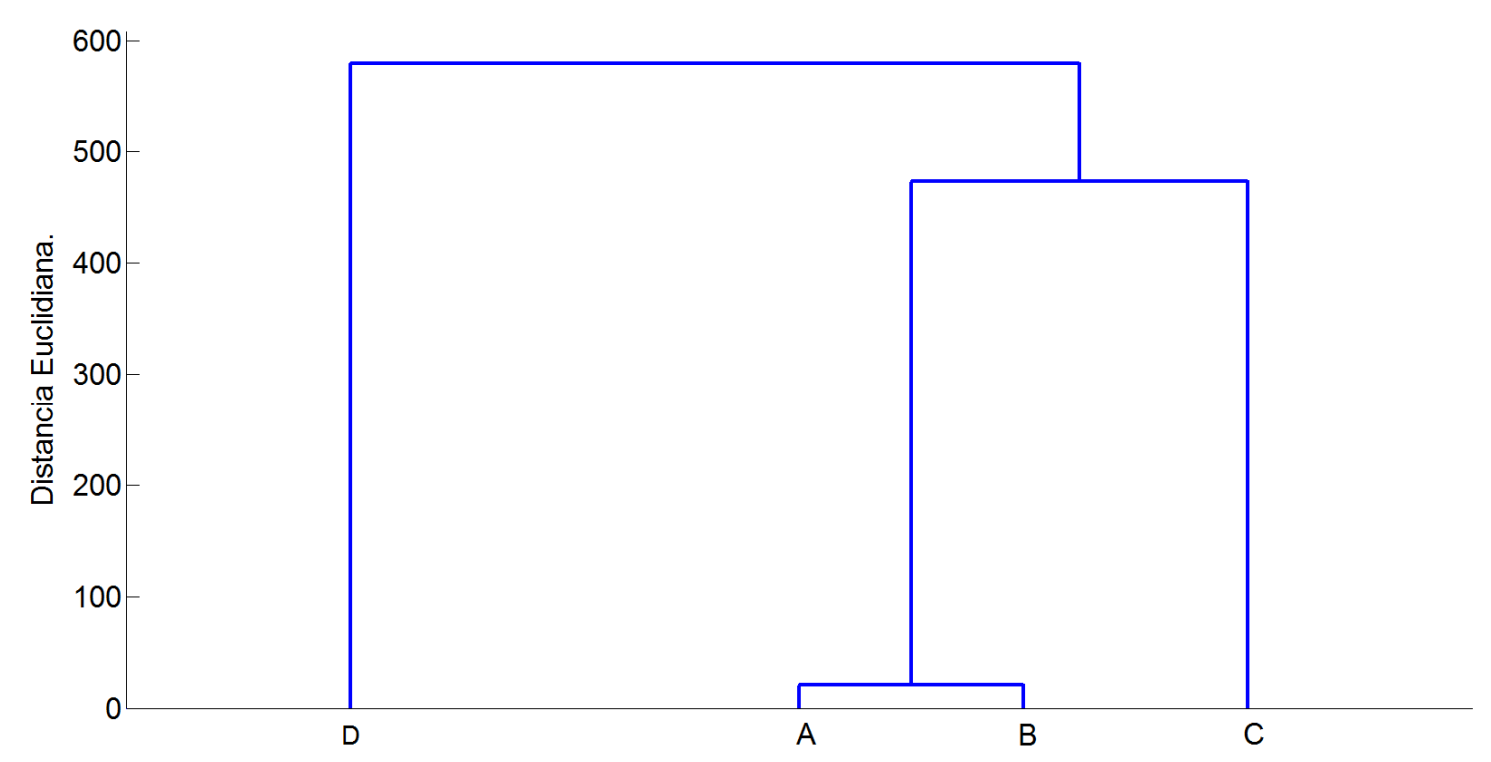

Figura 14: Dendograma referente aos espectros da Figura 13.

Observando o dendograma, temos no eixo $Y \circ$ valor da distância euclidiana e no eixo $X$ os grupos de espectros. Observa-se que o grupo $D$ possui uma distância de aproximadamente 600 em relação aos outros grupos. Portanto esse grupo de espectros possui a maior diferença entre os 4 grupos. Os outros 3 grupos restantes são similares, sendo o grupo A e B os mais similares.

Quando se faz uma análise de agrupamento não sabendo a priori quantos grupos existem, o dendograma pode fornecer informações referentes à homogeneidade dos espectros dentro de um grupo. Observando a Figura 14, podemos ver que o grupo $D$ não se divide depois de 600 enquanto que os grupos $A, B$ e $C$ se dividem depois. Portanto o grupo de espectros $D$ é mais homogêneo (menor variância interna) do que os grupos $A, B$ e C.

Existe outra forma de utilizar a análise de agrupamento cujo objetivo é agrupar os espectros de acordo com o tipo de tecidos dentro de um mapa espectral. Nesse caso se constroe um mapa com pseudocores de forma que cada cor represente um agrupamento. A Figura 15 mostra um exemplo de como é observada essa análise. 

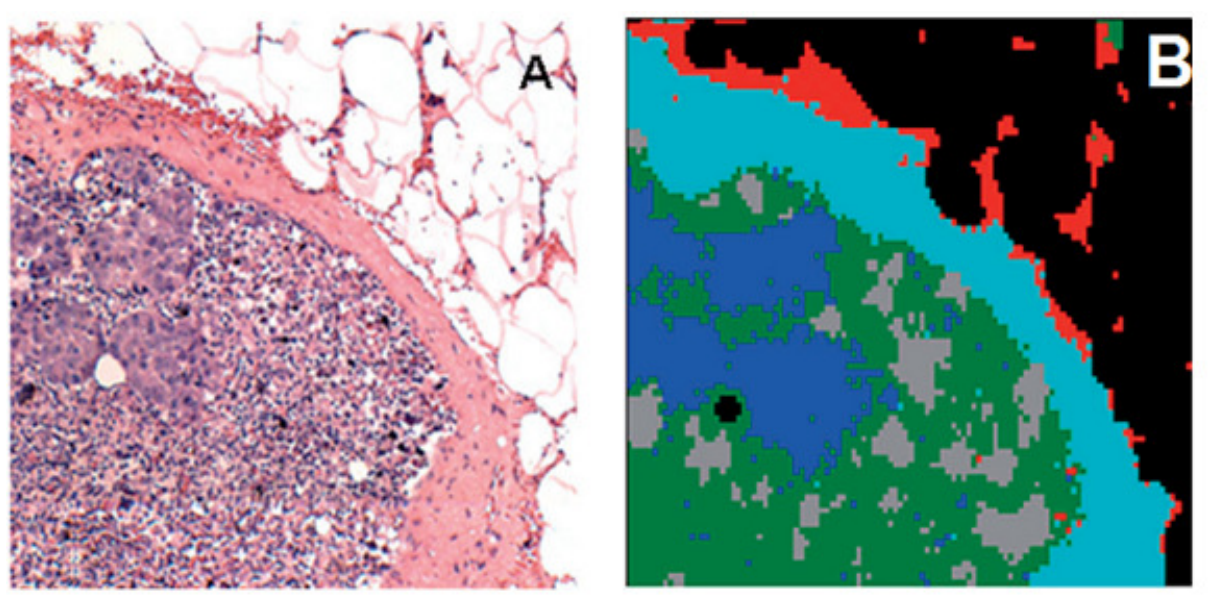

Figura 15: A-imagem histológica de um linfonodo corada com HE. B-Imagem construída a partir da análise de agrupamento com 5 grupos ${ }^{[12]}$.

\subsection{Histologia da glândula da tireóide ${ }^{[1,2]}$}

A tireóide é composta por diversos folículos que são constituídos por uma monocamada de epitélio cubóide, limitando espaços esféricos cheios de uma substância coloidal tendo como principal constituinte uma glicoiodoproteína. O tamanho desses folículos no adulto varia entre 200 a 900 micrometros. A glândula se apresenta envolvida por um tecido conjuntivo que envia septos para o interior do parênquima glandular. Esses septos chegam a todos os folículos, separando uns dos outros por uma fina fibra reticular, constituída principalmente por fibras reticulares.

A tireóide é uma glândula muito vascularizada apresentando uma extensa rede capilar sanguínea e linfática entre os folículos. As células dos capilares sanguíneos da tireóide são fenestradas, como ocorre comumente nos capilares das glândulas endócrinas. Essa disposição facilita a passagem do hormônio para dentro dos vasos.

Os aspectos dos folículos variam de acordo com a região da glândula assim como sua atividade funcional. Encontram-se folículos grandes cheios de colóide rodeados por células foliculares formando um epitélio cúbico e outros 
folículos menores apresentam um epitélio colunar. Apesar dessa grande variação no tamanho das células dos folículos, uma média desses valores pode indicar se a glândula encontra-se hipoativa ou hiperativa.

As células foliculares possuem uma lâmina basal rica em retículo endoplasmático granuloso e também grande quantidade de mitocôndrias. Nessa região acontecem vários processos importantes para a produção dos hormônios tireoidianos (triiodotirosina e Tetraiodotironina). O núcleo da célula apresenta uma forma esférica e fica situado na parte central da mesma. A parte extranuclear apresenta uma região com complexo de Golgi assim como algumas glandes para secreção da tiroglobulina.

Dentro da glândula da tireóide há outro tipo de célula. Essa célula é chamada de parafolicular, e é observada como agrupamentos isolados entre os folículos. Sua principal função é a produção de um hormônio chamado calcitonina que é responsável pela regulação do nível de cálcio no sangue. As Figura 16 e 17 mostram imagens histológicas da glândula da tireoide. 


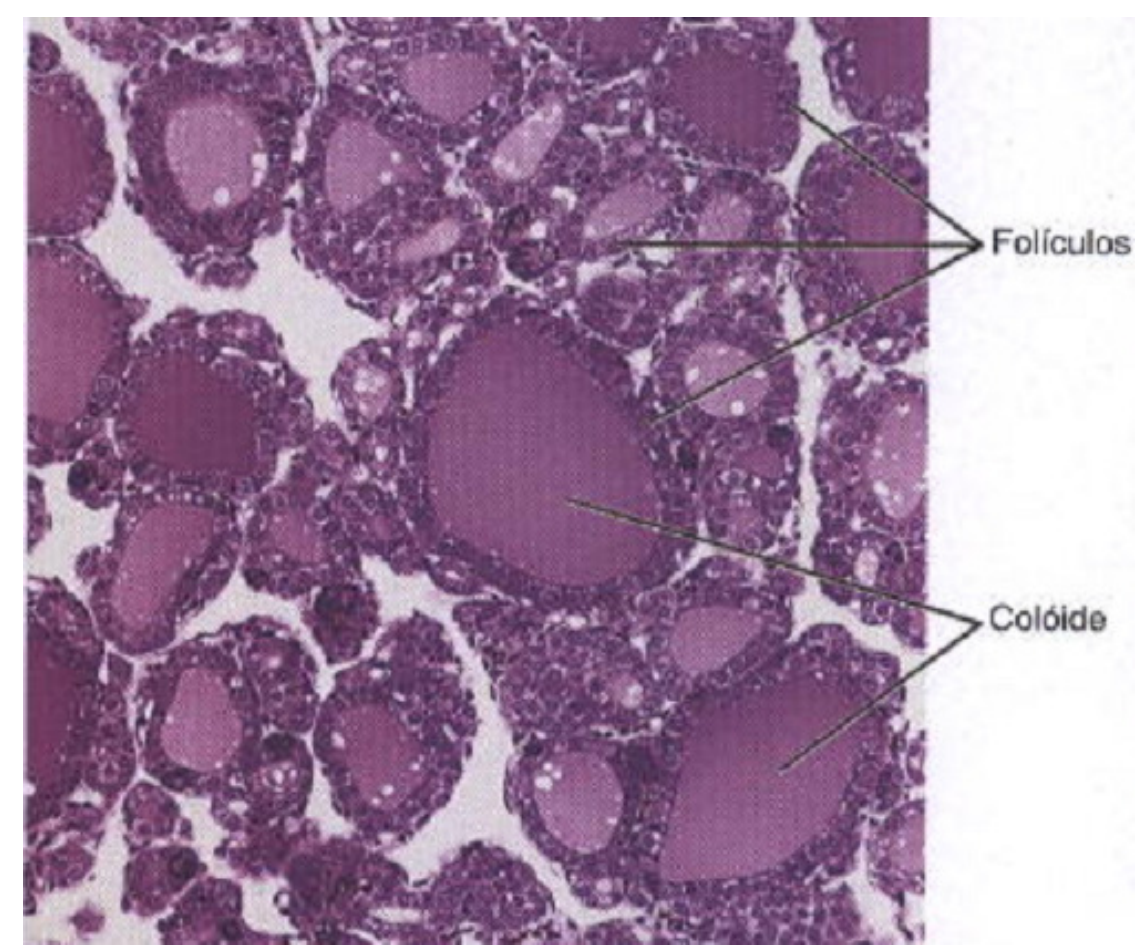

Figura 16: Microscopia de tecido tireoidiano corado com Hematoxilina e Eosina (HE) ${ }^{[6]}$.

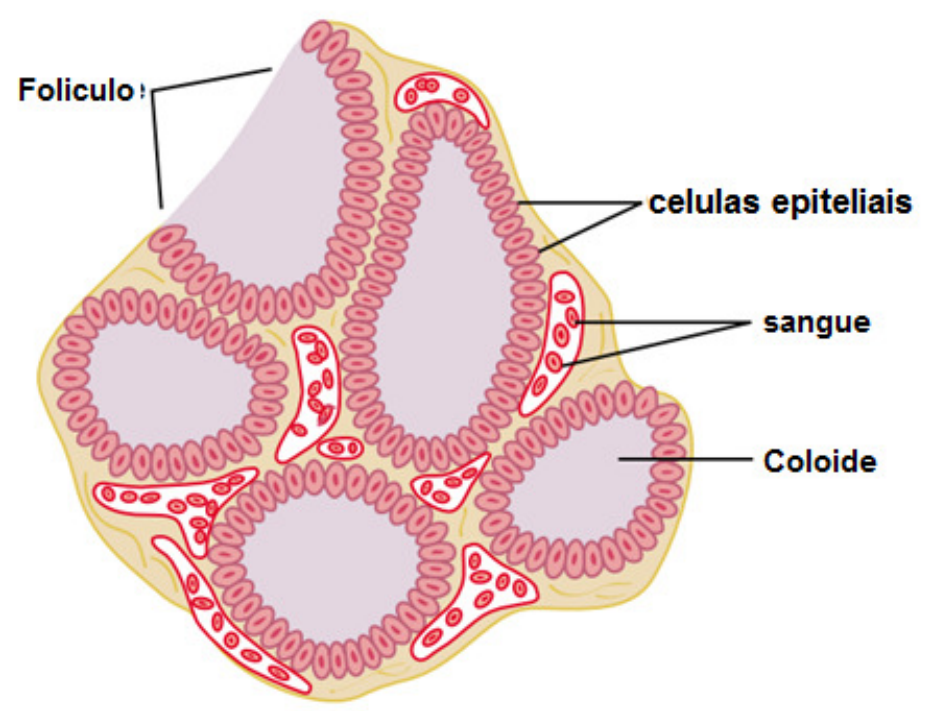

Figura 17: Desenho que representa a histologia da glândula da tireóide ${ }^{[2]}$.

\subsection{Fisiologia da tireóide ${ }^{[2,3]}$}

A tireóide é umas das maiores glândulas endócrinas do nosso corpo e pesa em torno de 17 gramas no adulto. Está localizada logo abaixo da laringe e 
anterior à traqueia. Ela secreta principalmente os hormônios Tetraiodotironina e triiodotirosina que são comumente chamados de T4 e T3 respectivamente. Além dos hormônios citados, a tireóide também produz um hormônio chamado calcitonina cuja principal função é controlar o nível de cálcio no organismo.

Os hormônios estimulantes do metabolismo (T3 e T4) estão diretamente relacionados com o aumento da taxa metabólica do nosso corpo. A falta total desses hormônios no nosso corpo leva a uma diminuição metabólica basal de até 50 \%, enquanto o excesso nos níveis desses hormônios pode até dobrar o taxa metabólica. O controle dos níveis desses hormônios no organismo é feito através de outro hormônio produzido pela hipófise chamado de hormônio estimulante da tireóide (TSH).

A tireóide produz os hormônios T3 e T4 numa proporção de aproximadamente 93 moléculas de T4 para cada 7 moléculas de T3. Apesar de quase todo hormônio T4 ser convertido em T3 nas células, os dois hormônios possuem um modo de ação similar, entretanto o hormônio T3 é aproximadamente 4 vezes mais potente que o T4.

A glândula tireóide possui uma característica particular que se deve ao fato de ser o único órgão do corpo humano que necessita de grandes quantidades de iodo. A glândula precisa desse elemento, pois para a formação dos hormônios T3 e T4, necessita-se de 3 e 4 átomos de iodo por molécula respectivamente.

\subsubsection{Formação dos hormônios}

As estruturas moleculares dos hormônios tireoidianos Triiodotirosina (T3) e Tetraiodotironina (T4) são mostradas na Figura 18. 


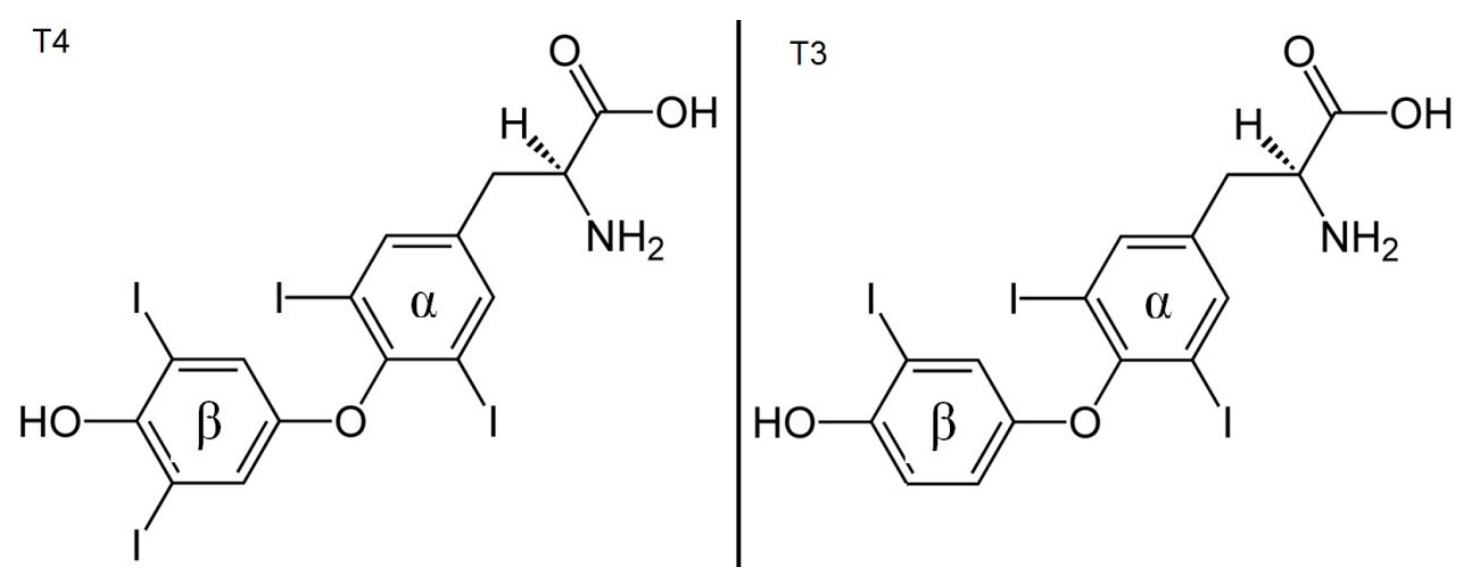

Figura 18: Estrutura da molecula dos hormônios tireoidianos.

As moléculas dos hormônios tireoidianos são formadas a partir de dois anéis fenólicos. Esses anéis na estrutura recebem a denominação de $\alpha$ e $\beta$.

A Figura 19 mostra o diagrama esquemático da formação dos hormônios tireoidianos. 


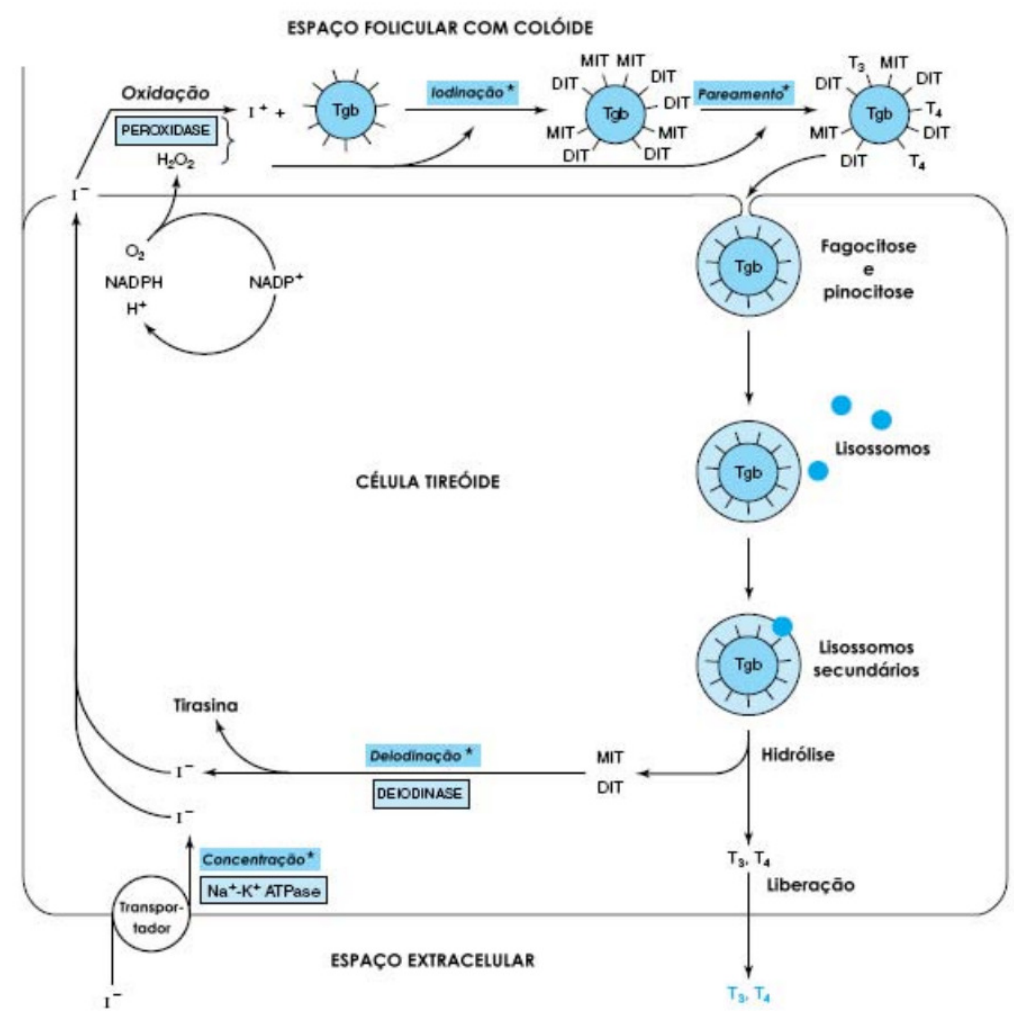

Figura 19: Diagrama que mostra o mecanismo celular para o transporte de iodo e a formação dos hormônios ${ }^{[42]}$.

O primeiro passo para a formação dos hormônios tireoidianos T3 e T4 é a concentração de iodo do sangue para dentro dos folículos. Por causa disto, a membrana basal das células foliculares possui a capacidade de bombear iodo para seu interior. Numa glândula normal essa concentração de iodo pode chegar até a 250 vezes comparada a presente no sangue.

Além do bombeamento do lodo, as células foliculares produzem uma glicoproteína chamada tiroglobulina. Cada molécula de tiroglobulina possui até 70 tirosinas, é a partir dos anéis fenólicos desses aminoácidos que começa a formação dos hormônios.

O iodo em sua forma nativa $\left(\mathrm{I}^{0}\right)$ precisa ser convertido em uma forma oxidada. Isso é necessário para que o átomo de iodo ligue-se à tirosina. Essa oxidação do iodo é feita através das enzimas oxidase e peroxidase. A peroxidase fica localizada na parte apical da membrana das células foliculares levando a formação de iodo oxidado próximo onde a célula secreta a tiroglobulina para dentro do colóide. Quando a produção de peroxidase é 
interrompida por qualquer fator adverso, a formação de hormônio é interrompida completamente.

Esse iodo oxidado vai ser ligado ao anel fenólico do aminoácido tirosina que está na cadeia peptídica da tiroglobulina. Esse processo é chamado de organificação ou iodinizaçao. Esse processo de ligação do iodo com o anel fenólico é extremamente lento, entretanto as células foliculares produzem uma enzima catalizadora de nome iosinase que torna esse processo de organificação extremamente rápido na ordem de algumas horas. O iodo pode se ligar em uma ou duas posições do anel fenólico da tirosina. Quando um iodo é ligado na posição 3 do anel aromático há formação da monoiodotirosina (MIT). Quando um segundo átomo de iodo é ligado na Monoiodotirosina na posição 5 do anel fenólico tem-se a formação da diiodotirosina (DIT). A MIT e DIT são precursores dos hormônios tireoidianos.

Após a formação destes precursores, ocorre o processo de pareamento dos mesmos. Esse processo é a ligação de 1 DIT e 1 MIT formando o triiodotirosina (T3) ou a ligação de 2 DIT formando 0 hormônio Tetraiodotironina (T4). É o último passo para a formação de uma molécula de hormônio. Esse processo pode demorar até algumas semanas para ocorrer dentro dos colóides.

Após o processo de pareamento, cada molécula de tiroglobulina possui até 30 moléculas de Tetraiodotironina e somente algumas de triiodotirosina. Esses hormônios podem permanecer ligados à estrutura do colóide por até 3 meses. Portanto a tiroglobulina pode ser considerada um reservatório de hormônio e, se por algum motivo, a produção de hormônios for interrompida, os efeitos fisiológicos dessa interrupção serão observados somente alguns meses depois.

A tiroglobulina é uma proteína que fica dentro da glândula tendo baixíssima concentração na corrente sanguínea. Portanto os hormônios são retirados da estrutura da proteína. Isso é feito pelas células foliculares que enviam pseudoextensões dentro dos colóides e captam os mesmos em pequenas porções. As células foliculares produzem uma enzima ( produzida no lisossomo) que digere a tiroglobulina e extrai os hormônios. Consequentemente 
esses hormônios são colocados na corrente sanguínea e disponibilizados para todos os órgãos do corpo.

Nesse processo de digestão da proteína sobram grandes quantidades dos precursores monoiodotirosina e diiodotirosina. Esses precursores não são secretados pela glândula para a corrente sanguínea. As células, por meio de uma enzima chamada deiodinase, removem o iodo desses precursores tendo como produto o aminoácido tirosina e iodo. A quantidade desses precursores na molécula de tiroglobulina é 3 vezes mais que os hormônios ${ }^{[43,44]}$.

\subsubsection{Tiroglobulina ${ }^{[45]}$}

A tiroglobulina é uma glicoproteína produzida pelas células foliculares e armazenada nos colóides. Ela possui características que a tornam única em nosso organismo. Dentre essas as duas mais notórias são o fato de ser a proteína encontrada nos mamíferos que contém grandes quantidades de lodo e a única capaz de produzir os hormônios tireoidianos T3 e T4. Essa produção dos hormônios Tireoidianos T3 e T4 está explicada no tópico anterior.

A tiroglobulina possui uma massa de aproximadamente $670 \mathrm{kDa}$ na sua forma mais estável e consiste de duas cadeias aparentemente idênticas contendo 2748 aminoácidos e 67 tirosinas cada.

A tiroglobulina apresenta diversos processos pós-transcripcionais. Dentre esses, o primeiro e talvez o mais importante, seja a glicosilação da proteína. A glicosilação é um processo que ocorre nas proteínas onde moléculas de açúcar são ligadas na cadeia peptídica principal. Existem dois tipos de glicosilação: a do tipo $\mathrm{N}$ e do tipo $\mathrm{O}$. A diferença entre as duas é a posição na qual o carboidrato irá se ligar à cadeia principal.

Há diversos trabalhos que mostram que a quantidade de carboidratos (açúcares) na tiroglobulina é variável ${ }^{[46]}$. Há relatos na literatura que mostram que existe uma variação na quantidade de carboidratos, bem como na quantidade total de moléculas de tiroglobulinas com pouca quantidade de iodo. As moléculas de carboidratos estão presentes na proteína por meio de ligações do tipo $\mathrm{N}$ tendo grande quantidade de manose. 
A tiroglobulina é considerada também uma iodoproteína, pois tem átomos de iodo ligados aos radicais fenólicos da tirosina. Existem diversos trabalhos na literatura que determinaram a quantidade de iodo de diversos mamíferos. Esses estudos mostram que tiroglobulina obtidas a partir tireóide com bócio ou que apresentam hiperplasia contém uma menor quantidade de iodo quando comparado com uma tireóide normal.

A conformação secundária da tiroglobulina depende da quantidade de iodo que a molécula possui devido ao processo de iodinização. Alguns trabalhos mostram que a tiroglobulina possui 2 conformações secundárias. Uma parte é puramente $\alpha$-hélice sendo altamente estruturada e contendo os hormônios (conteúdo de iodo da proteína). Outra parte é menos estruturada tendo uma conformação esclarecida.

\subsection{Lesão benigna da tireoide}

\subsubsection{Bocio $^{[5]}$}

O bócio é uma lesão benigna causada por uma hiperplasia que pode ter duas características, difusa ou nodular. Morfologicamente, o bócio apresenta áreas de proliferação de células foliculares tendo características bem similar a de uma neoplasia papilar. Esta característica esta presente em grande parto dos casos. Por isto estas estruturas macropapilares dentro do nódulo hiperplásico podem ser muito similar ao carcinoma papilifero sendo difícil a diferenciação pelo exame patológico.

Em alguns casos, O bócio nodular hiperplásico pode ser encapsulado, levando a características morfológicas semelhantes a adenomas pois atípicas celulares e irregularidade em seu limite. 


\section{MATERIAL E MÉTODOS}

\subsection{Amostras}

Microarray contendo tecidos tireoidianos foram comprados da empresa Biomax (US Biomax inc Rockville, EUA). Um microarray é um conjunto de tecidos provenientes de vários pacientes que são montados sobre uma única lâmina de microscópio. A Figura 20 mostra uma imagem de um microarray.

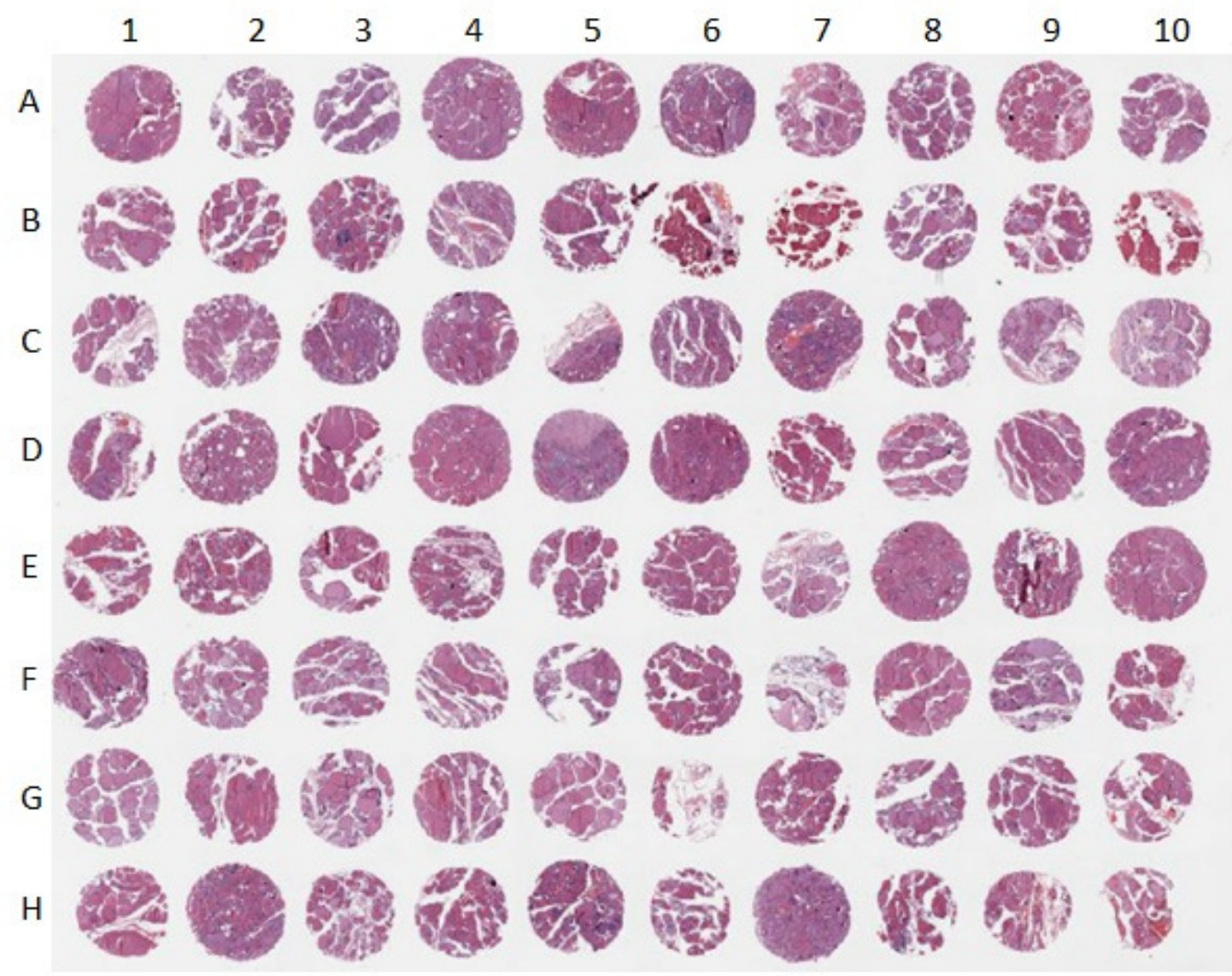

Figura 20: Imagem de um microarray produzido pela Biomax Inc.

Cada microarray consiste de 80 cortes histológicos em forma circular sendo que cada círculo é proveniente de um paciente. Cada círculo tem um diâmetro de aproximadamente $1,5 \mathrm{~mm}$, uma área de $0,07 \mathrm{~cm}^{2}$ e uma espessura de aproximadamente 5 mícrons. Todos os círculos recebem um código da seguinte forma: cada coluna é representada por um número e cada 
linha representada por uma letra em ordem alfabética. Portanto, o primeiro círculo da primeira linha e da primeira coluna recebe o código de A1 e assim sucessivamente.

Cada microarray vem acompanhado de uma tabela que contém informações sobre cada paciente e o laudo de um patologista. A Tabela 2 é corresponde à lâmina apresentada na Figura 20.

Tabela 2: Informações sobre os pacientes fornecidas pela Empresa Biomax inc.

\begin{tabular}{|c|c|c|c|c|c|c|c|}
\hline Pos & No. & Sex & Age & Organ & Pathology diagnosis & Image & Type $t$ \\
\hline $\mathrm{A} 1$ & 1 & M & 37 & Thyroid & Normal thyroid gland tissue & Image & Normal \\
\hline $\mathrm{A} 2$ & 2 & $\mathrm{~F}$ & 27 & Thyroid & Normal thyroid gland tissue & Image & Normal \\
\hline A3 & 3 & $\mathrm{~F}$ & 27 & Thyroid & Normal thyroid gland tissue & Image & Normal \\
\hline A4 & 4 & $\mathrm{M}$ & 18 & Thyroid & Normal thyroid gland tissue & Image & Normal \\
\hline A5 & 5 & $M$ & 68 & Thyroid & Normal thyroid gland tissue & Image & Normal \\
\hline A6 & 6 & $\mathrm{~F}$ & 46 & Thyroid & Normal thyroid gland tissue & Image & Normal \\
\hline A7 & 7 & $\mathrm{~F}$ & 30 & Thyroid & Normal thyroid gland tissue & Image & Normal \\
\hline A8 & 8 & $\mathrm{~F}$ & 53 & Thyroid & Normal thyroid gland tissue & Image & Normal \\
\hline A9 & 9 & $\mathrm{~F}$ & 30 & Thyroid & Normal thyroid gland tissue & Image & Normal \\
\hline A10 & 10 & $\mathrm{~F}$ & 34 & Thyroid & Normal thyroid gland tissue & Image & Normal \\
\hline B1 & 11 & $\mathrm{M}$ & 35 & Thyroid & Normal thyroid gland tissue & Image & Normal \\
\hline $\mathrm{B} 2$ & 12 & $\mathrm{~F}$ & 38 & Thyroid & Normal thyroid gland tissue & Image & Normal \\
\hline B3 & 13 & $\mathrm{~F}$ & 44 & Thyroid & Normal thyroid gland tissue & Image & Normal \\
\hline B4 & 14 & $\mathrm{M}$ & 31 & Thyroid & Normal thyroid gland tissue & Image & Normal \\
\hline B5 & 15 & $\mathrm{~F}$ & 44 & Thyroid & Normal thyroid gland tissue & Image & Normal \\
\hline B6 & 16 & $\mathrm{~F}$ & 35 & Thyroid & Normal thyroid gland tissue & Image & Normal \\
\hline B7 & 17 & $\mathrm{M}$ & 32 & Thyroid & Normal thyroid gland tissue & Image & Normal \\
\hline B8 & 18 & $\mathrm{~F}$ & 30 & Thyroid & Normal thyroid gland tissue & Image & Normal \\
\hline B9 & 19 & M & 23 & Thyroid & Normal thyroid gland tissue & Image & Normal \\
\hline $\mathrm{B} 10$ & 20 & $\mathrm{~F}$ & 36 & Thyroid & Normal thyroid gland tissue & Image & Normal \\
\hline $\mathrm{C} 1$ & 21 & M & 38 & Thyroid & Normal thyroid gland tissue & Image & Normal \\
\hline $\mathrm{C} 2$ & 22 & $\mathrm{~F}$ & 45 & Thyroid & Normal thyroid gland tissue & Image & Normal \\
\hline $\mathrm{C} 3$ & 23 & $\mathrm{~F}$ & 31 & Thyroid & Normal thyroid gland tissue & Image & Normal \\
\hline $\mathrm{C} 4$ & 24 & $\mathrm{~F}$ & 52 & Thyroid & Normal thyroid gland tissue & Image & Normal \\
\hline $\mathrm{C} 5$ & 25 & $\mathrm{~F}$ & 27 & Thyroid & Normal thyroid gland tissue & Image & Normal \\
\hline C6 & 26 & $\mathrm{~F}$ & 22 & Thyroid & Normal thyroid gland tissue & Image & Normal \\
\hline C7 & 27 & $\mathrm{~F}$ & 51 & Thyroid & Normal thyroid gland tissue & Image & Normal \\
\hline $\mathrm{C} 8$ & 28 & $\mathrm{~F}$ & 42 & Thyroid & Normal thyroid gland tissue & Image & Normal \\
\hline $\mathrm{C} 9$ & 29 & $\mathrm{~F}$ & 34 & Thyroid & Normal thyroid gland tissue & Image & Normal \\
\hline $\mathrm{C} 10$ & 30 & $\mathrm{M}$ & 48 & Thyroid & Normal thyroid gland tissue & Image & Normal \\
\hline D1 & 31 & $\mathrm{~F}$ & 48 & Thyroid & Normal thyroid gland tissue & Image & Normal \\
\hline D2 & 32 & $\mathrm{~F}$ & 42 & Thyroid & Normal thyroid gland tissue & Image & Normal \\
\hline D3 & 33 & $\mathrm{~F}$ & 36 & Thyroid & Normal thyroid gland tissue & Image & Normal \\
\hline D4 & 34 & $\mathrm{~F}$ & 45 & Thyroid & Normal thyroid gland tissue & Image & Normal \\
\hline D5 & 35 & $\mathrm{~F}$ & 26 & Thyroid & Normal thyroid gland tissue (with chronic thyroiditis)) & Image & Normal \\
\hline D6 & 36 & $\mathrm{~F}$ & 51 & Thyroid & Normal thyroid gland tissue & Image & Normal \\
\hline D7 & 37 & $\mathrm{~F}$ & 44 & Thyroid & Normal thyroid gland tissue & Image & Normal \\
\hline D8 & 38 & M & 21 & Thyroid & Normal thyroid gland tissue & Image & Normal \\
\hline D9 & 39 & $\mathrm{~F}$ & 52 & Thyroid & Normal thyroid gland tissue & Image & Normal \\
\hline D10 & 40 & $\mathrm{~F}$ & 37 & Thyroid & Normal thyroid gland tissue & Image & Normal \\
\hline E1 & 41 & $\mathrm{~F}$ & 40 & Thyroid & Normal thyroid gland tissue & Image & Normal \\
\hline E2 & 42 & $\mathrm{M}$ & 55 & Thyroid & Normal thyroid gland tissue & Image & Normal \\
\hline E3 & 43 & $\mathrm{~F}$ & 65 & Thyroid & Normal thyroid gland tissue & Image & Normal \\
\hline
\end{tabular}


O presente projeto utilizou dois tipos de microarrays: um microarray contendo 80 cortes de tecidos normais (denominação de th804); e outro contendo 35 bócios nodulares, 6 bócios difusos e 39 tireoidites (denominação de th805). Os resultados apresentados neste trabalho foram obtidos a partir da escolha aleatória de 20 cortes provenientes de pacientes normais e 20 cortes provenientes de pacientes com bócio nodular.

Para as medidas em microespectroscopia no infravermelho, os microarrays foram montado sobre uma lâmina que contém uma fina camada de prata e dióxido de estanho, a qual é altamente reflexiva na região do infravermelho ( kevley, cleveland $\mathrm{OH}$ ). Essa lâmina não foi corada com nenhum produto químico para evitar a contribuição dos corantes nos espectros infravermelhos.

Para correlacionar os resultados obtidos por espectroscopia com a análise histológica, foram comprados microrrays dos mesmos tipos, os quais foram depositados sobre uma lâmina de microscópio comum e corados com Hematoxilina e Eosina (HE). Os cortes para a montagem destas lâminas comparativas foram sequenciais ao cortes utilizados nas laminas usadas na aquisição das imagens por microespectroscopia FTIR.

O primeiro microarray, que foi montado sobre a lâmina altamente reflexiva no infravermelho (IR), sofreu um processo de desparafinização para que as bandas relacionadas a não interferisse no espectro infravermelho (IR). O processo de desparifinização utilizado no presente trabalho é amplamente reportado pela literatura ${ }^{[18,26,37,38,47]}$ e não há alterações nas proteínas ${ }^{[48]}$.

O processo de desparafinização foi realizado conforme as seguintes etapas:

1. A lâmina foi aquecida a $56^{\circ} \mathrm{C}$ durante 15 minutos.

2. A lâmina foi mergulhada em três banhos consecutivos de xileno durante 5 minutos. 
3. A lâmina foi mergulhada em dois banhos consecutivos de $100 \%$ de etanol durante um minuto.

4. A lâmina foi mergulhada em dois banhos consecutivos de etanol a $100 \%$ durante um minuto.

5. A lâmina foi mergulhada em dois banhos consecutivos de etanol a $95 \%$ durante um minuto.

6. A lâmina foi lavada cuidadosamente com água para remoção do etanol e seca.

Após o processo de desparafinização, a lâmina foi colocada num dissecador durante 24 horas para remover a água residual antes de ser realizada a medida.

Adicionalmente, foram obtidos comercialmente da Sigma-Aldrich os hormônios triiodotirosina (T3) e Tetraiodotironina (T4). Para as análises espectroscópicas, cada hormônio sintético foi dissolvido em água destilada. Uma gota desta solução contendo somente um dos hormônios foi depositada em lâminas de microscópio altamente reflexivas ao infravermelho (kevley, Chesterland, $\mathrm{OH}$ ) e secas durante 24 horas antes da medida.

\subsection{Aquisição dos espectros dos tecidos tireoidianos}

O sistema utilizado para aquisição dos dados espectrais foi Perkin Elmer, modelo Spotlight 400, que está acoplado a um microscópio. Esse equipamento possui dois sistemas de medida: point mode data collection e spectral mapping. O primeiro método foi utilizado para as medidas dos hormônios tireoidianos sintéticos e o segundo foi utilizado para aquisição dos dados.

O primeiro sistema utiliza um detector ( $\mathrm{HgCdTe})$ de elemento único com o tamanho de $100 \times 100 \mu \mathrm{m}$. O equipamento possui uma lente de magnificação 4 pela qual o feixe IR proveniente da amostra passa, levando ao aumento da resolução por um fator 4 . Esse sistema fornece a melhor relação sinal ruído, 
entretanto ele só coleta um espectro por vez, resultando a uma velocidade de medida baixa.

O segundo sistema é composto por um conjunto de 16 detectores de HgCdTe numa configuração 8X2, com um tamanho de 25X25 $\mu$ m cada um. Esse sistema, utilizando a mesma lente de magnificação 4, permite a aquisição de mapas espectrais com resolução de 6.25X6.25 $\mu \mathrm{m}$. Diferentemente do sistema anterior, esse sistema proporciona aquisição rápida de espectros, permitindo o mapeamento de aproximadamente $7000 \mu^{2}$ por segundo. Entretanto, ele coleta espectros com menor razão sinal ruído.

As imagens coletadas no presente trabalho foram feitas no modo transflexão (reflexão/transmissão) com resolução espectral de $4 \mathrm{~cm}^{-1}$, utilizando a média de 2 interferogramas por pixel. O background foi coletado numa região da lâmina que não continha nenhum tecido, usando a média de 120 interferogramas. Todo o equipamento foi purgado com ar seco mantendo a umidade relativa abaixo de 5\% para eliminar a contribuição do vapor d'água nos espectros. A Figura 21 mostra uma ilustração do modo de medida de transflexão.

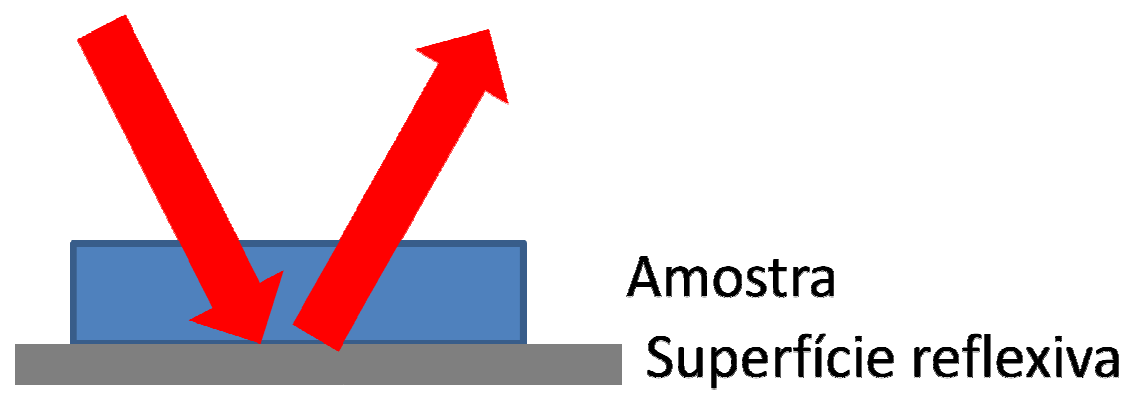

Figura 21: llustração do modo de transflexão de medida.

\subsection{Pré - processamento dos espectros dos tecidos tireoidianos}

As imagens hiper-espectrais obtidas neste trabalho possuíam aproximadamente 90.000 espectros, cada espectro contendo 1625 pontos de absorbância no intervalo de $750-4000 \mathrm{~cm}^{-1}$. Cada imagem espectral possuia aproximadamente 700 Megabytes dados brutos. A Figura 22 amostra uma 
imagem espectral sem processamento de uma amostra com área de 900 a $1800 \mathrm{~cm}^{-1}$.

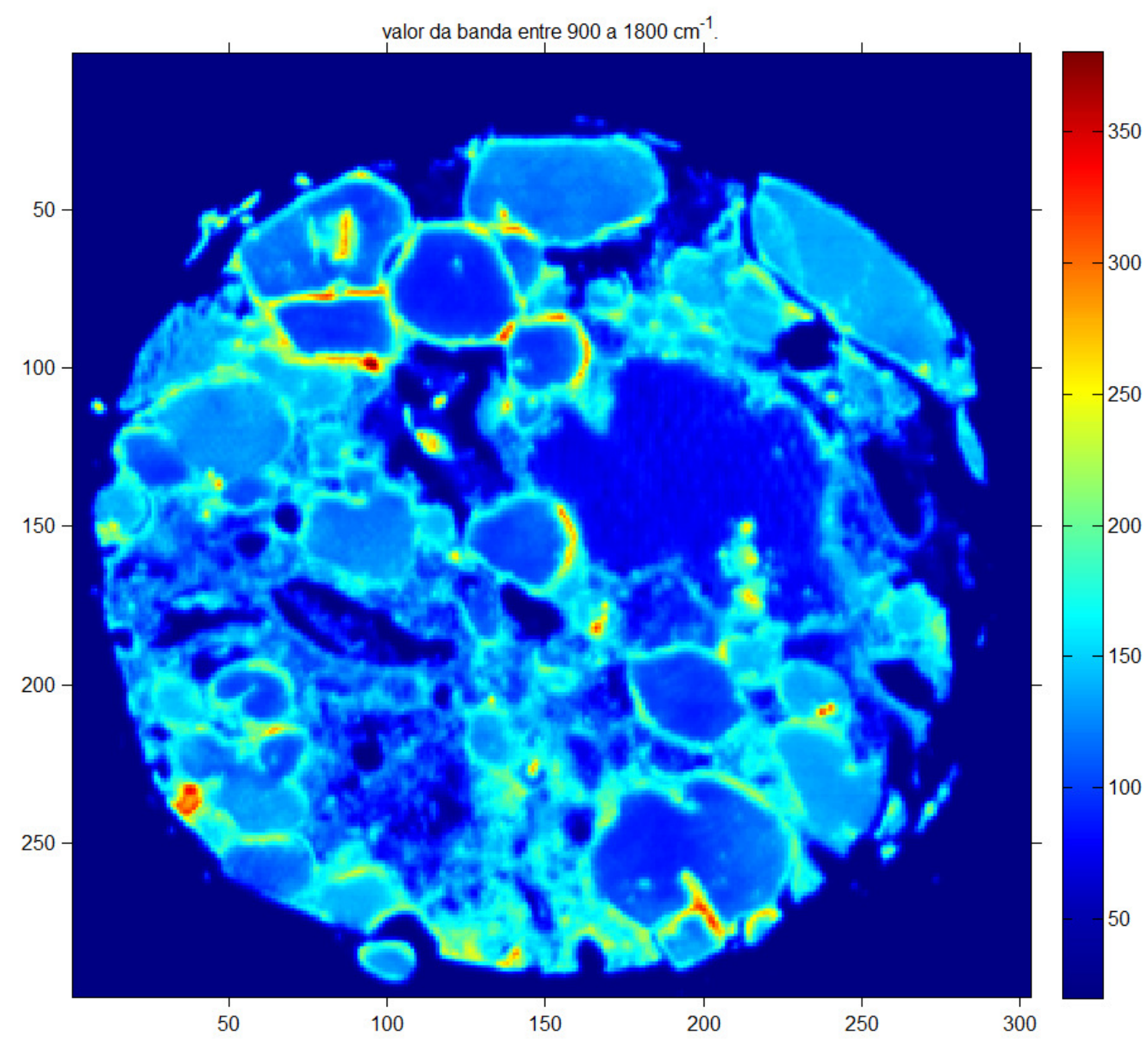

Figura 22: Imagem espectral sem processamento de uma amostra de bócio medida no presente trabalho.

O processamento das imagens espectrais foi realizado da seguinte forma:

- Remoção de pixels que não contêm amostra e/ou têm grande contribuição do espalhamento. 
- $\quad$ Remoção de ruídos utilizando a técnica de NAPC (noise adjust principal components)

- Restrição da região espectral entre $778-1800 \mathrm{~cm}^{-1}$

- Cálculos da segunda derivada utilizando o filtro svitz-golay com polinômio de segunda ordem e uma janela de 11 pontos.

- Remoção da contribuição relativa ao espalhamento dos espectros utilizando a metodologia de correção da fase.

- $\quad$ Normalização vetorial na região de $778 \mathrm{~cm}^{-1}-1800 \mathrm{~cm}^{-1}$.

- Criação de imagens com pseudocores utilizando a técnica de agrupamento hierárquico (HCA) em duas regiões espectrais: 900-1350 $\mathrm{cm}^{-1}$ e $778-1800 \mathrm{~cm}^{-1}$.

Cada um desses passos será explicado detalhadamente abaixo.

2.3.1 Remoção de pixels que não contêm amostra e/ou têm grande contribuição do espalhamento

Esta etapa tem como objetivo remover espectros com baixo valor da razão sinal ruído e/ou grandes contribuições devido ao espalhamento. Foi avaliado a região de $900-1800 \mathrm{~cm}^{-1}$, pois esta região encontra-se diversos modos vibracionais de compostos encontrados em tecidos biológicos.

Esses fatores geram diferenças nos espectros que não estão relacionados às diferenças bioquímicas na amostra, e podem impossibilitar encontrar padrões bioquímicos quando se realizam análises estatísticas multivariadas baseados em variância, tais como PCA e análise de agrupamento.

A remoção de pixel é feita por meio de testes de qualidade. Testes de qualidade são parâmetros, como por exemplo: área de uma banda, razão entre duas áreas, que são calculados em cada espectro e assim obtêm-se um número. Após a determinação desse número, encontram-se empiricamente 
valores mínimos e máximos. A Tabela 3 mostra os valores mínimos e máximos dos parâmetros calculados para o presente trabalho.

Tabela 3: Apresentação dos parâmetros calculados, valores mínimos e máximos obtidos para o teste de qualidade.

\begin{tabular}{|l|c|c|}
\hline \multicolumn{1}{|c|}{ Parâmetro } & Valor mínimo & Valor Máximo \\
\hline $\begin{array}{l}\text { área } 1600-1750 \\
\mathrm{~cm}^{-1}\end{array}$ & 5 & 500 \\
\hline $\begin{array}{l}\text { Valor máximo na } \\
\text { região de 1480 - } \\
1800 \mathrm{~cm}^{-1}\end{array}$ & 1640 & 1670 \\
\hline $\begin{array}{l}\text { Valor de área entre } \\
900-1800 \mathrm{~cm}^{-1}\end{array}$ & 15 & 400 \\
\hline $\begin{array}{l}\text { Razão de áreas da } \\
\text { amida II (1480 - } \\
\left.1580 \quad \mathrm{~cm}^{-1}\right) \text { por } \\
\text { amida I (1580 - } \\
\left.1480 \mathrm{~cm}^{-1}\right)\end{array}$ & \\
\hline
\end{tabular}

2.3.2 Remoção de ruídos utilizando a técnica de NAPC (noise adjust principal components)

Apesar de ter sido realizada a remoção de espectros que contem pequena razão sinal ruído utilizando teste de qualidade, também se utilizou um algoritimo de redução de ruído. O método utilizado no presente trabalho foi noise adjust principal components (NAPC). Esse método consiste na remoção de padrões de ruído dos espectros utilizando os padrões de ruído do instrumento de medida. Estes padrões foram obtidos dos espectros coletados nas regiões da lâmina que não continham amostras.

A seleção desses padrões de ruído em cada mapa espectral foi feita por meio de um teste de qualidade utilizando a área do espectro entre 900 $1800 \mathrm{~cm}^{-1}$. Os espectros cuja a área foi menor que 5 foram agrupados para formar o padrão. A Figura 23 mostra o mapa espectral contendo somente 0 
sinal referente ao ruído. A cor azul escura representa os pixels que foram removidos.

Para a reconstrução dos espectros foram utilizados os primeiros 40 PCs que representam mais de 99,6 \% da variância total em todas as amostras.

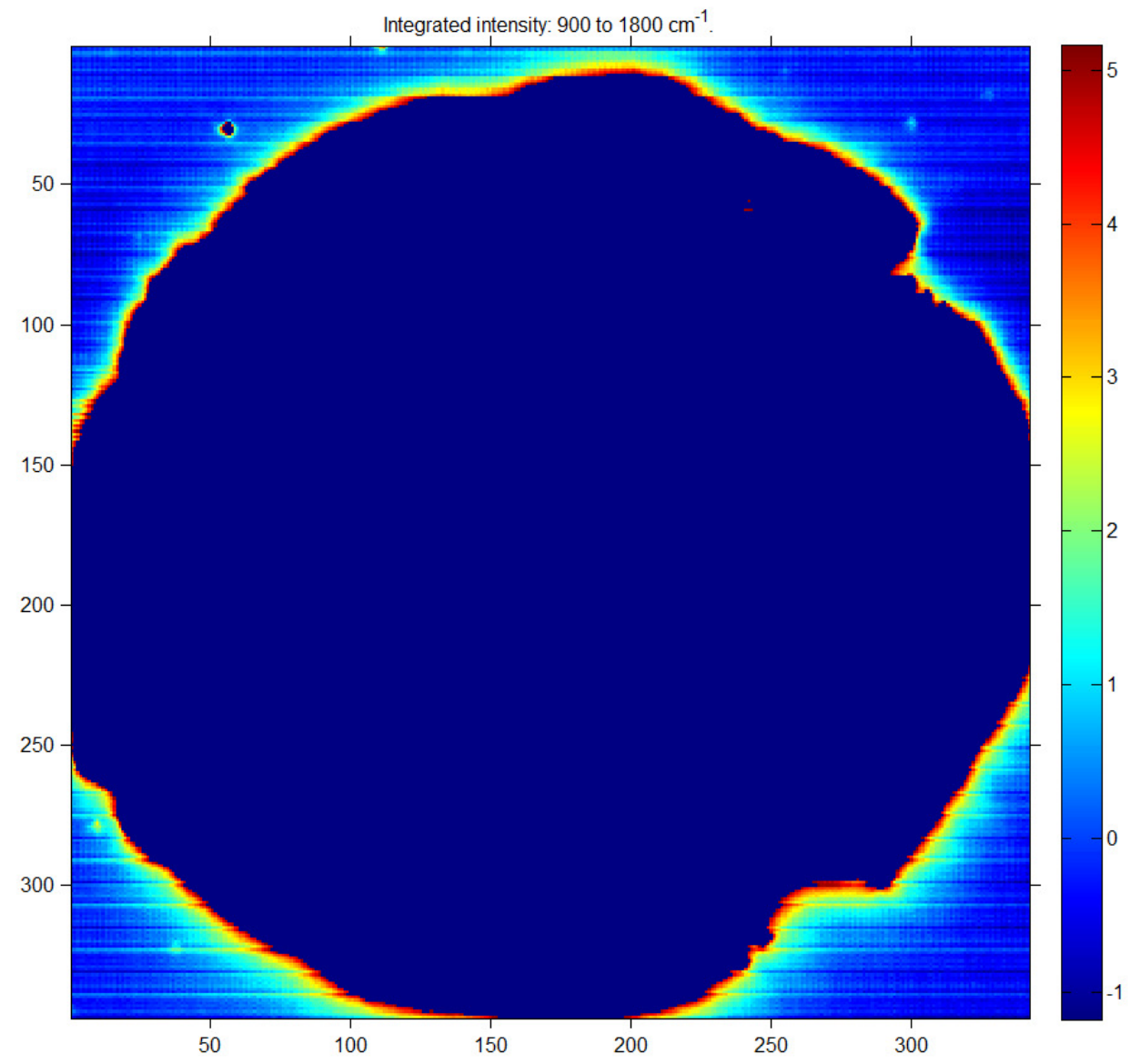

Figura 23: Mapa espectral representativo contendo somente o sinal referente ao ruído

2.3.3 Restrição da região espectral entre 778 - $1800 \mathrm{~cm}^{-1}$

O presente trabalho só utilizou a região espectral entre 778 a $1800 \mathrm{~cm}^{-1}$. Essa região foi escolhida, pois apresenta diversas bandas dos principais compostos bioquímicos encontrados em material biológico, tais como proteínas, DNA, RNA e lipídios ${ }^{[23]}$. Portanto, apesar dos espectros serem adquiridos na região entre $750 \mathrm{~cm}^{-1}$ a $4000 \mathrm{~cm}^{-1}$, apenas a região de 778 a $1800 \mathrm{~cm}^{-1}$ foi analisada. 
2.3.4 Cálculos da segunda derivada utilizando o filtro SavitzkyGolay

Foi calculada a segunda derivada de todos os espectros utilizando o filtro de suavização Savitzky-Golay com uma janela de 11 pontos e polinômio de 2 o ordem. Esse tipo de filtro de suavização é amplamente empregado em espectroscopia, e sua função é remover ruídos e bandas finas d'água na região entre 1350 e $1800 \mathrm{~cm}^{-1}$, as quais estão relacionados a modos rotacionais.

2.3.5 Correção do espalhamento dos espectros utilizando a correção da fase

A remoção do espalhamento Mie foi feita utilizando a técnica de correção de fase. Este procedimento foi feito em cada segunda derivada do espectros da imagem. Construía-se espectros utilizando 16 valores de fase entre 0 e $90^{\circ}$. O espectro utilizado foi o que apresentou o menor valor na banda da amida I no menor numero de onda.

Este metodo apresenta diversas vantagens computacionais permitindo a correção de 5 mil espectros por segundo, levando apenas alguns segundos para corrigir todos os espectros de um mapa espectral contendo aproximadamente 90 mil espectros.

\subsubsection{Normalização vetorial na região de $778 \mathrm{~cm}^{-1}-1800 \mathrm{~cm}^{-1[49]}$}

Para os espectros poderem ser comparados um com os outros se faz necessária uma normalização dos mesmos. Existem diversas formas de normalizar os espectros, no presente trabalho se utilizou a normalização vetorial que tem como principal característica remover o efeito da espessura da amostra nos espectros.

A normalização vetorial é realizada em cada espectro conforme a Equação 24. 


$$
X_{n \text { normalizado }}=\left(\frac{X_{n}-\operatorname{media}(X)}{\text { desviopadrao }(X)}\right)
$$

Equação 24

onde: $X$ representa um vetor do espectro, $n$ representa o número de onda correspondente dentro vetor.

2.3.7 Imagens com pseudocores utilizando a técnica de agrupamento hierárquico (HCA)

Após ter sido feito o pré-processamento dos mapas espectrais, foi realizada uma análise hierárquica de agrupamento utilizando as regiões de 900 - $1800 \mathrm{~cm}^{-1}$ e 900 - $1350 \mathrm{~cm}^{-1}$. Para essa análise foi utilizada a distância euclidiana para o cálculo da matriz de similaridade e o método de Ward para realizar o agrupamento.

A partir do agrupamento realizado, para cada amostra foram montados 14 mapas contendo de 2 a 15 cores, com objetivo de relacionar qual destes mapas teria melhor relação com estruturas histológicas. A Figura 24 mostra um mapa de pseudocores com 3 e 9 agrupamentos e uma imagem histológica correspondente.
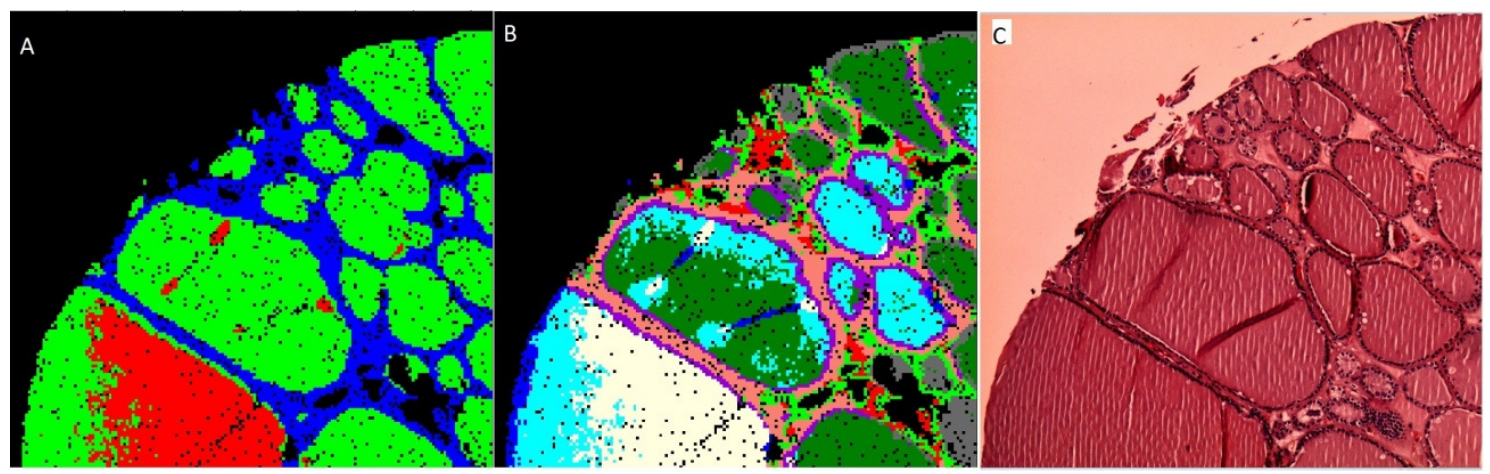

Figura 24: A- imagem de HCA com 3 agrupamentos, B- 6 agrupamentos, C - imagem histológica correspondente.

Desta forma é possível utilizar a imagem histológica para definir as estruturas representadas na imagem espectral. Utilizando a Figura 24 como 
exemplo, suponhamos que queiramos todos os espectros referentes aos colóides desse tecido, então, pegaremos os espectros dos agrupamentos verdes e vermelhos da Figura 24-a. Caso precisemos dos espectros das células foliculares, pegaremos o agrupamento roxo da figura 3-b.

Foi também construído um mapa com a intensidade da segunda derivada no número de onda de $1468 \mathrm{~cm}^{-1}$, com o objetivo de observar a distribuição espacial dos precursores dos hormônios.

\subsection{Análise dos coloides}

Após a correlação entre as imagens de pseudocores e as imagens histológicas, todos os agrupamentos que não estavam relacionados com os colóides foram removidos da imagem espectral. $O$ objetivo desta análise foi observar as diferenças bioquímicas entre os coloides de cada tecido.

Para isto foi feita uma nova análise de agrupamento utilizando distância euclidiana para cálculo da matriz de similaridade e o método de Wards para o agrupamento utilizando somente a região da amida I (1600 - $\left.1700 \mathrm{~cm}^{-1}\right)$.

Essa última análise de agrupamento foi feita com o objetivo de determinar a distribuição espacial dos padrões conformacionais da tiroglobulina, e tentar correlacionar com outros fatores bioquímicos tais como glicosilação e quantidade iodo.

\subsection{Hormônios tireoidianos sintéticos}

\subsubsection{Aquisição dos espectros}

A fim de identificar a contribuição dos hormônios tireoidianos nos espectros dos tecidos, os espectros de FTIR dos hormônios tireoidianos triiodotirosina (T3) e Tetraiodotironina (T4) foram coletados por microespectroscopia no IR. 
As medições FTIR foram feitas em modo de transflexão utilizando um sistema de imagem de FTIR (Spectrum 1/Spotlight 400, Perkin Elmer, Shelton, $\mathrm{CT}$ ), com um detector $\mathrm{HgCdTe}$ de único elemento com área de $100 \mu \mathrm{m} \times 100$ $\mu \mathrm{m}$. O espectro de cada hormônio foi obtido com resolução espectral de $4 \mathrm{~cm}^{-1}$ a partir da média de 1.024 interferogramas entre $700 \mathrm{~cm}^{-1} \mathrm{e} 4000 \mathrm{~cm}^{-1}$.

\subsubsection{Análise dos espectros}

Os espectros foram importados para o software Matlab e foram convertidos para a segunda derivada utilizando o filtro Savitzky-Golay com um polinômio de segunda ordem e uma janela de 11 pontos (os mesmos utilizados anteriormente). Após a obtenção da segunda derivada foi feita uma normalização vetorial na região de $778 \mathrm{~cm}^{-1}$ até $1800 \mathrm{~cm}^{-1}$ 


\section{RESULTADOS E DISCUSSÃO}

\subsection{Dados espectrais dos hormônios tireoidianos}

A tireóide produz três hormônios como a triiodotirosina, tetraiodotironina e calcitonina que controlam uma variedade de processos fisiológicos. Uma das principais informações para um correto diagnóstico da uma desordem da glândula é a quantidade de hormônios que a glândula secreta, normalmente realizado por meio de um teste de sangue.

A presente seção visa apresentar os espectros obtidos a partir de hormônios sintéticos, e identificar eventuais bandas presentes no espectro infravermelho do tecido tireoidiano, que esteja relacionado aos hormônios. Esta informação, obtida a partir de um corte histológico pode ser de grande valia, pois permitirá estabelecer a quantidade de hormônio presente dentro da região da glândula analisada.

Abaixo a Figura 25 mostra os espectros dos hormônios triiodotirosina (T3), Tetraiodotironina (T4), diiodotirosina (DIT), tirosina e tecido tireoidiano. Os espectros referentes a tirosina e diiodotirosina foram obtidos da literatura ${ }^{[50]}$. 


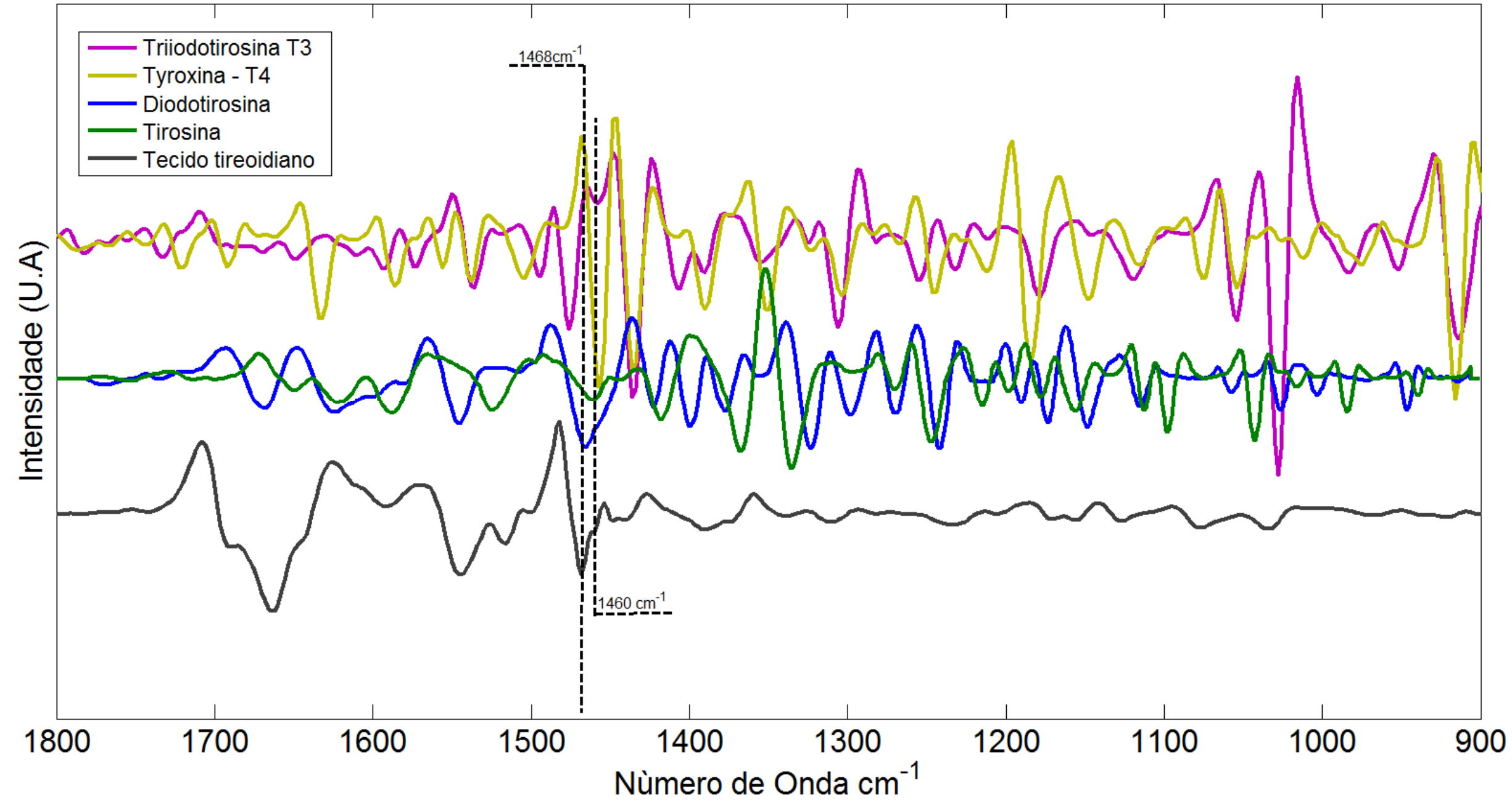

Figura 25: Segunda derivada do espectro dos hormônios triiodotirosina - T3 (roxo); Tetraiodotironina - T4 (Mostarda); diiodotirosina - DIT (azul), tirosina (verde) e tecido tireoidiano (cinza). 
Os espectros referentes aos hormônios T3 e T4 mostram fortes bandas em 916, 1190, 1458, 1476 e $1630 \mathrm{~cm}^{-1}$. No espectro da diiodotirosina observase uma banda forte em $1468 \mathrm{~cm}^{-1}$. No espectro proveniente de tecido tireoidiano observam-se diversas bandas intensas entre $900-1800 \mathrm{~cm}^{-1}$, entretanto as únicas bandas que conseguimos correlacionar aos hormônios e/ou seus precursores é $1468 \mathrm{~cm}^{-1}$ além de um ombro em $1458 \mathrm{~cm}^{-1}$.

Alvarez et al. ${ }^{[51]}$ utiliza cálculos teóricos que mostram que os hormônios T3 e T4 possuem um modo vibracional em $1461 \mathrm{~cm}^{-1}$. Este modo vibracional está relacionado à vibração do anel fenólico quando um átomo de iodo está ligado ao anel $\beta$. Portanto, acredita-se que o ombro observado em $1458 \mathrm{~cm}^{-1}$ no espectro dos tecidos tireoidianos está relacionado à quantidade de hormônios.

Apesar de não ser observada a banda em $1468 \mathrm{~cm}^{-1}$ nos espectros dos hormônios e tirosina, a mesma é visualizada no espectro da DIT que é um dos precursores dos hormônios. A diferença entre a molécula de tirosina e DIT são os dois átomos de iodo ligados ao anel fenólico. Portanto, acredita-se que essa banda em $1468 \mathrm{~cm}^{-1}$ esta relacionada com a quantidade de iodo ligado à tirosina, a qual está ligada à cadeia peptídica da tiroglobulina.

Portanto supõe-se que fazendo o mapa espectral da banda em $1468 \mathrm{~cm}^{-}$ 1 obtém-se uma imagem relacionada à distribuição de iodo ligado a tiroglobulina. Este resultado é importante, pois este tipo de informação bioquímica obtida dentro de um corte histológico pode ajudar o patologista no diagnóstico de neoplasias tireoidianas. No melhor do nosso conhecimento, ainda não há técnicas na literatura que reportem este tipo de quantificação diretamente no tecido em uma lâmina histológica.

Na Figura 26, observam-se 2 mapas com a intensidade em 1458 e 1468 $\mathrm{cm}^{-1}$ que estão relacionados à quantidade de hormônios tireoidianos e seu precursor DIT, respectivamente. Observa-se uma relação inversa na intensidade entre esses dois números de onda. Em regiões que possuem grandes quantidades de precursor, há pequenas quantidades de hormônios e vice-versa. 

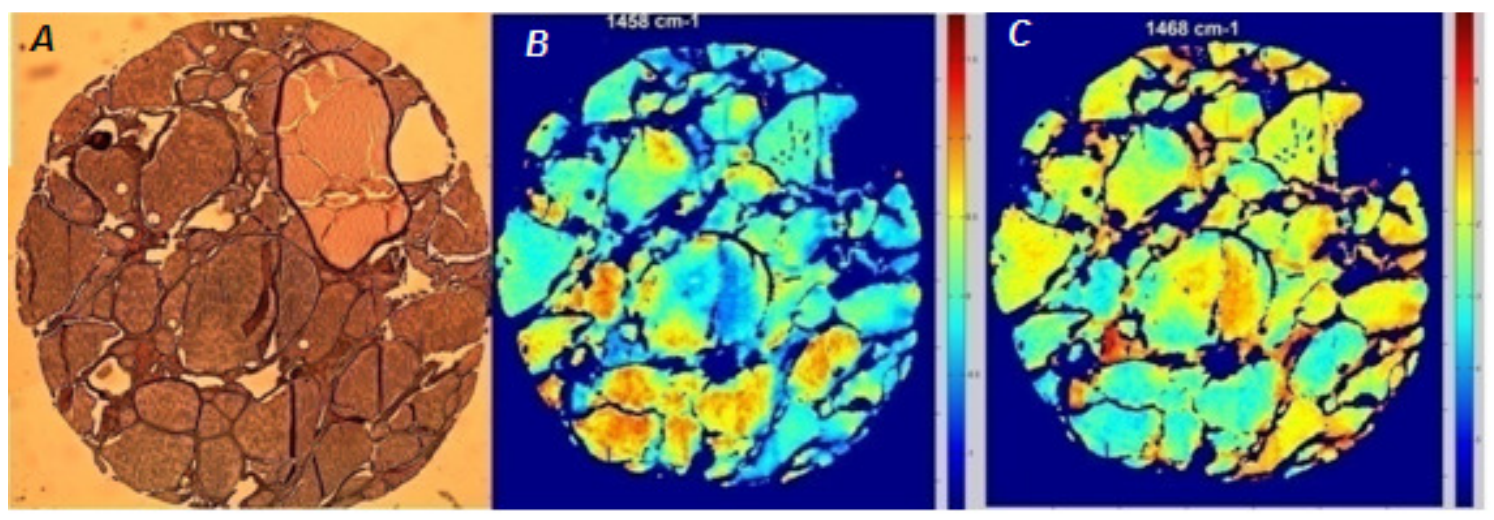

Figura 26: A - imagem histológica corada com HE, B - intensidade da $2 \circ$ derivada em $1458 \mathrm{~cm}^{-1}, \mathrm{C}$ - intensidade da $2^{\circ}$ derivada em $1468 \mathrm{~cm}^{-1}$.

Apesar da banda em $1458 \mathrm{~cm}^{-1}$ ser extremamente ativa no IR, como pode ser observado no espectro do hormônio, a intensidade dela é aproximadamente três vezes menor do que a intensidade em $1468 \mathrm{~cm}^{-1}$, que está relacionada ao seu precursor. Esse resultado era esperado, pois a tiroglobulina possui três vezes mais moléculas de mono e diiodotirosina do que moléculas de hormônios ao final do processo de formação ${ }^{[45]}$. 


\subsection{Dados espectrais dos tecidos normais}

Existem diversos trabalhos sobre informações bioquímicas da tireoide, mas ainda hoje ela é estudada devido a sua complexidade bioquímica. Ela apresenta características únicas tais como uma histologia singular e por ser a única glândula do nosso organismo que necessita de iodo para seu correto funcionamento ${ }^{[2]}$.

Devido a esta complexidade bioquímica foi necessária a caracterização espectroscópica dos tecidos tireoidianos normais. O objetivo foi determinar quais processos fisiológicos e padrões bioquímicos são possíveis de determinar através desta técnica, para permitir desenvolver futuras ferramentas que auxiliem num melhor diagnóstico.

A Figura 27 mostra uma imagem de agrupamento feita com dados da região espectral entre $900-1800 \mathrm{~cm}^{-1}$. Os padrões observados neste corte também foram observados em todos os outros cortes histológicos provenientes de outros pacientes normais.
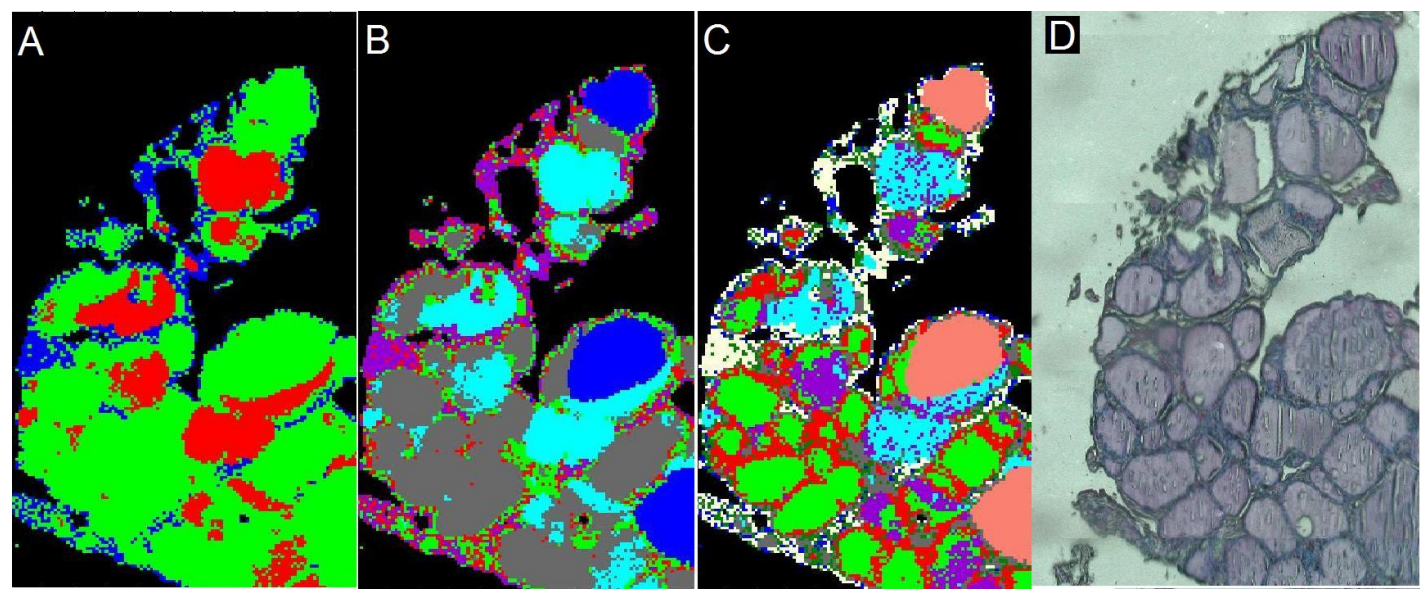

Figura 27- Imagens dos agrupamentos construída a partir de dados espectrais da região entre $900 \mathrm{e} 1800 \mathrm{~cm}^{-1}$ : A - três agrupamentos; B - seis agrupamentos; C - nove agrupamentos. Imagem histológica (HE) - D.

A Figura 27 com 3 e 6 agrupamentos revelam somente os colóides, pois as principais mudanças bioquímicas estão relacionadas a diferentes conformações secundárias da tiroglobulina, que são o principal constituinte dos coloides. Essas diferenças na conformação secundária são observadas na 
região da amida I, a qual tem a maior variância dentro da base dos dados espectrais, portanto a maior contribuição para matriz de similaridade que foi utilizada na análise de agrupamento (HCA).

A Figura 27 - C mostra a imagem obtida pela técnica de HCA com 9 agrupamentos. Observa-se uma "pixelization" dentro de alguns coloides que não está relacionada com nenhuma mudança morfológica. Isto pode estar relacionado a contribuições dispersivas, principalmente divido ao espalhamento Mie, que distorce bandas principalmente nas regiões da amida I e II. Entretanto, não há grandes diferenças no índice de refração dentro dos coloides que justifique uma grande contribuição no espalhamento, uma vez que esses são constituídos quase em sua totalidade por uma solução coloidal de

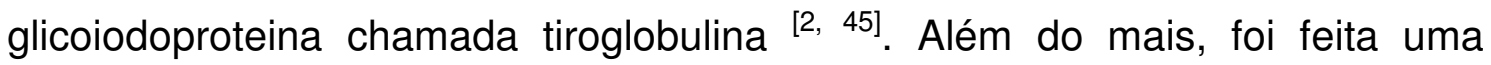
correção de fase nos espectros a fim de eliminar esta contribuição devido ao espalhamento, que já foi testada e reportada pela literatura ${ }^{[12,26,52]}$.

Foi observado na Figura 27-C (9 agrupamentos) que o agrupamento vermelho está fortemente relacionado com as células foliculares. Entretanto, ele tem uma espessura um pouco maior do que das células observadas na imagem HE (Figura 27-D). Isso não pode ser atribuído a efeitos de espalhamento Mie, porque nessas regiões não tem grandes diferenças no índice de refração devido à anatomia da própria glândula.

Acredita-se que este efeito observado no agrupamento vermelho seja devido a similaridades bioquímicas entre as células foliculares e os coloides. Estas células são uma monocamada epitelial cercada pelos coloides que são produzidos e processados pela própria célula ${ }^{[6]}$. Portanto os espectros dessas células têm uma grande quantidade de tiroglobulina que torna difícil a separação nesta região espectral, pois a região de amida I (proteínas) possui a maior contribuição na matriz de similaridade quando a análise de agrupamento foi realizada.

A Figura 28 mostra imagens de agrupamentos feitas na região espectral de 900 a $1350 \mathrm{~cm}^{-1}$. As células foliculares já são reveladas na imagem com 4 agrupamentos (Figura 28-A), sendo semelhante a imagem com seis 
agrupamentos (Figura 28-B). Esse resultado sugere que as células foliculares possuem um espectro bem homogêneo entre 900 ate $1350 \mathrm{~cm}^{-1}$. A imagem de agrupamento com 9 cores está bem relacionada com a imagem histológica, e não possui qualquer efeito de "pixelization" dentro dos coloides. Portanto a região entre $900-1350 \mathrm{~cm}^{-1}$ foi a que melhor separou células foliculares e colóides quando comparada a região de $900-1800 \mathrm{~cm}^{-1}$.

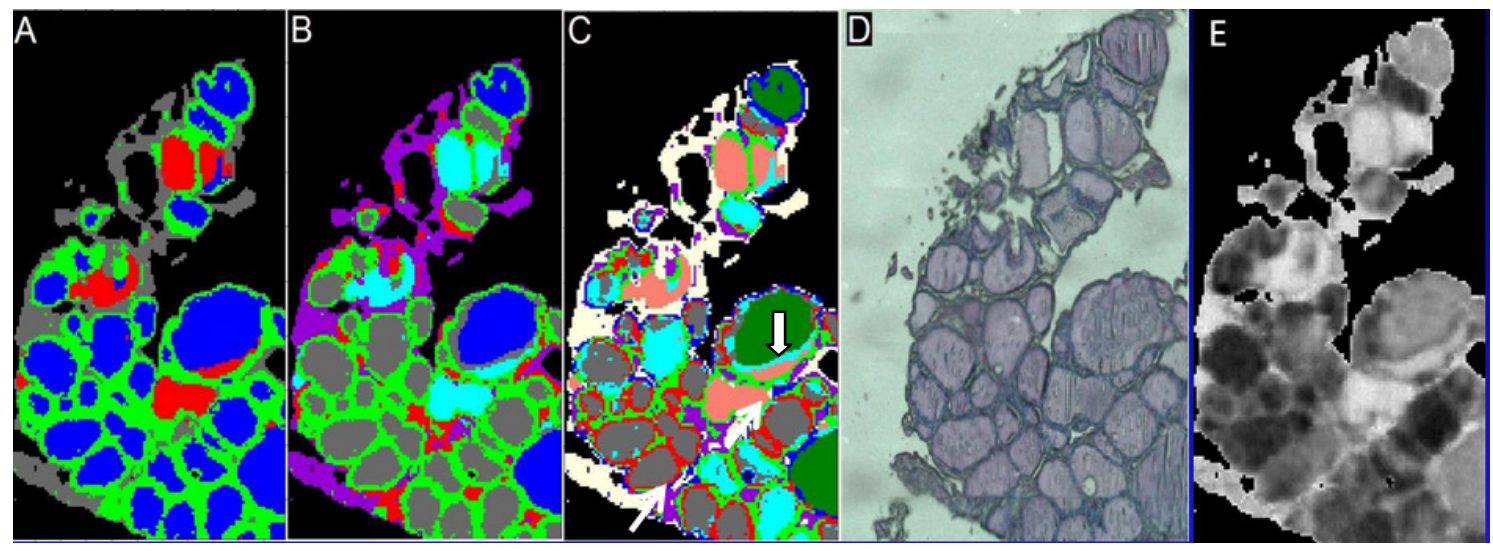

Figura 28: Imagens de agrupamentos construídas a partir de dados espectrais da região entre 900 e $1350 \mathrm{~cm}^{-1}$. A - 4 agrupamentos; B - 6 agrupamentos; C - 9 agrupamentos. Dimagem do tecido corado com HE. E - intensidade do espectro em $1468 \mathrm{~cm}^{-1}$, regiões mais escuras possuem intensidade maior.

Na Figura 28 - C nota-se que os agrupamentos verdes e vermelhos estão mais bem relacionados às células foliculares do que na Figura 27 . Isso ocorre porque restringir a região de análise entre $900-1350 \mathrm{~cm}^{-1}$ tem como consequência o aumento da contribuição das bandas de DNA e RNA na matriz de correlação, enfatizando as diferenças bioquímicas entre os coloides e as células foliculares.

Diante do exposto acima, verifica-se que a coleta de espectros de uma monocamada de células foliculares é bastante difícil, pois essas células estão alocadas nas bordas dos coloides e possuem uma espessura por volta de 10 mícrons ${ }^{[53]}$, logo a imagem precisa ter alta resolução espacial. Há muitos trabalhos na literatura ${ }^{[13,38,54,55]}$ que ao utilizar resolução próxima ao limite de difração na obtenção de espectros fazem a média de 4 pixels vizinhos, formando um pixel médio para aumentar a razão sinal ruído. Entretanto, isso diminui a resolução espacial da imagem para 12,5 mícrons, que no caso dos 
tecidos tireoidianos torna o pixel maior do que o tamanho das células foliculares. Neste trabalho, não foi necessário utilizar essa metodologia, pois coletamos bons espectros com alta razão sinal ruídos utilizando a resolução de 6,25 mícrons.

A Figura 28 - E, mostra a intensidade em $1468 \mathrm{~cm}^{-1}$ a qual está relacionada à quantidade de mono e diiodotirosina. Observa-se que as quantidades desses precursores estão relacionadas com as cores verde, ciano, salmão, cinza da Figura 28 - C, que por sua vez podem ser associados aos colóides. Nota-se que áreas que possuem grandes quantidades de iodotirosina (áreas escuras na Figura 28-E) são cobertas pelo agrupamento cinza, enquanto áreas claras são cobertas pelo agrupamento salmão.

Essa relação entre os agrupamentos dos coloides e a intensidade em $1468 \mathrm{~cm}^{-1}$ só é observada quando se constrói a imagem de agrupamento utilizando a região de $900-1350 \mathrm{~cm}^{-1}$. Esta região tem diversas bandas de glicosacarídeos $\left(1000-1100 \mathrm{~cm}^{-1}\right)$ e amida III $\left(1200-1400 \mathrm{~cm}^{-1}\right)^{[56]}$. Sabe-se que a amida III é sensível a ligações laterais na cadeia peptídica principal, a qual pode ser relacionada a glicosilação da tiroglobulina ${ }^{[56]}$. Portanto a análise de agrupamento utilizando essa região pode agrupar os espectros de acordo com padrões de glicosilação.

A Figura 29 mostra o espectro médio dos colóides e das células foliculares. Os espectros são bem similares, portanto o espectro médio das células possui uma grande contribuição da tiroglobulina, principalmente na região da amida $\mathrm{I}\left(1600-1700 \mathrm{~cm}^{-1}\right)$. Esse resultado é esperado, pois os colóides são produzidos e processados pelas células. 


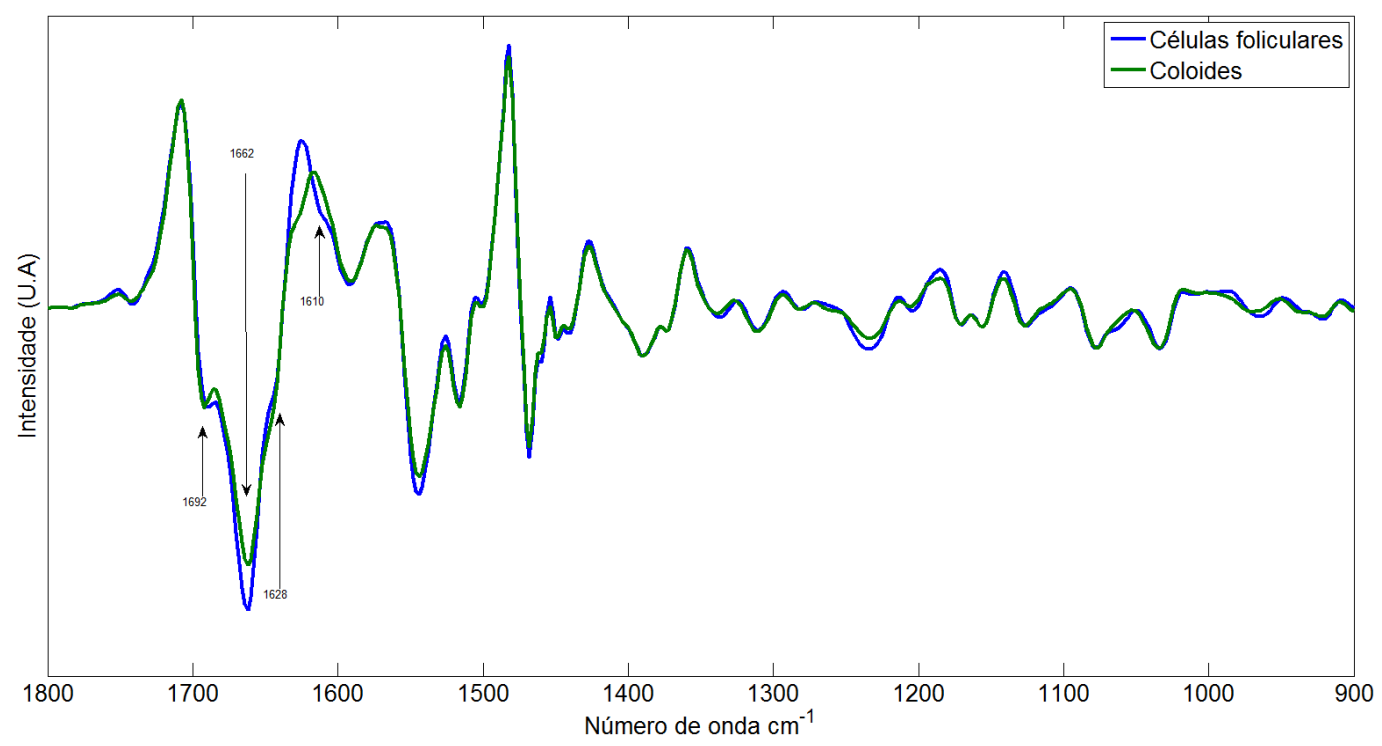

Figura 29: Média das segundas derivadas dos espectros das células foliculares (azul) e dos colóides (verde).

No espectro médio das células nota-se um ombro na região de $1610 \mathrm{~cm}^{-1}$ que está relacionado ao aminoácido tirosina ${ }^{[57,58]}$. Esse modo vibracional está relacionado com estiramento C-C do anel fenólico. Há trabalhos na literatura que mostram ${ }^{[45]}$ que a tireóide possui uma grande quantidade de tirosina para a produção da tiroglobulina, e consequentemente para produzir os hormônios T3 e T4. Nos colóides não se observou esse ombro, possivelmente devido à grande parte dessa tirosina já ter sido iodinizada e convertida em mono ou diiodotirosina.

A Figura 30 mostra os espectros médios dos agrupamentos relacionados aos colóides. Observa-se que as maiores diferenças nos colóides estão na região da amida I (1600 $\left.-1700 \mathrm{~cm}^{-1}\right)$, que é extremamente sensível a estrutura secundária. Nos espectros verde, ciano e cinza nota-se uma sobreposição de três picos: 1694, 1628 e $1662 \mathrm{~cm}^{-1}$. Os dois primeiros picos indicam a estrutura secundária $\beta$ folha, enquanto que o último indica a estrutura $\alpha$-hélice. $O$ espectro salmão apresenta um padrão completamente diferente dos outros três espectros, não mostrando claramente nenhuma das duas estruturas secundárias. 


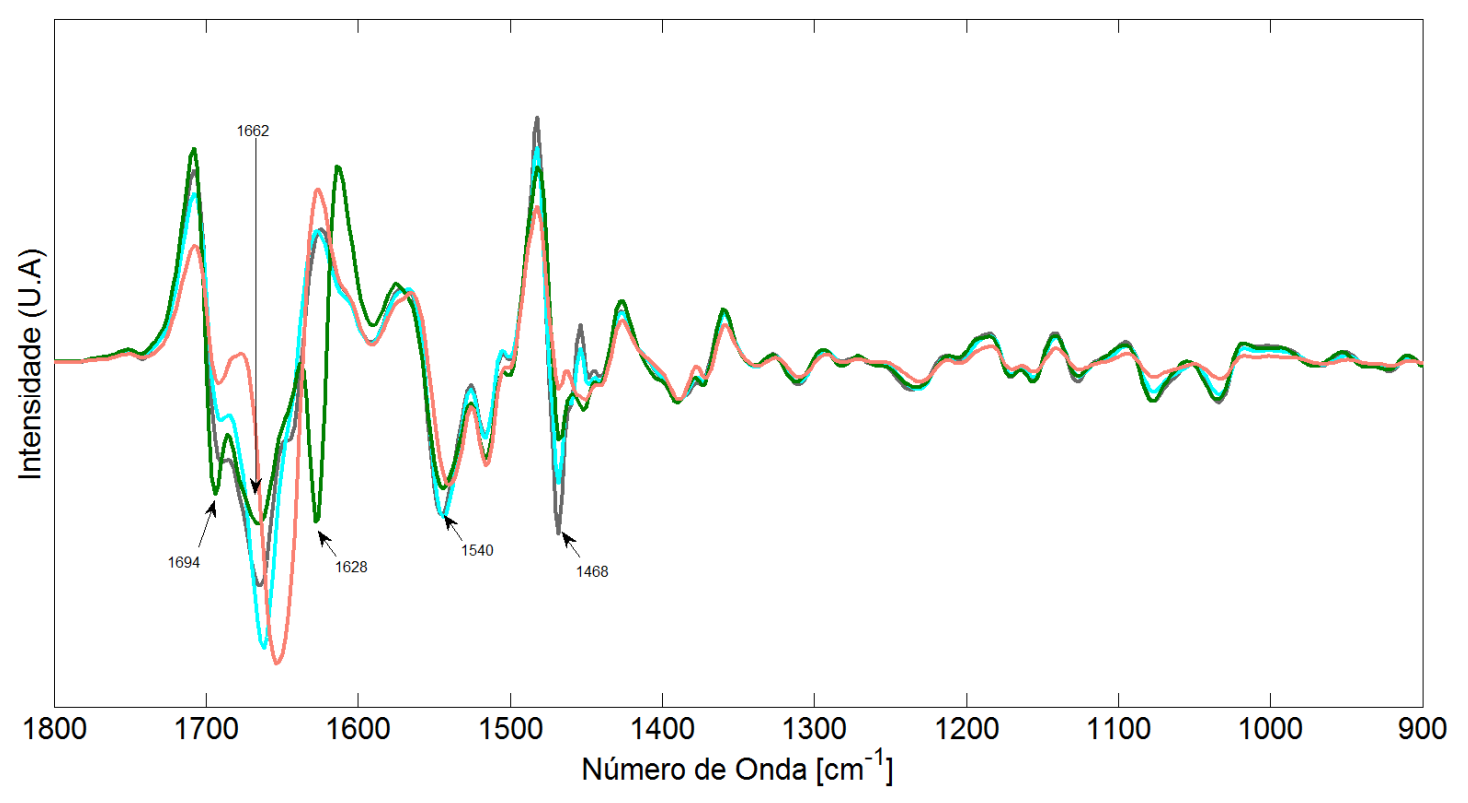

Figura 30: Média das segundas derivadas dos espectros dos agrupamentos relacionados aos coloides vistos na figura 28 -C.

Também se observa diferenças na região da amida II (1480-1580 $\left.\mathrm{cm}^{-1}\right)$, principalmente na banda em torno de $1540 \mathrm{~cm}^{-1}$ que é relacionada a um acoplamento de estiramento $\mathrm{C}-\mathrm{N}$ com flexão $\mathrm{N}-\mathrm{H}$. Possivelmente, esta diferença pode estar relacionada a estruturas secundárias da proteína ou a cadeias laterais ligadas com cadeia peptídica principal.

Além das observações relatadas, há diferenças na região de baixo número de onda observam-se diferenças de intensidade na região de $1000 \mathrm{a}$ $1100 \mathrm{~cm}^{-1}$. Essa região é amplamente estudada, pois possui diversos modos vibracionais relacionados à diferentes tipos de açucares ${ }^{[23]}$.

Os dados até aqui relatados mostram que a região entre $900-1350 \mathrm{~cm}^{-1}$ é a melhor para a realização das análises de agrupamento. Para verificar se esta região pode ser utilizada em qualquer corte histológico de uma glândula tireoidiana foram realizadas 2 análises de PCA com 4 mil espectros de células foliculares e 4 mil espectros de coloides provenientes de 20 pacientes normais.

Na Figura 31-A a análise de PCA foi feita na região de $900-1350 \mathrm{~cm}^{-1}$ enquanto na Figura 31-B a análise foi feita na região entre $900-1800 \mathrm{~cm}^{-1}$. Verifica-se que a melhor separação ocorre quando se utiliza a região de 900 - 
$1350 \mathrm{~cm}^{-1}$. O mesmo foi obtido nas análises de agrupamento cujos resultados são apresentados nas Figura 27 e Figura 28.

Apesar da região de 900 - $1350 \mathrm{~cm}^{-1}$ possuir menor quantidade de informação espectral que a região de $900-1800 \mathrm{~cm}^{-1}$, a analise de PCA assim como de agrupamento tornam se melhores, pois há um aumento da contribuição das bandas de DNA e RNA na matriz de correlação, enfatizando as diferenças bioquímicas entre os coloides e as células foliculares.
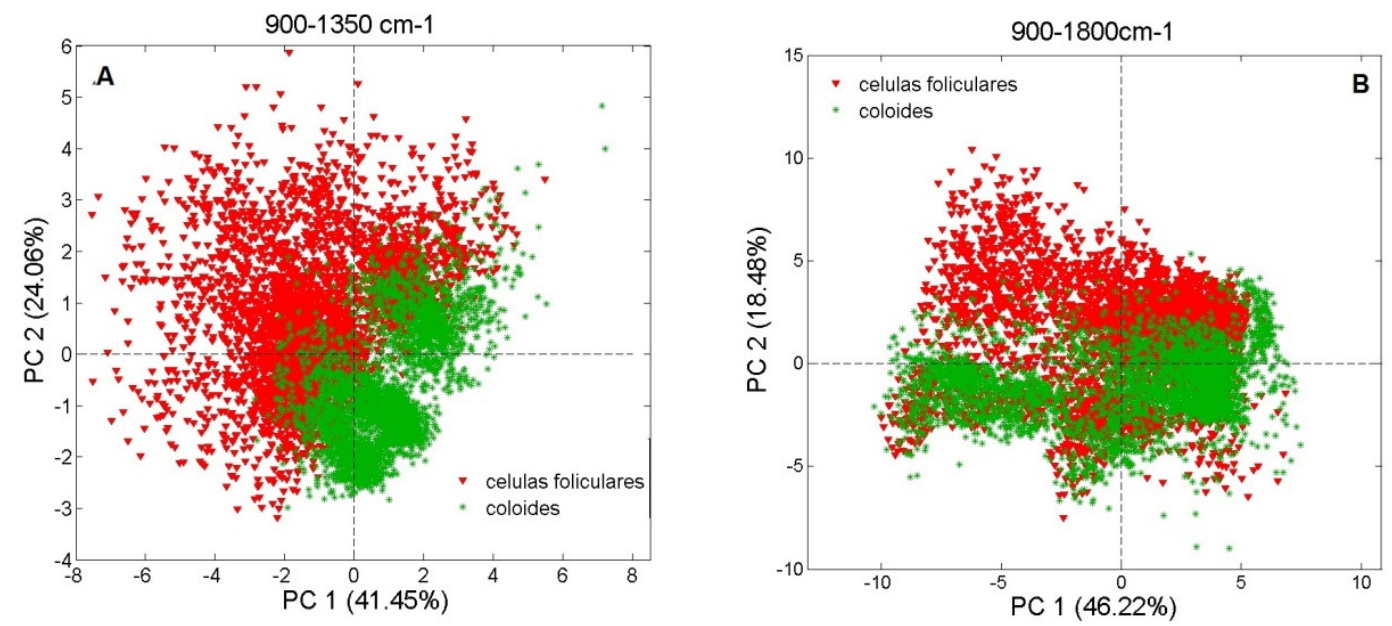

Figura 31: Gráfico do PCA scores de células foliculares (vermelho) e colóides (verde) provenientes de 20 tecidos sadios utilizando as regiões: A - $900-1350 \mathrm{~cm}^{-1}$, B- $900-1800$ $\mathrm{cm}^{-1}$. 


\subsection{Dados espectrais dos tecidos com bócio nodular}

A Figura 32 mostra uma imagem de agrupamento feita com dados da região espectral entre $900-1800 \mathrm{~cm}^{-1}$ proveniente de um tecido diagnosticado com bócio nodular. A imagem com 3 agrupamentos (Figura 32-A) revela somente os colóides e não separa os outros tipos de tecidos. Na Figura 32-B com 6 agrupamentos é possível observar além dos coloides, as células foliculares (agrupamento azul e roxo).
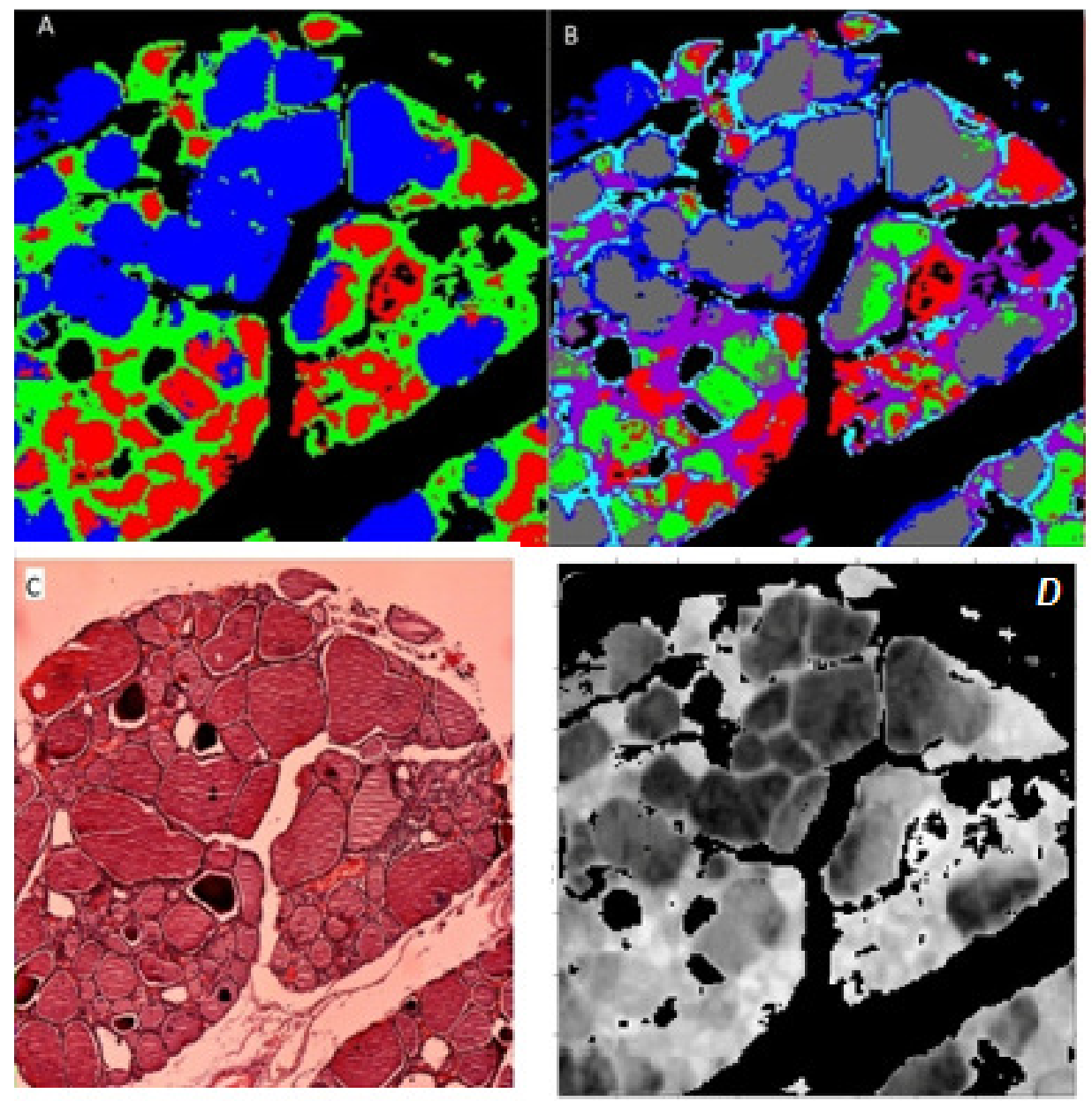

Figura 32 Imagens de agrupamentos construídas a partir de dados espectrais da região entre 900 e $1800 \mathrm{~cm}^{-1}$. A - 3 agrupamentos; B - 6 agrupamentos; C- imagem do tecido corado com HE. E - intensidade do espectro em $1468 \mathrm{~cm}^{-1}$, regiões mais escuras possuem intensidade maior.

Verifica-se que existe uma relação entre os agrupamentos dos coloides com os agrupamentos das células foliculares. O agrupamento cinza (coloide) é rodeado pelo agrupamento azul (células foliculares), enquanto que 0 
agrupamento roxo (células foliculares) circunda os agrupamentos vermelho e verde (coloides). Os folículos cobertos pelos agrupamentos azul e cinza possuem uma maior quantidade de iodo ligada a tiroglobulina (Figura 32-D) do que os folículos cobertos pelos agrupamento roxo e verde. Esses resultados também foram observados em todos os 20 pacientes com bócio nodular no presente estudo.

A Figura 32 possui algumas regiões que não estão fortemente relacionadas com a imagem histológica, como ocorreu nos tecidos provenientes de pacientes normais. Os motivos para isto já foram mencionados nos resultados dos tecidos normais (espalhamento Mie e diferenças na amida I).

A Figura 33 mostra a imagem de agrupamento obtida a partir da região espectral de 900 - $1350 \mathrm{~cm}^{-1}$. A imagem de agrupamento obtida apresenta maior relação com a imagem histológica apesar de utilizar menos informação espectral do que a Figura 32. Também é possível perceber a presença de dois padrões bioquímicos dentro dos folículos como observado na Figura 32. A Figura 33-C com 8 agrupamentos apresentou melhor correlação com a imagem histológica. 

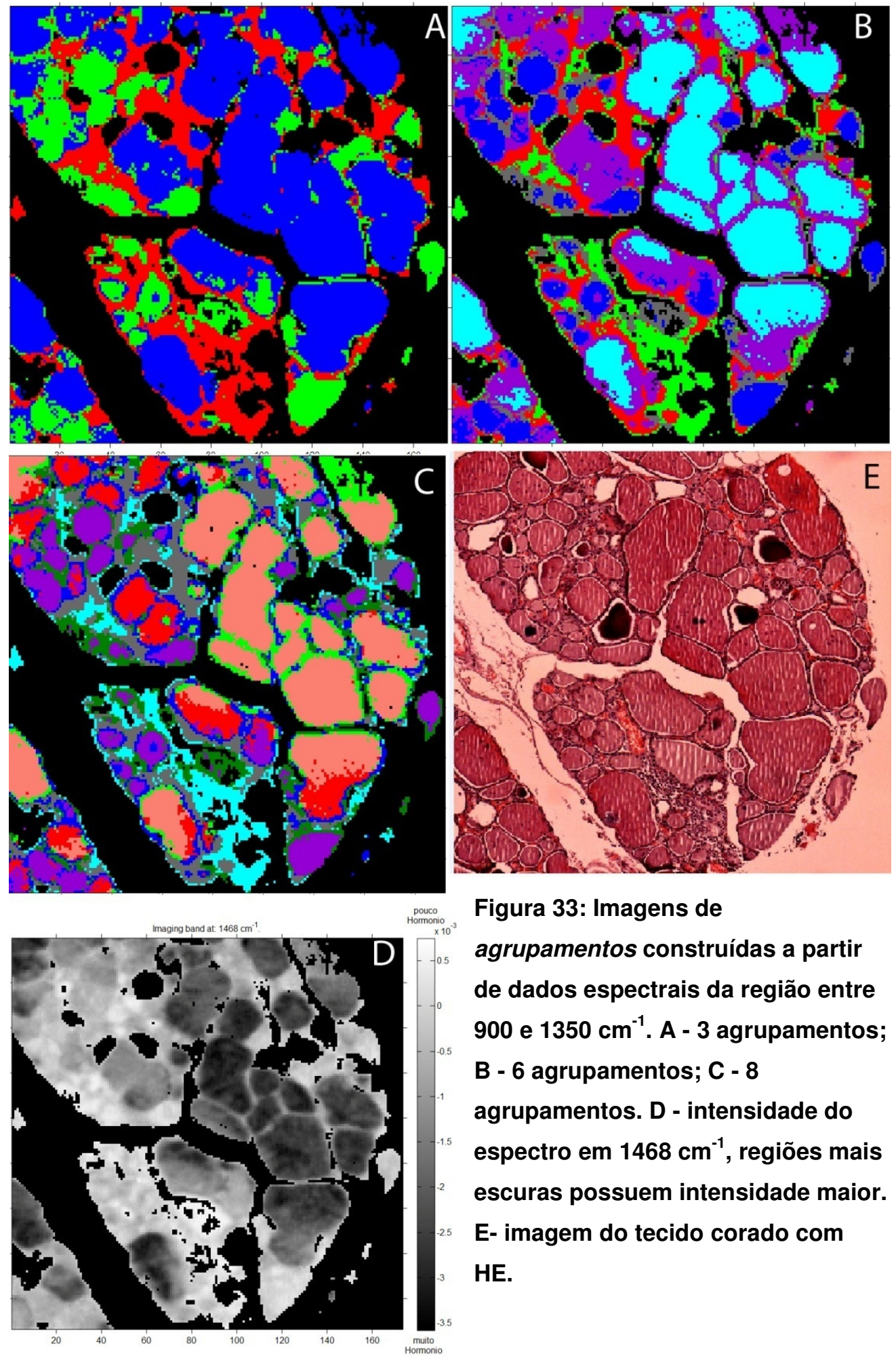

Figura 33: Imagens de

agrupamentos construídas a partir de dados espectrais da região entre 900 e $1350 \mathrm{~cm}^{-1}$. A - 3 agrupamentos;

B - 6 agrupamentos; C - 8 agrupamentos. D - intensidade do espectro em $1468 \mathrm{~cm}^{-1}$, regiões mais escuras possuem intensidade maior. E- imagem do tecido corado com HE.

A Figura 34 são os espectros médios dos agrupamentos relacionados às células foliculares, e mostram diferenças espectrais. A maior diferença bioquímica observada se encontra na região da amida I $\left(1600-1700 \mathrm{~cm}^{-1}\right)$ que está relacionada principalmente a diferenças na estrutura secundária ${ }^{[56]}$. O espectro verde possui três picos nesta região $\left(1692 \mathrm{~cm}^{-1}, 1662 \mathrm{~cm}^{-1} \mathrm{e}\right.$ 
$1640 \mathrm{~cm}^{-1}$ ) enquanto o espectro ciano apresenta somente dois picos $\left(1688 \mathrm{~cm}^{-1}\right.$ e $\left.1654 \mathrm{~cm}^{-1}\right)$. Além da região da amida I, observa-se também um deslocamento na região da amida II $\left(1540 \mathrm{~cm}^{-1}\right)$ assim como uma diferença de intensidade no pico $1468 \mathrm{~cm}^{-1}$. Na região de $900-1350 \mathrm{~cm}^{-1}$ as maiores diferenças estão na região glicosacarídeos $\left(1000-1100 \mathrm{~cm}^{-1}\right)$.

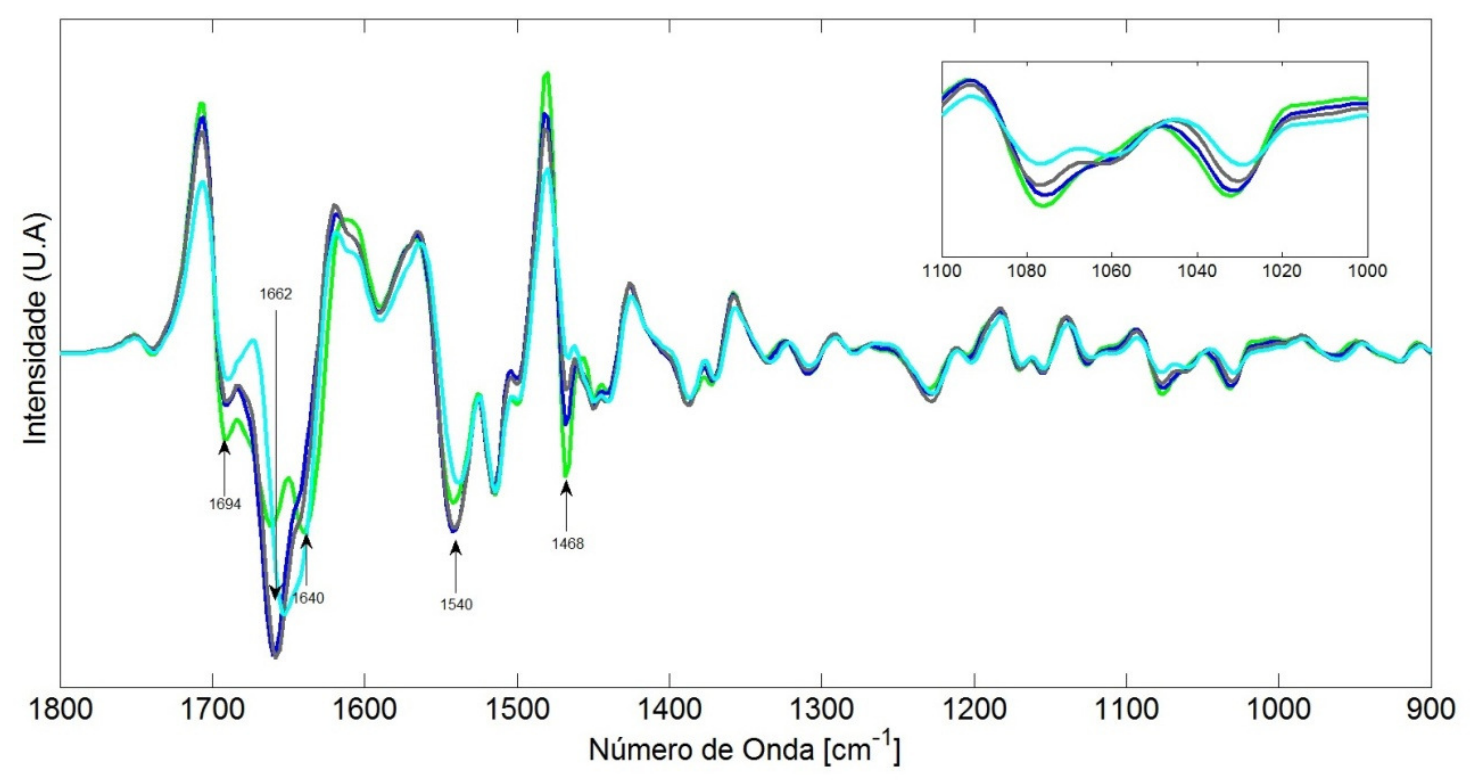

Figura 34: Média das segundas derivadas dos espectros dos agrupamentos relacionados às células foliculares obtidos a partir da Figura 33-C. $O$ detalhe mostra a região dos carboidratos.

Observa-se que o agrupamento verde (Figura 33-C) tem um espectro muito similar ao do tecido normal na região da amida I, pois há uma sobreposição entre a conformação $\alpha$-hélice e folha $\beta$, assim como intensa banda em $1468 \mathrm{~cm}^{-1}$.

No espectro ciano quase não se identifica o pico de $1468 \mathrm{~cm}^{-1}$, que está relacionado com a quantidade de iodo ligado a tiroglobulina, indicando, que as células foliculares deste agrupamento apresentam uma pequena quantidade de hormônios. Também se observa uma diferença na forma do pico da amida I em relação aos tecidos normais. Ainda analisando o espectro ciano, observa-se na região dos glicosacarídeos (1000 - $1100 \mathrm{~cm}^{-1}$ ) uma menor quantidade de açúcares em relação ao espectro verde. Isso pode ser um indicativo de que as células do agrupamento ciano apresentam uma maior atividade celular, 
levando a uma maior quantidade de açúcares metabolizados, característica observada em células hiperplásicas ${ }^{[5]}$. Esta característica também é observada na lâmina histológica (Figura 33-C), pois as células cobertas pelo agrupamento ciano apresentam tamanho maior.

Conforme o exposto, o espectro ciano (Figura 33-C) apresenta várias características bioquímicas que não são observados em tecidos sadios, indicando que estas características podem estar relacionadas ao bócio nodular, enquanto o agrupamento verde apresenta maior similaridade bioquímica com o tecido normal.

A Figura 35 mostra os espectros dos agrupamentos relacionados aos colóides. Os espectros médios dos coloides possuem diferenças bioquímicas, as mais observadas estão nas regiões de amida I (1600-1700 $\left.\mathrm{cm}^{-1}\right)$ e amida II. Além dessas, pequenas mudanças na região de amida III e diferenças de intensidade na região dos açúcares são notadas.

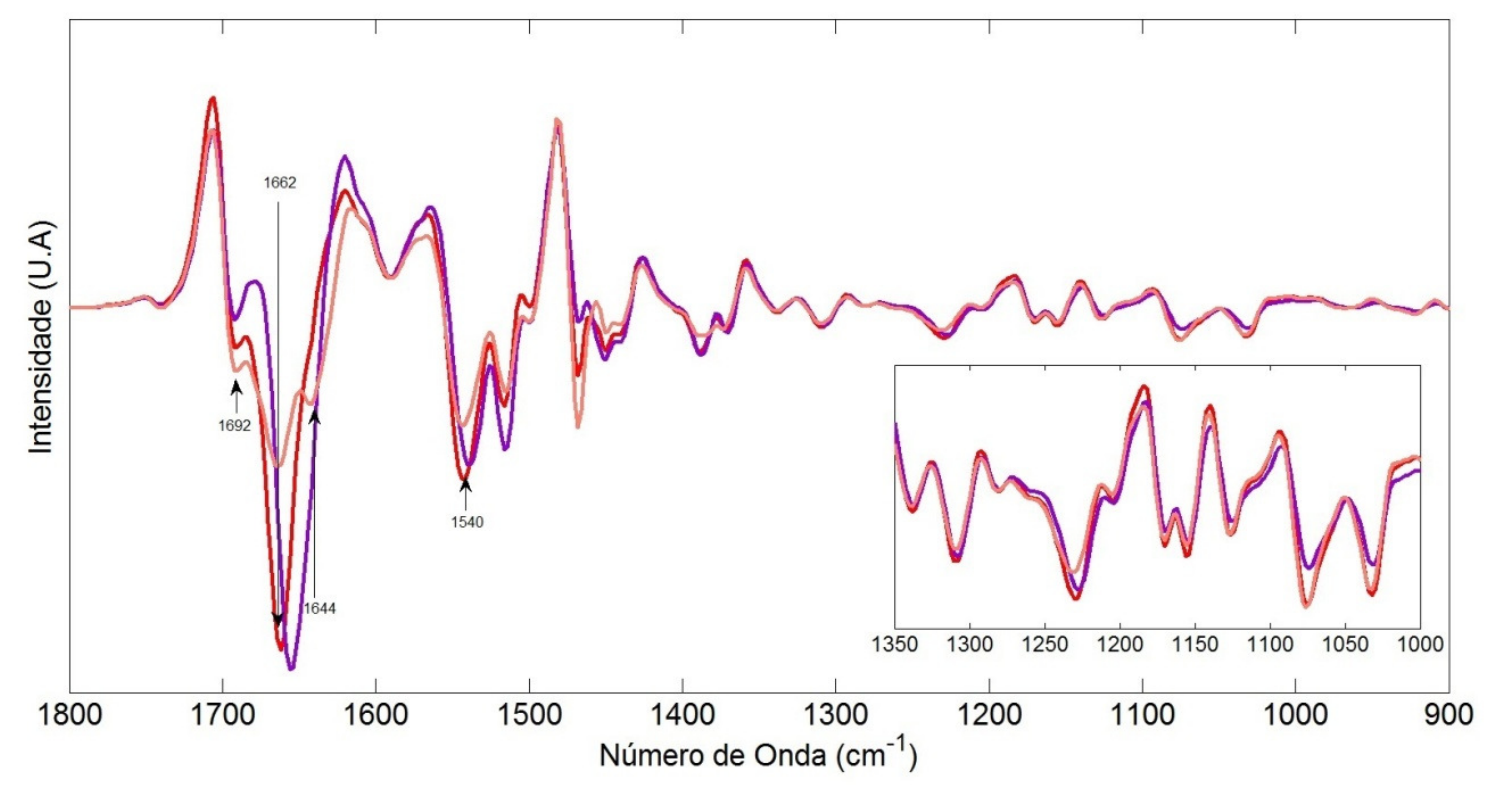

Figura 35: Média das segundas derivadas dos espectros dos agrupamentos relacionados aos coloides obtidos a partir da Figura 33-CErro! Fonte de referência não encontrada..

O espectro da cor salmão (Figura 35) tem três picos na região da amida I $\left(1692 \mathrm{~cm}^{-1}, 1662 \mathrm{~cm}^{-1}\right.$ e $\left.1644 \mathrm{~cm}^{-1}\right)$. A quantidade de iodo nesse agrupamento é maior, sugerindo que nesses coloides há uma grande quantidade de iodo ligado à estrutura da tiroglobulina. Na região dos carboidratos $\left(1000-1100 \mathrm{~cm}^{-}\right.$ 
$\left.{ }^{1}\right)$ esse agrupamento apresenta maior intensidade do pico em $1074 \mathrm{~cm}^{-1}$ o que pode indicar uma glicosilação da tiroglobulina. Esses padrões também são encontrados nos coloides do tecido normal. Portanto os coloides relacionados com o agrupamento salmão possuem uma fisiologia normal.

O espectro roxo apresenta grandes diferenças na região da amida I não possuindo uma conformação $\alpha$-hélice $\left(1660 \mathrm{~cm}^{-1}\right)$ nem folha $\beta\left(1692 \mathrm{~cm}^{-1} \mathrm{e}\right.$ $1640 \mathrm{~cm}^{-1}$ ). Nota-se que este agrupamento possui uma menor quantidade de lodo (intensidade em $1468 \mathrm{~cm}^{-1}$ ) como podemos observar na Figura 32-D. Portanto, possui uma menor quantidade de hormônio ligado a tiroglobulina. Uma das razões para essa baixa formação de hormônios nesses coloides pode estar relacionada a uma baixa glicosilação da tiroglobulina, pois há trabalhos na literatura que mostram a relação da glicosilação com formação dos precursores dos hormônios ${ }^{[59,60]}$.

O espectro roxo também apresenta diferenças na regiões dos açucares, no caso demonstrada pela menor intensidade do pico $\left(1076 \mathrm{~cm}^{-1}\right)$ que está relacionada a um tipo de açúcar chamado manose. Há trabalhos na literatura que mostram que a manose tem importante contribuição na glicosilação de proteínas especialmente na tiroglobulina ${ }^{[46]}$. Além disso, há mudanças na região da amida II e III nas bandas relacionadas às vibrações do grupo amina $(\mathrm{N}-\mathrm{H})$ que reforçam esta hipótese.

Essas características bioquímicas presentes no agrupamento roxo não são parecidas com as relatadas em coloides provenientes de pacientes sadios. O espectro vermelho apresenta uma mistura entre os espectros salmão e roxo, portanto os coloides do agrupamento vermelho podem indicar um estágio inicial da doença ou a fase de transição de um tecido sadio para um doente. 


\subsection{Dados espectrais dos Coloides}

Os coloides são espaços vazios dentro dos folículos que são preenchidos por uma substância produzida pelas células foliculares que delimitam os folículos. Essa substância, em forma coloidal, tem como seu principal constituinte a tiroglobulina. A tiroglobulina é uma iodoglicoproteína com características particulares tais como ser a única capaz de formar os hormônios T3 e T4 ${ }^{[1,2]}$.

Por todas as características apresentadas, a caracterização espectroscópica dos coloides podem trazer informações bioquímicas importantes que podem explicar diversos processos fisiológicos das células foliculares assim como anomalias na atividade da glândula como um todo.

Os resultados obtidos a partir da análise preliminar dos coloides foram surpreendentes num primeiro momento, uma vez que nunca foi reportado pela literatura $^{[16,17,61-63]}$, diferenças tão grandes na região da amida I entre tecidos sadios e neoplásicos. Essas diferenças podem estar relacionadas as conformações secundárias da proteína.

Iremos mostrar e discutir os mapas espectrais somente dos coloides de tecidos provenientes de pacientes sadios e com bócio nodular. Para isso foi feito um processamento adicional de tal forma a remover todas as regiões dos mapas que não possuíam espectros relacionados com os coloides.

\subsubsection{Tecidos normais.}

A Figura 36 mostra uma imagem de agrupamento hierárquico construída com dados espectrais da região da amida I $\left(1600-1700 \mathrm{~cm}^{-1}\right)$ proveniente de um tecido sadio. 


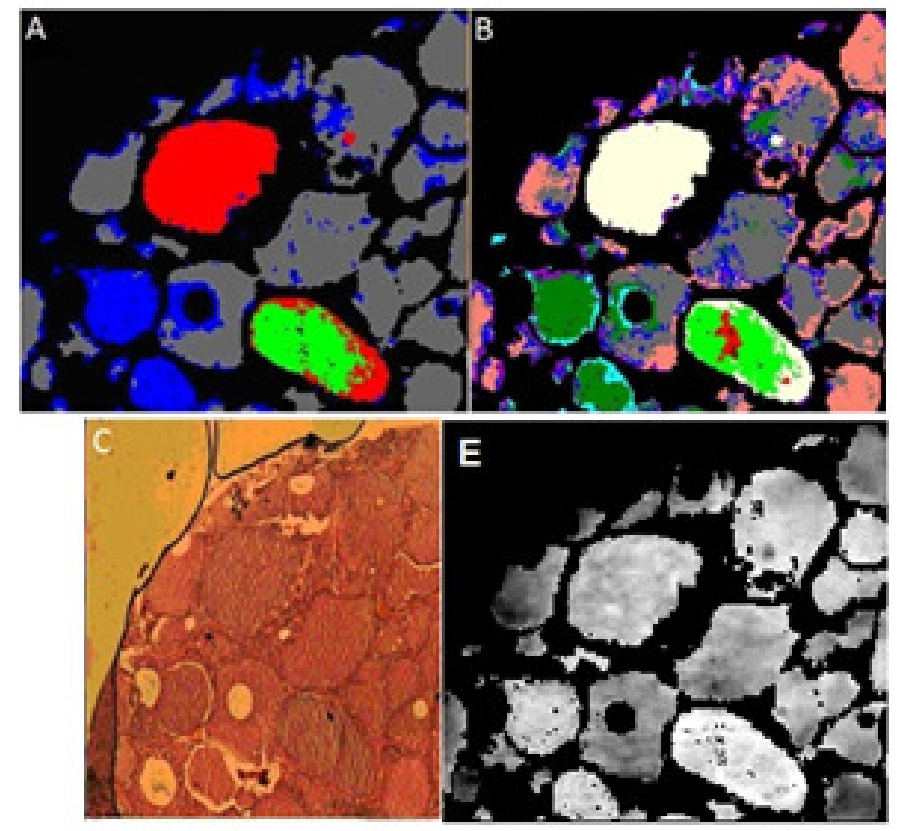

Figura 36: Imagem de agrupamento construída com dados da região de $1600-1700 \mathrm{~cm}^{-1}$. A - 4 agrupamentos; B - 9 agrupamentos; C- imagem histológica (HE); E - imagem em escala de cinza contendo a intensidade da banda em $1468 \mathrm{~cm}^{-1}$ áreas escuras contêm maior intensidade.

A Figura 34-A contendo 4 agrupamentos mostra que alguns coloides estão cobertos quase totalmente pelo agrupamento cinza enquanto outros estão cobertos por dois agrupamentos verde/vermelho ou azul/cinza.

A figura contendo 9 agrupamentos (Figura 36-B) mostra que 0 agrupamento azul e cinza da imagem com 4 agrupamentos (Figura 36-A) foram divididos em 6 agrupamentos ( azul,cinza,verde escuro, roxo,ciano, salmão). Os agrupamentos verde e vermelho da Figura 36-A ficaram divididos somente em 3 agrupamentos. Portanto os agrupamentos cinza e azul da Figura 36-A apresentam uma maior heterogeneidade (diferenças bioquímicas) que os agrupamentos verde e vermelho da mesma imagem. Esse resultado pode ser um indicativo de que estes agrupamentos (cinza e azul) possam estar em um processo fisiológico diferente dos coloides cobertos com os agrupamentos verde e vermelho.

A Figura 37 mostra segunda derivada média dos agrupamentos da Figura 36-A 
O espectro médio dos agrupamentos vermelho e verde (Figura 37) apresentam um banda forte em $1628 \mathrm{~cm}^{-1}$ a qual está relacionada ao aminoácido tirosina. O modo vibracional desta banda é a combinação de flexões C-C dentro do anel fenólico ${ }^{[51]}$. A intensidade desse pico é inversamente proporcional a pico em $1468 \mathrm{~cm}^{-1}$. Esses resultados sugerem que esses 2 agrupamentos (verde e vermelho) sugere que a forma da tiroglobulina na qual o aminoácido tirosina não fora convertido em monoiodotirosina e diiodotirosina que são precursores dos hormônios tireoidianos.

Esse processo ocorre de maneira extremamente rápida, pois a glândula produz uma enzima chamada iosinase para catalisar essa reação ${ }^{[2]}$. Portanto é extremamente difícil pegar cortes histológicos no exato momento em que ocorre esse processo fisiológico. Esta é uma das razões por que não foi observado esse processo fisiológico em todos os cortes histológicos.

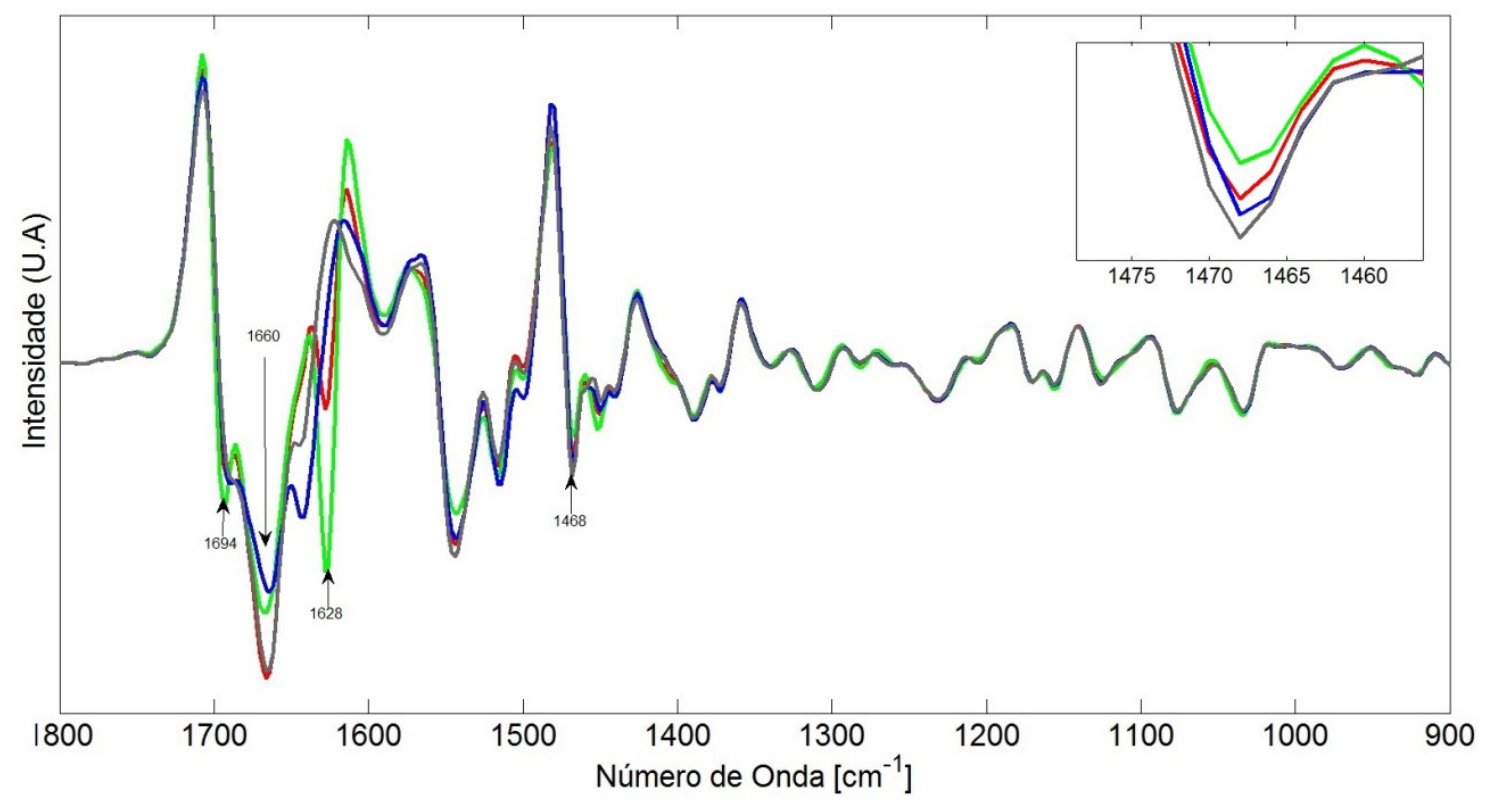

Figura 37: Média das segundas derivadas dos espectros dos agrupamentos mostrados na Figura 36-A. $O$ detalhe mostra a região de um modo vibracional relacionado aos precursores dos hormonios.

Os outros 6 agrupamentos (azul,cinza, verde escuro, roxo, ciano e rosa da Figura 36-B) mostram o padrão espectral mais comum encontrado nos dados provenientes de pacientes sadios. Esses agrupamentos revelam uma banda mais intensa em $1468 \mathrm{~cm}^{-1}$ e uma ausência da banda em $1628 \mathrm{~cm}^{-1}$ 
(relacionada à tirosina). Na região da amida I esses agrupamentos revelam claramente uma mistura de conformações $\alpha$-hélice e folha $\beta$. Os espectros desses agrupamentos revelam relação entre a conformação secundária e a intensidade em $1468 \mathrm{~cm}^{-1}$. A intensidade desse pico está diretamente relacionada à intensidade em $1664 \mathrm{~cm}^{-1}$ (conformação $\alpha$-hélice) e inversamente proporcional ao pico de $1694 \mathrm{~cm}^{-1}$ (conformação folha $\beta$ ).

Esses resultados sugerem que esse padrão espectral esteja relacionado à ultima etapa do processo de formação dos hormônios na qual 2 moléculas de diiodotirosina e/ou monotirosina são acopladas. Esse processo não é tão rápido quanto o de iodinizaçao da tirosina, portanto é mais fácil de se observar num corte histológico. Há trabalhos na literatura que mostram que a tiroglobulina possui uma estrutura secundária $\alpha$-hélice nas partes da cadeia que possuem os hormônios, ou seja, na parte que contem iodo ${ }^{[64,65]}$.

Os espectros provenientes de pacientes normais não apresentam grandes diferenças na regiões dos carboidratos $\left(1000-1100 \mathrm{~cm}^{-1}\right)$ que podem estar relacionados a diferenças de glicosilação assim como na região da amida III ${ }^{[56,66]}$. Apesar da região da amida III não ser fortemente ativa no infravermelho, ela é extremamente sensível a cadeias laterais ligadas a cadeia peptídica. Portanto, esses resultados sugerem que os espectros provenientes de pacientes normais não apresentam grandes diferenças em glicosilação.

A Figura 38 mostra o espectro médio obtido da aná lise de agrupamento utilizando espectros provenientes de 20 pacientes normais. Observa-se uma mistura de duas conformações secundárias ( $\alpha$-hélice, folha $\beta$ ) e também um ombro em $1628 \mathrm{~cm}^{-1}$ que está relacionado ao aminoácido tirosina. Observamse também as mesmas relações entre o pico em $1468 \mathrm{~cm}^{-1}$ (relacionadas aos precursores dos hormônios) e a estrutura secundária (região da amida I). Na região da amida II observam-se pequenos shifts e diferenças em intensidade.

Na região de carboidratos (1000 $-1100 \mathrm{~cm}^{-1}$ ) assim como na região da amida III (1200-1400 cm $\left.\mathrm{cm}^{-1}\right)$ não se apresentam grandes diferenças. Estes resultados sugerem que existe um padrão bem especifico de glicosilação nos pacientes sadios. 


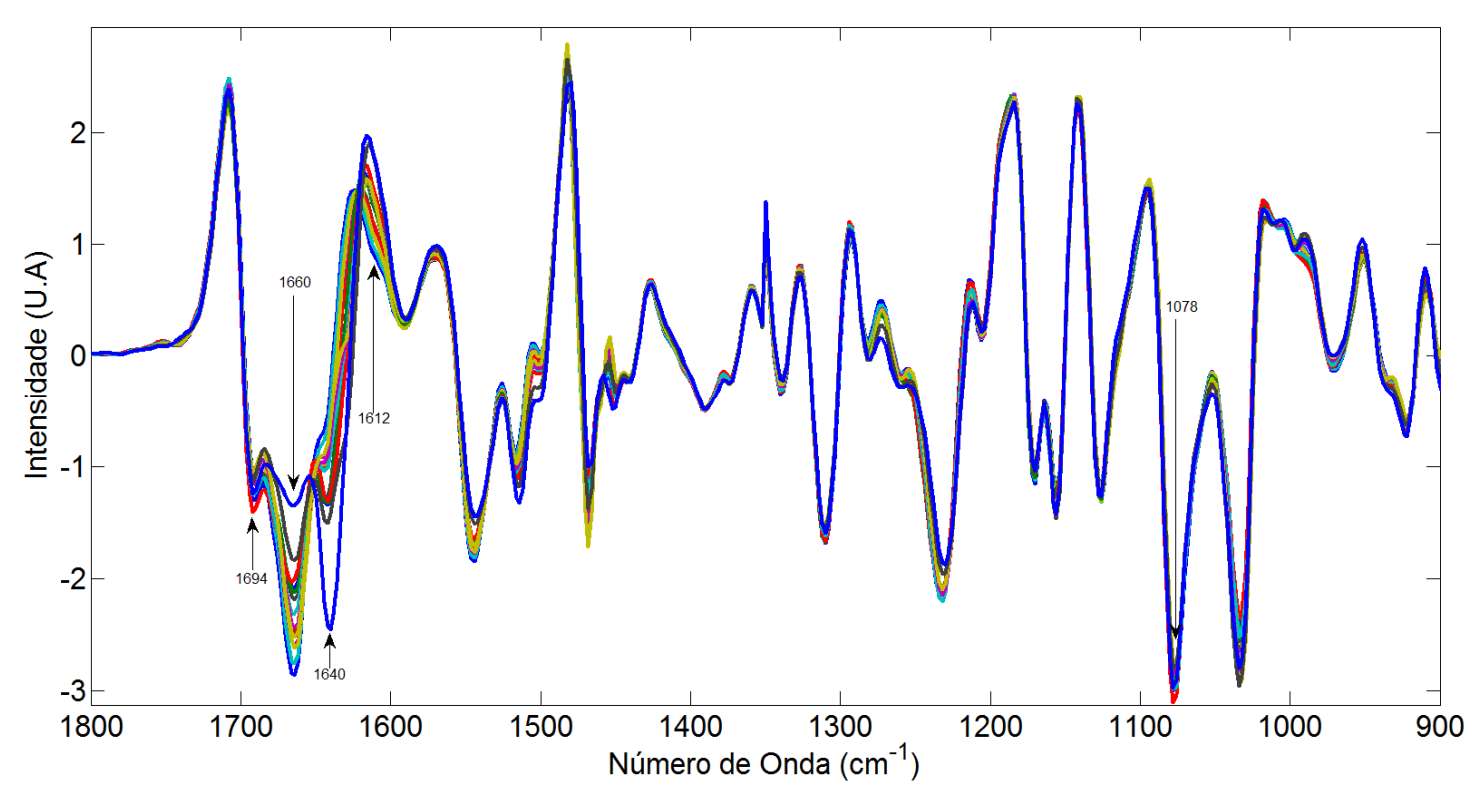

Figura 38: Média das segundas derivadas dos espectros obtidos pela análise de agrupamento de dados provenientes de 20 tecidos sadios.

A Figura 39 mostra a relação entre a banda em $1468 \mathrm{~cm}^{-1}$ e $1662 \mathrm{~cm}^{-1}$ (folha $\beta$ ) assim como $1640 \mathrm{~cm}^{-1}$ ( $\alpha$-hélice) com dados provenientes de 20 pacientes.

A Figura 39 mostra a relação entre o processo de formação da iodotirosina (intensidade em $1468 \mathrm{~cm}^{-1}$ ) e mudanças na estrutura secundária da tiroglobulina. Não existem trabalhos na literatura que mostram essas mudanças na estrutura secundária da tiroglobulina devido a iodinizaçao dos anéis fenólicos presentes na cadeia peptídica da tiroglobulina. Entretanto há dois trabalhos ${ }^{[64,65]}$ na literatura que mostram que a tiroglobulina possui 2 conformações secundárias. Uma altamente estruturada em forma a-hélice a qual possui as moléculas de hormônios e outra pouco estruturada que não possui hormônios. Porém, o estudo não conseguiu determinar exatamente a estrutura secundária dessa parte. Os resultados apresentados aqui sugerem que essa parte a qual não tem moléculas de hormônios ligadas possui uma estrutura folha $\beta$. 


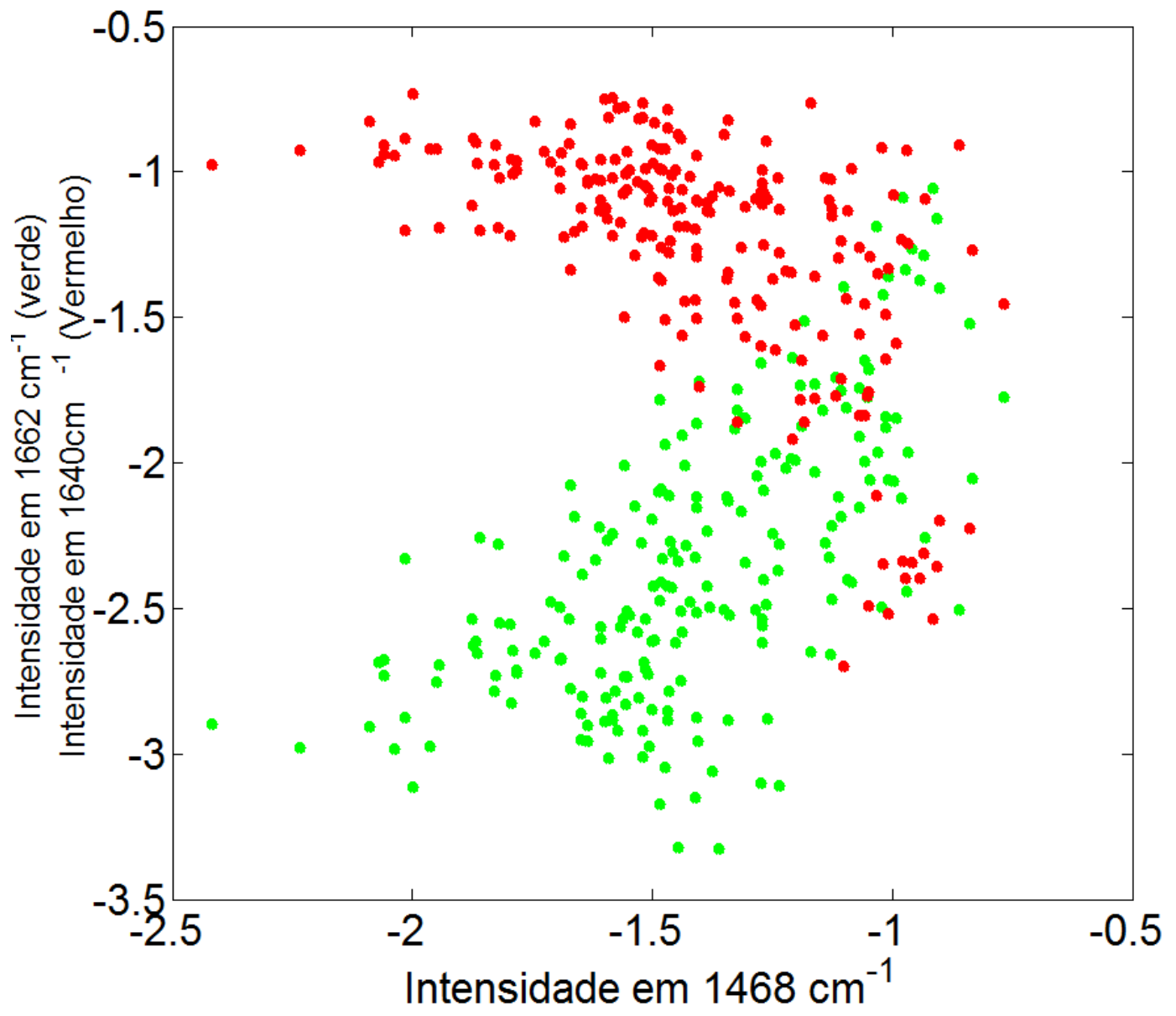

Figura 39: Intensidade da banda em $1468 \mathrm{~cm}^{-1}$ pelas bandas em $1662 \mathrm{~cm}^{-1}$ e $1640 \mathrm{~cm}^{-1}$.

\subsubsection{Bócio Nodular.}

A Figura 40 mostra uma imagem de agrupamento construída a partir dos dados espectrais da região da amida I proveniente de um tecido com bócio nodular.

A Figura 40-A mostra uma imagem de agrupamento contendo 3 grupos. Essa imagem mostra que alguns coloides são cobertos somente por 1 grupo (azul) enquanto outros são cobertos por 2 (verde e vermelho).

A Figura 40-B mostra uma imagem de agrupamento contendo 6 grupos. Observa-se que o agrupamento roxo manteve a mesma área do que 0 agrupamento azul na Figura 40-A. Isso mostra que esses coloides cobertos pelos agrupamentos azuis (Figura 40-A) possuem uma padrão espectral bem 
definido na região amida I. Esse agrupamento está associado com áreas claras da Figura 40-D, portanto apresenta pequenas quantidades de iodo ligado a tiroglobulina comparado com outras regiões da imagem. Esses coloides estão cercados por células que apresentam tamanho maior. A literatura mostra que tiroglobulina de tecidos com bócio nodular possuem menor quantidade de iodo comparada com os tecidos normais ${ }^{[45]}$.

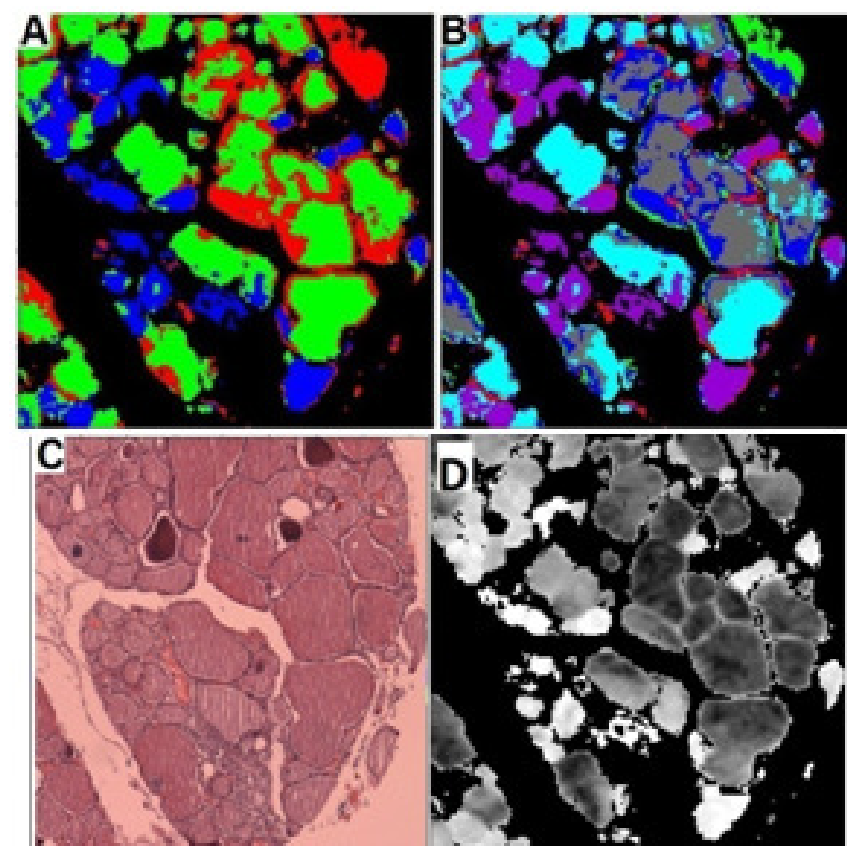

Figura 40: Imagem de agrupamento construída com dados da região de 1600 a $1700 \mathrm{~cm}^{-1}$ de um tecido com bócio nodular. A - 4 grupos; B- 6 grupos. C-imagem histológica (HE). $E$ - imagem em escala de cinza contendo a intensidade da banda em $1468 \mathrm{~cm}^{-1}$ áreas escuras contem maior intensidade.

Os outros agrupamentos (ciano,cinza,azul e verde) da Figura 40-B estão relacionados às regiões com grandes quantidades de iodotirosina (áreas escuras da Figura 40-D) e estão circundados com células que apresentam características morfológicas semelhantes às encontradas no tecido normal.

A Figura 41 mostra o espectro médio dos agrupamento da Figura 40-B. 


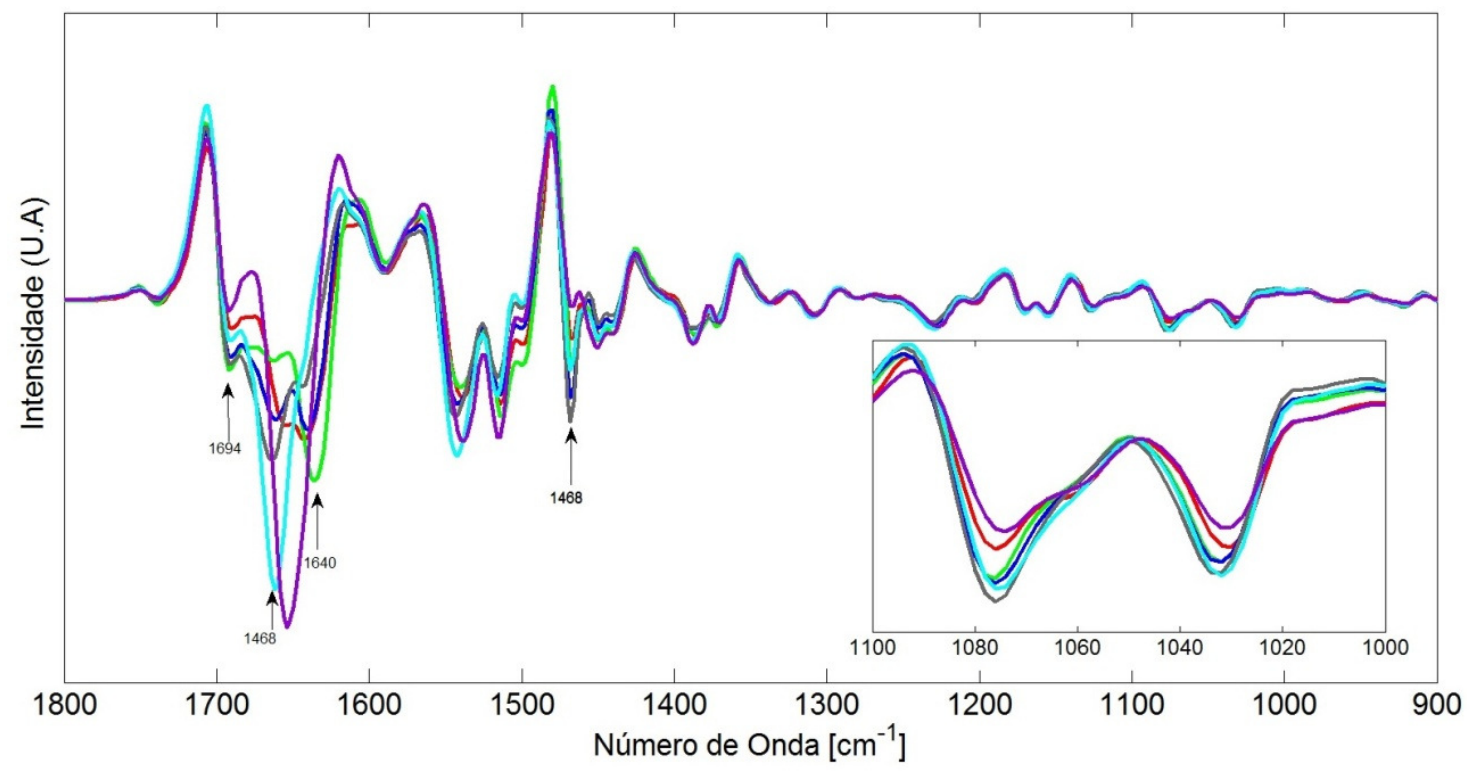

Figura 41 Média das segundas derivadas dos espectros obtidos da análise de agrupamento da Figura 40-B. 0 detalhe mostra a região dos carboidratos.

O espectro roxo apresenta um padrão na região da amida I que não é uma mistura entre as conformações $\alpha$-hélice e folha $\beta$ assim como não apresenta a banda de $1468 \mathrm{~cm}^{-1}$, portanto não possui iodo ligado à estrutura da tiroglobulina. $\mathrm{Na}$ região dos carboidratos, esse espectro apresenta menor intensidade em $1070 \mathrm{~cm}^{-1}$ que esta relacionado a manose ${ }^{[67]}$. Esse açúcar esta presente na tiroglobulina ${ }^{[46]}$ devido a glicosilação do tipo N. Formas da tiroglobulina que possuem baixa quantidade de manose, ou seja forma não glicosilada, são deficientes na formação dos hormônios. Essas formas de tiroglobulina são comumente encontradas em tecidos com bócio nodular ${ }^{[68]}$.

Os outros espectros médios (Figura 41) dos agrupamentos cinza, ciano, vermelho, azul e verde apresentam padrões espectrais similares aos encontrados nos espectros provenientes de tecidos sadios. Na região da amida I, esses 5 espectros apresentam 3 picos nas bandas $1660 \mathrm{~cm}^{-1}$ relacionado a conformação $\alpha$-hélice, $1640 \mathrm{~cm}^{-1}$ e $1694 \mathrm{~cm}^{-1}$ relacionado a conformação folha $\beta$. Existe um relação entre a intensidade de $1660 \mathrm{~cm}^{-1} \mathrm{com}$ a intensidade em $1468 \mathrm{~cm}^{-1}$, na qual esta relacionado aos precursores da iodotirosina. Na região dos carboidratos estes espectros apresentam a maior intensidade na banda de $1078 \mathrm{~cm}^{-1}$. Estas características relatadas aqui também foram observadas nos colóides provenientes de tecidos sadios já apresentados na seção anterior. 
Esses dois padrões bioquímicos encontrados em todos os cortes histológicos provenientes de tecidos com bócio nodular ocorrem normalmente pois há uma mistura de tecido sadio com hiperplásico.

Os padrões observados no corte mostrado na Figura 40 também foram observados nos outros cortes. Para mostrar estes padrões foi feito uma análise de agrupamento com dados provenientes de 20 pacientes com bócio. Os espectros médios obtidos desta análise de agrupamento está na Figura 42.

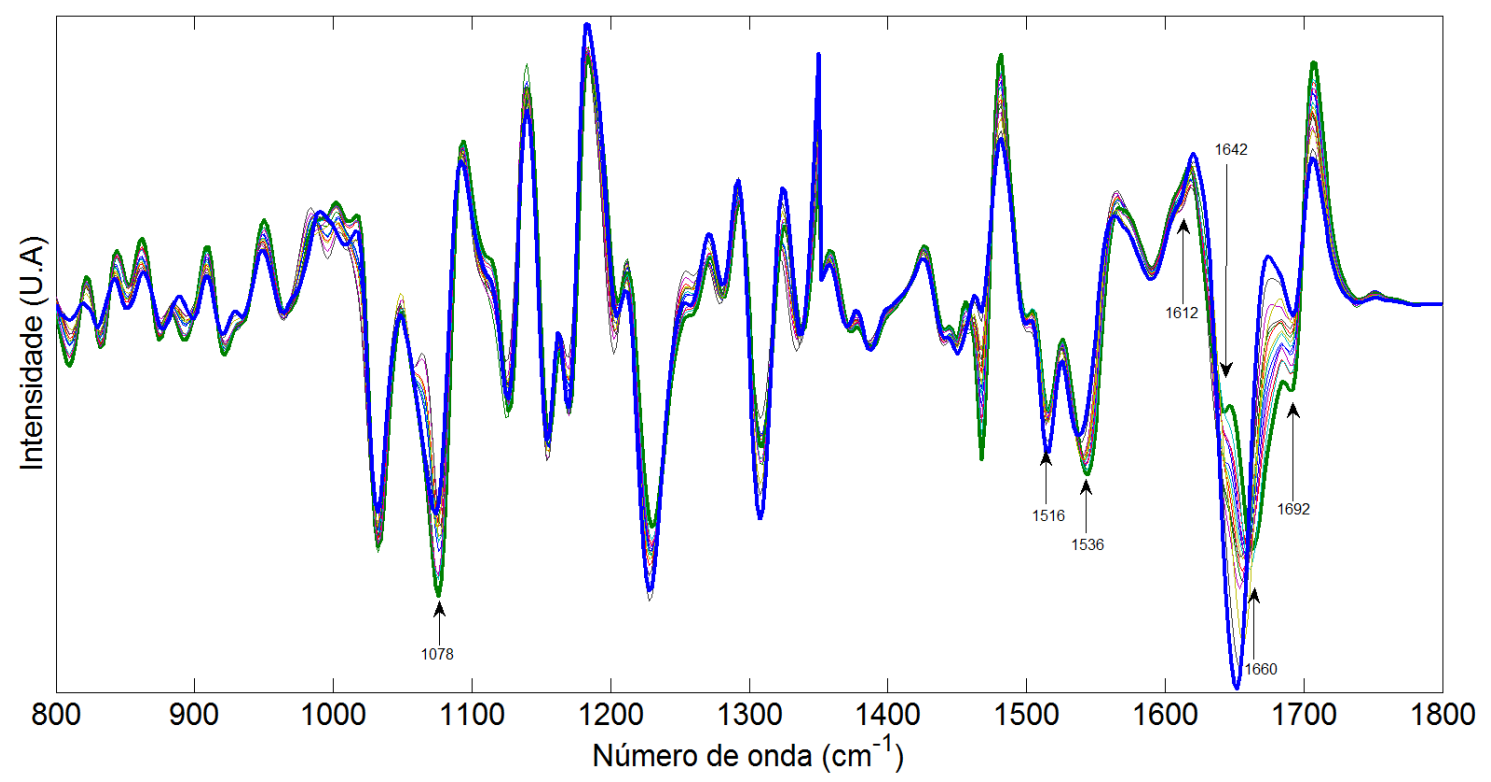

Figura 42: Média das segundas derivadas dos espectros da análise de agrupamento com 15 grupos da região de 1600 a $1700 \mathrm{~cm}^{-1}$ com dados provenientes de 20 tecidos com bócio nodular.

A análise de agrupamento da Figura 42 mostra que 2 espectros apresentam padrões completamente distintos e outros espectros são uma mistura entre estes dois padrões.

O primeiro padrão distinto observado (espectro verde escuro com linha grossa) mostra características bem semelhantes às observadas nos coloides dos tecidos sadios. Na região da amida I observa-se 3 picos sendo o mais intenso o de $1662 \mathrm{~m}^{-1}$ na qual esta relacionado a conformação $\alpha$-hélice e dois menos intenso (1692 cm e $1642 \mathrm{~cm}^{-1}$ ) nos quais estão relacionados a conformação folha $\beta$. 
$\mathrm{Na}$ banda de $1468 \mathrm{~cm}^{-1}$, a qual esta relacionada à quantidade de iodotirosina, esse espectro apresenta a banda mais intensa. Esse resultado era esperado, pois foi observado na Figura 39 que existe uma relação entre a iodinização da tirosina e mudanças na conformação secundária.

$\mathrm{Na}$ região dos carboidratos observa-se que este espectro possui a maior intensidade em $1078 \mathrm{~cm}^{-1}$ a qual está relacionada com oligossacarídeos. Os oligossacarídeos são cadeias de açúcar contendo mais de 10 monossacarídeos. A literatura mostra que esse tipo de cadeia é encontrado na tiroglobulina devido à glicosilação do tipo $\mathrm{N}$ e o principal açúcar contido nessas cadeias é a manose ${ }^{[69]}$.

O segundo padrão observado (espectro azul com linha grossa) apresenta um padrão totalmente diferente dos tecidos sadios. A região da amida I não apresenta nenhuma das duas conformações ( $\alpha$-hélice ou folha $\beta$ ). Esse espectro apresenta uma ombro em $1612 \mathrm{~cm}^{-1}$ a qual está relacionada ao aminoácido tirosina. A tiroglobulina (principal constituinte dos coloides) possuem grandes quantidades de tirosina, pois é através dos anéis fenólicos deste aminoácido que começa todo o processo de formação dos hormônios ${ }^{[65]}$.

A banda de $1468 \mathrm{~cm}^{-1}$ apresenta a menor intensidade (iodotirosa) e um ombro em $1612 \mathrm{~cm}^{-1}$. Portanto este segundo padrão indica que a tirosina não fora totalmente convertida em iodotirosina.

$\mathrm{Na}$ região da amida II observam-se diferenças de intensidade em $1516 \mathrm{~cm}^{-1}$ e $1536 \mathrm{~cm}^{-1}$. Entretanto essa segunda banda apresenta um grande shift para baixo número de onda em relação ao primeiro padrão. Essa banda $\left(1536 \mathrm{~cm}^{-1}\right.$ ) tem modo vibracional um acoplamento entre flexão $\mathrm{N}-\mathrm{H}$ e estiramento C-N ${ }^{[56]}$.

Na região dos carboidratos observa-se a menor intensidade na banda de oligossacarídeos $\left(1078 \mathrm{~cm}^{-1}\right)$ e não se observa a banda em $1058 \mathrm{~cm}^{-1}$ devido falta de manose ${ }^{[23]}$. A literatura relata que a tiroglobulina proveniente de glândulas com bócio possui menores quantidades de terminais do tipo $\mathrm{N}$ glicosilados e, portanto uma menor quantidade dos polissacarídeos de manose $^{[45]}$. 
Na região da amida III, observam-se diversas diferenças principalmente em bandas relacionadas com ligações do tipo C-N. Apesar da região da amida III não ser altamente ativa no infravermelho, ela é sensível a cadeias laterais ligadas na cadeia peptídica principal. Portanto estas diferenças em modos vibracionais relacionados às ligações carbono nitrogênio podem estar associadas a mudanças em glicosilação do tipo N. Spiro et al. ${ }^{[70]}$ mostram que a tiroglobulina apresenta diversos terminais tipo $\mathrm{N}$ nos quais é possível glicosilar.

O processo de glicosilação da tiroglobulina ocorre no interior das células foliculares, portanto as discrepâncias que observamos nos espectros dos coloides estão ligadas as mudanças derivadas dos processos bioquímicos destas. Diante disso, os resultados aqui apresentados referentes aos colóides, podem contribuir em processos fisiológicos que ocorrem dentro das células.

Os outros espectros são uma combinação entre os dois padrões descritos nos parágrafos anteriores. Acreditamos que esses outros apresentam diversos estágio do desenvolvimento do bócio. Portanto a técnica de microespectroscopia FTIR pode distinguir dentro de um corte histológico padrões bioquímicos relacionados a bócio, assim como a tecido normal.

Este resultado é muito importante para a literatura, pois quando se faz 0 exame de punção por agulha fina, muitas vezes, o material coletado apresenta pouca ou nenhuma célula dificultando a análise do patologista. Entretanto muitas vezes há uma considerável quantidade de colóide a qual pode ser analisado por FTIR conforme exposto neste trabalho.

\subsubsection{Comparação entre colóides normais e com bócio nodular}

Nos tecidos provenientes de pacientes com bócio foram encontrados padrões espectrais (semelhanças bioquímicas) de pacientes sadios. Desta forma, os números de onda que apresentam grandes valores de variância nos espectros provenientes de bócio aliados a uma pequena variância nos tecidos normais indicam diferenças entre os grupos sadios e com bócio. A Figura 43 
mostra a variância em função do número de onda dos espectros proveniente de 20 tecidos sadios e 20 tecidos com bócio nodular.

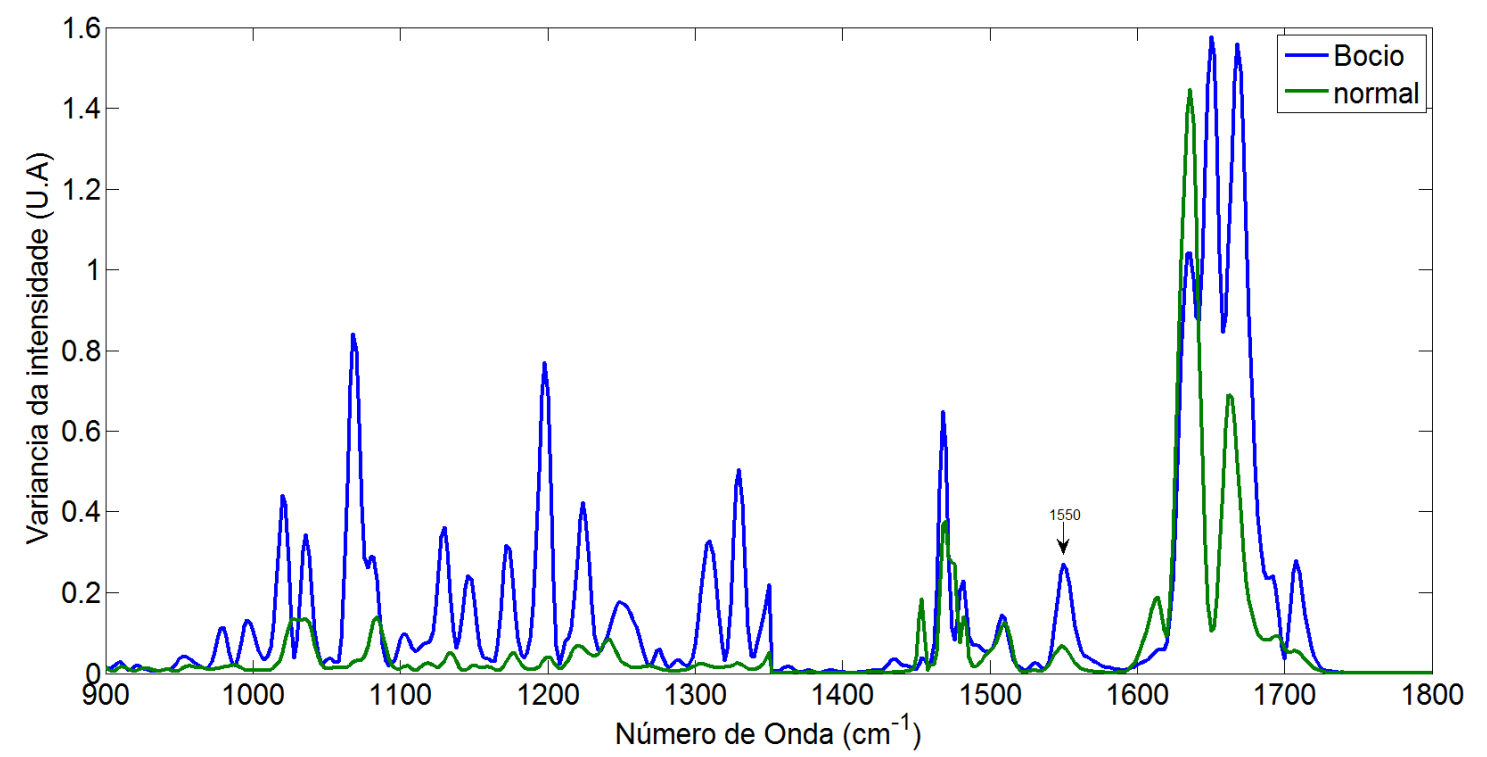

Figura 43: Variância em função do número de onda dos espectros provenientes de pacientes sadios e com bócio nodular.

Observa-se que há grandes valores da variância na região da amida I tanto para os tecidos sadios assim como para o bócio. Esse resultado era esperado, pois essa região está relacionada à conformação secundária e, no caso da tiroglobulina, ela apresenta grandes diferenças devidas ao processo de formação dos hormônios.

Na região da amida II $\left(1500 \mathrm{~cm}^{-1}\right.$ a $\left.1600 \mathrm{~cm}^{-1}\right)$ não se observam grandes valores de variância nos tecidos normais, somente nos tecidos com bócio. 0 valor máximo de variância para essa região está em $1550 \mathrm{~cm}^{-1[24]}$. Este pico em esta relacionado a um modo vibracional do grupo amina que consequentemente pode estar ligado a glicosilaçao do tipo $\mathrm{N}$.

$\mathrm{Na}$ região de carboidratos (1000 a $1100 \mathrm{~cm}^{-1}$ ) e amida III (1200 $1400 \mathrm{~cm}^{-1}$ ) observa-se que somente os dados de bócio apresentam grandes valores de variância. Esse fato pode estar ligado a diferenças de glicosilação que se observa somente nos dados provenientes de tecidos diagnosticados com bócio nodular. 
A Figura 44 mostra um gráfico de PC1 Por PC2 construído a partir de 4 mil espectros normais e 4 mil espectros com bócio nodular.

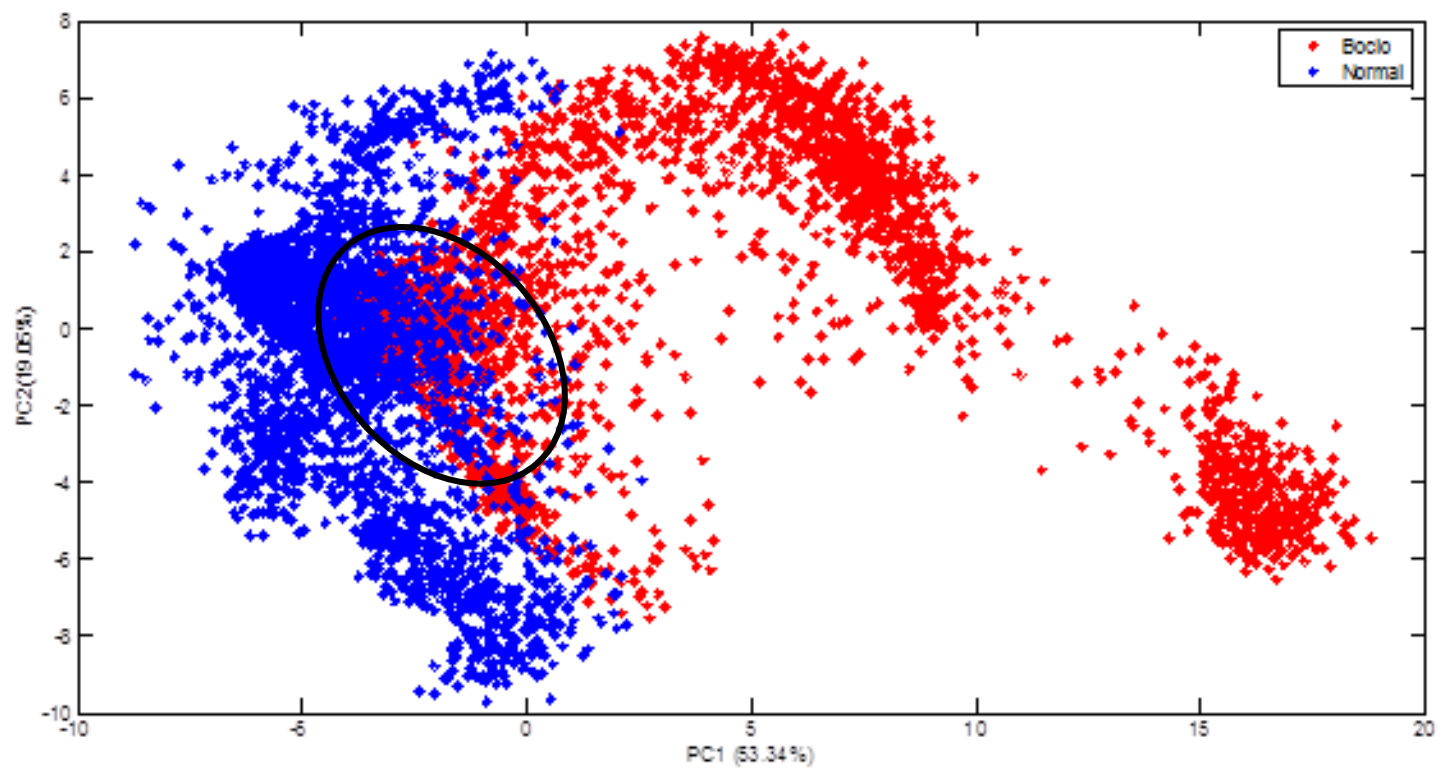

Figura 44: PC1 por PC2 construído por análise de PCA a partir de 4 mil espectros de pacientes normais e 4 mil espectros de pacientes com bócio nodular.

Na Figura 44 observa-se que a análise de PCA não consegue distinguir completamente os espectros provenientes de tecidos sadios dos provenientes de bócio nodular apesar das grandes diferenças bioquímicas observadas nos espectros. Isso acontece devido a duas razões:

1. As variáveis PC1 e PC2 só correspondem a 72,39\% da variância total dos espectros, portanto não está apresentando totalmente a informação.

2. Foram observados padrões espectrais (bioquímicos) dentro dos dados de bócio semelhantes aos de tecidos normais. Isso ocorre, pois os colóides são reservatórios de hormônios dentro da tireóide podendo ficar armazenados até 3 meses na glândula. Portanto o paciente pode ter colóides produzidos num momento fisiológico considerado normal e mesmo assim apresentar um quadro patogênico.

O gráfico construído em 3 dimensões de PC1, PC2 e PC3 (não mostrados aqui) que continham mais de $82 \%$ da variância total não apresentou uma distinção completa entre tecido sadio e com bócio. Então a região na qual 
ocorre a intersecção (área circulada na Figura 44) entre tecido com bócio e normal se deve a explicação 2

Todos os resultados apresentados neste estudo são importantes para 0 desenvolvimento e implementação de futuros métodos de diagnósticos em tireoide baseados em microespectroscopia FTIR e análise estatística supervisionada . Isso porque a princip al forma de diagnóstico dos patologistas é baseada em avaliar a morfologia das células encontradas no aspirado dos tecidos. Contudo, numa considerável parte desses aspirados, devido à morfologia da glândula e sua localização, eles possuem pequenas quantidades de células tornando difícil um diagnóstico patológico. Enquanto que outros desses aspirados possuem quantidades de coloide suficiente para fornecer informações por meio da técnica de microespectroscopia FTIR para o diagnóstico das enfermidades. 


\section{TRABALHOS FUTUROS.}

A partir dos resultados aqui explanados se torna necessário como trabalhos futuros:

- Análise de tecidos com padrões foliculares por microespectroscopia FTIR.

- Método comparativo para determinar a quantidade de iodo ligado a tiroglobulina.

- Analise supervisionada com o objetivo de classificar tecidos com padrões foliculares, Bocio e normais. 


\section{CONCLUSÃO}

\section{A partir do presente trabalho foi possível :}

- Desenvolver uma metodologia de processamento de mapas espectrais utilizando tecidos tireoidianos. A região entre $900-1350 \mathrm{~cm}^{-1}$ foi a que gerou melhores resultados.

- Obter espectros dos hormônios tireoidianos e de seus precursores. Observou-se em $1458 \mathrm{~cm}^{-1}$ um modo vibracional referente aos hormônios nos tecidos tireoidianos. Nas medidas dos precursores se observaram diversas bandas intensas, mas somente se identificou a banda de $1468 \mathrm{~cm}^{-1}$ nos tecidos tireoidianos.

- Observar os padrões bioquímicos encontrados nos tecidos normais e bócio. Dentre as diferenças entre estes dois grupos, a principal está na região da amida I e banda $1468 \mathrm{~cm}^{-1}$ que está relacionada com quantidade de iodo ligado à tiroglobulina.

- Observar mudanças na região da amida I a qual está relacionada com conformação secundária da tiroglobulina. Essas mudanças estão relacionadas ao processo de iodinização da molécula.

- Constatar que diferenças na glicosilação da tiroglobulina geram diferenças na estrutura da proteína que podem ser observadas principalmente na região da amida III, e que formas com pouca glicosilação podem indicar a incapacidade de fazer a hormonogênese.

- Mostrar o potencial da utilização de métodos supervisionados (SVMSupport vector machine) para desenvolvimento de métodos de diagnóstico automatizado usando micro FTIR. 


\section{APÊNDICE - DESENVOLVIMENTO MATEMATICO DA ANÁLISE DE COMPONENTES PRINCIPAIS}

Suponha que temos uma matriz com $n$ colunas e $P$ linha. Cada linha representa um vetor contendo um espectro e cada coluna é um número de onda. Assim temos a matriz $\mathrm{nXp}$ denada por:

$$
X_{n x p}=\left(\begin{array}{ccc}
X_{11} & \cdots & X_{p 1} \\
\vdots & \ddots & \vdots \\
X_{1 n} & \cdots & X_{p n}
\end{array}\right)
$$

O vetor de médias $(\mu)$ de cada número de onda é definido como:

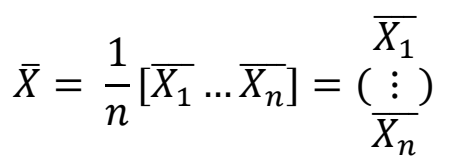

Onde $X_{i}$ é média amostral de inésimo número de onda do vetor $X$.

A matriz de covariância $\sum$ pxp é definida da seguinte forma:

$$
S_{p x p}=\left(\begin{array}{ccc}
S_{11} & \cdots & S_{1 p} \\
\vdots & \ddots & \vdots \\
S_{p 1} & \cdots & S_{p p}
\end{array}\right)
$$

Onde $S_{i j}$ é definido da seguinte forma:

$$
S_{i j}=\frac{\sum_{l=1}^{n}\left(X_{i l-}-\bar{X}_{l}\right)\left(X_{i j-}-\bar{X}_{J}\right)}{n-1}
$$

$S_{i j}$ é covariância entre dois vetores (espectros) da matriz X. A matriz de covariância é uma matriz simétrica pois $S_{n p}=S_{p n} \forall n \neq p$ sendo a diagonal principal a variância da variável $p$. Os autovalores desta matriz $\left(\lambda_{1}, \lambda_{2}, \ldots, \lambda_{p}\right)$ são não negativos. Para essa matriz $S_{p x p}$ existe uma matriz ortogonal $\left(\mathrm{O}_{\mathrm{pxp}}\right)$, isto é, $O^{\prime} O=O O=I_{p x p}$ tal que:

$$
O^{\prime} \Sigma O=\begin{array}{ccc}
\lambda_{1} & 0 & 0 \\
0 & \lambda_{2} & 0 \\
0 & 0 & \lambda_{p}
\end{array}=\Lambda
$$


Onde $\lambda_{1} \geq \lambda_{2} \geq \cdots \geq \lambda_{p}$ são os autovalores ordenados em ordem decrescente da matriz $\sum_{p x p}$ que é similar à matriz $\Lambda_{p x p}$, o que implica em dizer que:

(i) $\operatorname{det}\left(\Sigma_{p x p}\right)=\left|\Sigma_{p x p}\right|=\left|\Lambda_{p x p}\right|=\prod_{i=1}^{p} \lambda_{i}$

(ii) $\operatorname{traço}\left(\Sigma_{p x p}\right)=\operatorname{traço}\left|\Lambda_{p x p}\right|=\lambda_{1}, \lambda_{2}, \ldots, \lambda_{p}$

A i-ésima coluna da matriz $O_{p x p}$ é o autovalor normalizado $e_{i}$ correspondente ao autovalor $\lambda_{\mathrm{i}}$, que e dado por:

$$
e_{i}=\left[\begin{array}{c}
e_{1} \\
\vdots \\
e_{i p}
\end{array}\right]
$$

Então, a matriz $O$ é dada por $O=\left[e_{1} \ldots e_{p}\right]$ e pelo teorema da decomposiçao espectral tem-se a seguinte igualdade válida:

$$
\Sigma_{\text {pxp }}=0 \Lambda 0^{\prime}=\sum_{\mathrm{i}=1}^{\mathrm{p}} \lambda_{\mathrm{i}} \mathrm{e}_{\mathrm{i}} \mathrm{e}_{\mathrm{i}}{ }^{\prime}
$$

Sendo $e_{i}$ um vetor de norma igual a 1 , isto é:

$$
\left\|e_{i}\right\|=\left(e_{i 1}^{2}+e_{i 2}^{2}+\cdots+e_{i p}^{2}\right)^{\frac{1}{2}}=1
$$

Assim, temos então um vetor aleatório $X=\left(X_{1}, X_{2}, \ldots, X_{p}\right)^{\prime}$ com o vetor de médias $\mu=\left(\mu_{1}, \mu_{2}, \ldots, \mu_{p}\right)^{\prime}$ e a matriz de covariância $\Sigma_{\text {pxp }}$. Sejam $\lambda$ os autovalores dessa matriz, com os repectivos autovalores normalizados $e_{1}, e_{2}, \ldots e_{p}$ isto é, os autovalores $e_{i}$ satisfazem as seguintes condições:

(i) $e_{i} e_{j}=0$ para todo $i \neq j$;

(ii) $e_{i} e_{j}=1$ para todo $i=1,2, \ldots, p$

(iii) $\Sigma_{\text {pxp }} \mathrm{e}_{\mathrm{i}}=\lambda_{\mathrm{i}} \mathrm{e}_{\mathrm{i}}$ para todo $i=1,2, \ldots, p$

sendo 0 autovetor $e_{i}$ denotado por $e_{i}=\left(e_{i 1}, e_{i 2}, \ldots, e_{i p}\right)$. Considere um vetor aleatório $Y=O^{\prime} X$, onde $\mathrm{O}_{\mathrm{pxp}}$ é a matriz ortogonal definida anteriormente e constituída dos autovalores normalizados da matriz de covariância, ou seja: 


$$
O_{p x p}=\left(\begin{array}{ccc}
e_{11} & \cdots & e_{p 1} \\
\vdots & \ddots & \vdots \\
e_{1 p} & \cdots & e_{p p}
\end{array}\right)=\left[e_{1} \ldots e_{p}\right]
$$

O vetor $Y$ é composto por $p$ combinações lineares das variáveis aleatórias do vetor $\mathrm{X}$, tem vetor média igual a $O^{\prime} \mu$ e matriz de covariância $\Lambda_{p x p}$ que é uma matriz diagnonal como a XX. Desse modo surge a ideia de utilizar as combinações lineares em $\mathrm{Y}$, como forma alternativa de se representar a estrutura de covariâncias do vetor $X$, tentando obter uma redução do espaço de variáveis, passando da diminuição $P$ para uma dimensão $K$ onde $K<P$. Assim, ao invés de utilizar o vetor aleatório original na análise de dados, utilizam-se as $\mathrm{k}$ combinações lineares principais. Os vetores $\mathrm{X}$ e $\mathrm{Y}$ têm a mesma variância total, sendo que a j-ésima componente principal da matriz $\Sigma_{\mathrm{pxp}}, j=1,2, \ldots, p$ é definida como:

$$
Y_{j}=e_{j}^{\prime} X=e_{j 1} X_{1}+e_{j 2} X_{2}+\ldots+e_{j p} X_{p}
$$

A primeira componente principal será sempre a mais representativa em termos de variância total e a p-ésima é sempre a de maior representatividade. A figura $X X$ ilustra as componentes principais no caso de duas variáveis. Cada ponto do sistema X1 e X2 é projetado em um novo sistema de coordenadas Y1 e Y2.

$\mathrm{Na}$ prática, a matriz de covariância é desconhecida e precisa ser estimada através dos dados amostrais coletados. Em geral, é estimada pela matriz de covariância amostral. Algumas propriedades das componentes principais são apresentadas a seguir:

(i) A variância estimada de $\mathrm{Y}_{\mathrm{j}}$ é igual $\lambda_{\mathrm{j}}, j=1,2, \ldots, p$;

(ii) a variância total explicada pela j-ésima componente amostral é dada por:

$$
\frac{\operatorname{Var}\left[\widehat{Y}_{J}\right]}{\text { Var total estimada de } X}=\frac{\widehat{\lambda}_{l}}{\sum_{i=1}^{p} \widehat{\lambda_{1}}}
$$




\section{REFERÊNCIAS:}

1. D. Kirsten, "The thyroid gland: physiology and pathophysiology," Neonatal network : NN 19, (2000).

2. A. C. G. a. J. E. Hall, Textbook of medical physiology (Elsevier Saunders,, Philadelphia, 2006).

3. D. G. Gardner, D. M. Shoback, and F. S. Greenspan, Greenspan's basic \& clinical endocrinology, 9th ed., Lange medical book (McGraw-Hill Medical, New York, 2011), pp. xii, 880 p.

4. C. S. B. Teixeira, R. A. Bitar, H. S. Martinho, A. B. O. Santos, M. A. V. Kulcsar, C. U. M. Friguglietti, R. B. da Costa, E. A. L. Arisawa, and A. A. Martin, "Thyroid tissue analysis through Raman spectroscopy," Analyst 134, (2009).

5. V. K. R. S. Cotran, T. Collins and S. L. Robbins,, pathologic basis of disease (Saunders, philadelphia, 1999).

6. $\quad$ L. C. U. Junqueira, J. Carneiro, and A. N. Contopoulos, "Basic histology," in A Concise medical library for practitioner and student, (Lange Medical Publications, Los Altos, Calif., 1975), p. v.

7. M. L. Matsuo S, LEONI, S.G,HAJJAR, D, RECARTE-FILHO, J.C.; EBINA K.N, KIMURA E.T. , "marcadores biologicos de tumores tiroidianos," arq. Bras. Endocrinol. Metab 48, 10 (2004).

8. P. Rout and S. Shariff, "Diagnostic value of qualitative and quantitative variables in thyroid lesions," Cytopathology 10, 171-179 (1999).

9. Y. Mizukami, T. Michigishi, A. Nonomura, M. Noguchi, and H. Nakamura, "Thyroid carcinoma: clinical, pathologic correlations," Crit Rev Oncol Hematol 18, 67-102 (1995).

10. A. F. Garcia-Flores, L. Raniero, R. A. Canevari, K. J. Jalkanen, R. A. Bitar, H. S. Martinho, and A. A. Martin, "High-wavenumber FT-Raman spectroscopy for in vivo and ex vivo measurements of breast cancer," Theoretical Chemistry Accounts 130, 1231-1238 (2011).

11. L. B. Mostaco-Guidolin, L. S. Murakami, M. R. Batistuti, A. Nomizo, and L. Bachmann, "Molecular and chemical characterization by Fourier transform infrared spectroscopy of human breast cancer cells with estrogen receptor expressed and not expressed," Spectroscopy-an International Journal 24, 501-510 (2010).

12. B. Bird, M. Romeo, N. Laver, and M. Diem, "Spectral detection of micrometastases in lymph node histo-pathology," Journal of Biophotonics 2, 37-46 (2009).

13. B. Bird, M. S. Miljkovic, S. Remiszewski, A. Akalin, M. Kon, and M. Diem, "Infrared spectral histopathology (SHP): a novel diagnostic tool for the accurate classification of lung cancer," Laboratory investigation; a journal of technical methods and pathology 92, (2012).

14. T. Pereira, M. Dagli, G. Mennecier, and D. Zezell, "Influence of Fixation Products Used in the Histological Processing in the FTIR Spectra of Lung Cells," Spectroscopy-an International Journal 27, 399-402 (2012).

15. P. Lasch, M. Diem, W. Hansch, and D. Naumann, "Artificial neural networks as supervised techniques for FT-IR microspectroscopic imaging," J Chemometr 20, 209-220 (2006). 
16. P. Lasch, W. Haensch, D. Naumann, and M. Diem, "Imaging of colorectal adenocarcinoma using FT-IR microspectroscopy and cluster analysis," Bba-Mol Basis Dis 1688, 176-186 (2004).

17. P. Lasch, M. Diem, and D. Naumann, "FT-IR microspectroscopic imaging of prostate tissue sections," $P$ Soc Photo-Opt Ins 5321, 1-9 (2004).

18. M. Diem, M. Miljkovic, B. Bird, T. Chernenko, J. Schubert, E. Marcsisin, A. Mazur, E. Kingston, E. Zuser, K. Papamarkakis, and N. Laver, "Applications of Infrared and Raman Microspectroscopy of Cells and Tissue in Medical Diagnostics: Present Status and Future Promises," Spectroscopy-an International Journal 27, (2012).

19. D. L. Pavia, G. M. Lampman, and G. S. Kriz, Introduction to spectroscopy : a guide for students of organic chemistry, 3rd ed. (Harcourt College Publishers, Fort Worth, 2001), pp. xiv, 579, 515, 547, $578 \mathrm{p.}$

20. W. O. George, P. S. Mclntyre, D. J. Mowthorpe, and ACOL (Project), Infrared spectroscopy, Analytical Chemistry by Open Learning (Published on behalf of ACOL, London, by Wiley, Chichester [West Sussex] ; New York, 1987), pp. xx, 537 p.

21. L. B. Mostaço-guidolin, "caracterizaçao Bioquimica de celulas sadias e neoplasicas atraves de espectroscopia vibracional.," (Universidade de São Paulo., Ribeirao Preto, 2009).

22. M. R. Bastistuti, "Classificação de fungos através da espectroscopia no infravermelho por transformada de Fourier.," (Universidade de São Paulo, Ribeirão Preto, 2012).

23. Z. Movasaghi, S. Rehman, and I. U. Rehman, "Fourier transform infrared (FTIR) spectroscopy of biological tissues," Applied Spectroscopy Reviews 43, 134-179 (2008).

24. H. N. Holman, M. C. Martin, E. A. Blakely, K. Bjornstad, and W. R. McKinney, "IR spectroscopic characteristics of cell cycle and cell death probed by synchrotron radiation based fourier transform IR spectromicroscopy," Biopolymers 57, 329-335 (2000).

25. D. M. Z. Thiago M Pereira, Benjamin Bird, Milos Miljković and Max Diem, "The characterization of normal thyroid tissue by micro-FTIR Spectroscopy," Analyst (2013).

26. M. Miljkovic, B. Bird, and M. Diem, "Line shape distortion effects in infrared spectroscopy," Analyst 137, (2012).

27. M. Born and E. Wolf, Principles of optics : electromagnetic theory of propagation, interference and diffraction of light, 7th expanded ed. (Cambridge University Press, Cambridge, U.K. ; New York ;, 1999), pp. xxxiii, $952 \mathrm{p}$.

28. M. Romeo and M. Diem, "Correction of dispersive line shape artifact observed in diffuse reflection infrared spectroscopy and absorption/reflection (transflection) infrared micro-spectroscopy," Vibrational Spectroscopy 38, 129-132 (2005).

29. P. Bassan, A. Kohler, H. Martens, J. Lee, H. J. Byrne, P. Dumas, E. Gazi, M. Brown, N. Clarke, and P. Gardner, "Resonant Mie Scattering (RMieS) correction of infrared spectra from highly scattering biological samples," Analyst 135, 268-277 (2010). 
30. P. Bassan, H. Byrne, F. Bonnier, J. Lee, P. Dumas, and P. Gardner, "Resonant Mie scattering in infrared spectroscopy of biological materials - understanding the 'dispersion artefact'," Analyst 134, 1586-1593 (2009).

31. P. Bassan, H. Byrne, J. Lee, F. Bonnier, C. Clarke, P. Dumas, E. Gazi, M. Brown, N. Clarke, and P. Gardner, "Reflection contributions to the dispersion artefact in FTIR spectra of single biological cells," Analyst 134, 1171-1175 (2009).

32. R. E. Roger, "A Faster Way to Compute the Noise-Adjusted Principal Components Transform Matrix," leee T Geosci Remote 32, 1194-1196 (1994).

33. P. Bassan, A. Kohler, H. Martens, J. Lee, E. Jackson, N. Lockyer, P. Dumas, M. Brown, N. Clarke, and P. Gardner, "RMieS-EMSC correction for infrared spectra of biological cells: Extension using full Mie theory and GPU computing," Journal of Biophotonics 3, 609-620 (2010).

34. S. Sharma, Applied multivariate techniques (J. Wiley, New York, 1996), pp. xviii, 493 p.

35. M. Diem, K. Papamarkakis, J. Schubert, B. Bird, M. J. Romeo, and M. Miljkovic, "The Infrared Spectral Signatures of Disease: Extracting the Distinguishing Spectral Features Between Normal and Diseased States," Applied Spectroscopy 63, 307a-318a (2009).

36. T. Raykov and G. A. Marcoulides, "An introduction to applied multivariate analysis," (Routledge, New York, 2008), pp. x, 485 p.

37. B. Bird, M. Miljkovic, M. J. Romeo, J. Smith, N. Stone, M. W. George, and M. Diem, "Infrared micro-spectral imaging: distinction of tissue types in axillary lymph node histology.," BMC Clin Pathol 8, 8 (2008).

38. A. I. Mazur, J. L. Monahan, M. Miljkovic, N. Laver, M. Diem, and B. Bird, "Vibrational spectroscopic changes of B-lymphocytes upon activation," Journal of Biophotonics 6, 101-109 (2013).

39. B. Bird, M. Miljkovic, S. Remiszewski, A. Akalin, M. Kon, and M. Diem, "Infrared spectral histopathology (SHP): a novel diagnostic tool for the accurate classification of lung cancer," Lab Invest 92, 1358-1373 (2012).

40. B. Bird, M. Miljkovic, N. Laver, and M. Diem, "Spectral Detection of Micro-Metastases and Individual Metastatic Cells in Lymph Node Histology," Technol Cancer Res T10, 135-144 (2011).

41. D. Naumann and M. Diem, "Modern biophotonic trends in microbiological and medical diagnostics," Journal of Biophotonics 3, 492-492 (2010).

42. E. A. d. R. Lunardelli, "Efeitos dos modelos experimentais de hipertireoidismo e hipotireoidismo sobre aspectos bioquimicos e compatamentais em ratos adultos," (Universidade Federal do Rio Grande do Sul, Porto Alegre, 2007).

43. K. Sorimachi and N. Ui, "Comparison of the iodoamino acid distribution in various preparations of hog thyroglobulin with different iodine content and subunit structure," Biochim Biophys Acta 342, 30-40 (1974).

44. M. Rolland, M. F. Montfort, L. Valenta, and S. Lissitzky, "lodoamino acid composition of the thyroglobulin of normal and diseased thyroid glands. Comparison with in vitro iodinated thyroglobulin," Clin Chim Acta 39, 95108 (1972).

45. V. Deshpande and S. G. Venkatesh, "Thyroglobulin, the prothyroid hormone: chemistry, synthesis and degradation," Biochimica Et 
Biophysica Acta-Protein Structure and Molecular Enzymology 1430, 157178 (1999).

46. N. Ui, "Neutral and Amino Sugar Composition of Thyroglobulin Comparison of Compositions of Different Fractions of Hog Thyroglobulin and of Thyroglobulins from Various Animal Species," J Biochem-Tokyo 74, 593-599 (1973).

47. T. Pereira, Diem M,Bird B, Miljkovic M,Zezell ZM, "(Submetido) The differences of thyroglobulin from normal and goiter patient using infrared spectral imaging.," Lab Invest (2013).

48. E. Ó. Faoláin, M. B. Hunter, J. M. Byrne, P. Kelehan, H. A. Lambkin, H. J. Byrne, and F. M. Lyng, "Raman spectroscopic evaluation of efficacy of current paraffin wax section dewaxing agents," Journal of Histochemistry \& Cytochemistry 53, 121-129 (2005).

49. P. Bassan, A. Sachdeva, J. Lee, and P. Gardner, "Substrate contributions in micro ATR of thin samples: Implications for analysis of cells, tissue and biological fluids," Analyst (2013).

50. NIST, "standard reference Data Program" (NIST, 2013), retrieved http://webbook.nist.gov/cgi/cbook.cgi?ID=C300390\&Mask=80.

51. R. M. S. Alvarez, R. N. Farias, and P. Hildebrandt, "Comparative vibrational analysis of thyronine hormones using infrared and Raman spectroscopy and density functional theory calculations," J Raman Spectrosc 35, 947-955 (2004).

52. B. Bird, K. Bedrossian, N. Laver, M. Miljkovic, M. J. Romeo, and M. Diem, "Detection of breast micro-metastases in axillary lymph nodes by infrared micro-spectral imaging," Analyst 134, 1067-1076 (2009).

53. P. Rout and S. Shariff, "Diagnostic value of qualitative and quantitative variables in thyroid lesions," Cytopathology 10, 171-179 (1999).

54. E. J. Marcsisin, C. M. Uttero, A. I. Mazur, M. Miljkovic, B. Bird, and M. Diem, "Noise Adjusted Principal Component reconstruction to optimize infrared microspectroscopy of individual live cells," Analyst 137, 29582964 (2012).

55. P. Lasch, M. Boese, A. Pacifico, and M. Diem, "FT-IR spectroscopic investigations of single cells on the subcellular level," Vibrational Spectroscopy 28, 147-157 (2002).

56. A. Barth, "Infrared spectroscopy of proteins," Biochimica Et Biophysica Acta-Bioenergetics 1767, 1073-1101 (2007).

57. R. Hienerwadel, A. Boussac, J. Breton, B. A. Diner, and C. Berthomieu, "Fourier transform infrared difference spectroscopy of photosystem II tyrosine D using site-directed mutagenesis and specific isotope labeling," Biochemistry 36, 14712-14723 (1997).

58. A. Barth, "The infrared absorption of amino acid side chains," Progress in Biophysics \& Molecular Biology 74, 141-173 (2000).

59. B. MALLET, P. LEJEUNE, N. BAUDRY, P. NICCOLI, P. CARAYON, and J. FRANC, "N-GLYCANS MODULATE IN-VIVO AND IN-VITRO THYROID-HORMONE SYNTHESIS - STUDY AT THE N-TERMINAL DOMAIN OF THYROGLOBULIN," Journal of Biological Chemistry 270, $29881-29888$ (1995).

60. A. B. Rawitch, H. G. Pollock, and S. X. Yang, "THYROGLOBULIN GLYCOSYLATION - LOCATION AND NATURE OF THE N-LINKED 
OLIGOSACCHARIDE UNITS IN BOVINE THYROGLOBULIN," Arch. Biochem. Biophys. 300, 271-279 (1993).

61. S. Boydston-White and M. Diem, "Infrared spectroscopic studies of Myeloid Leukemia (ML-1) cells at different phases of the cell cycle," Optical Diagnostics and Living Cells li, Proceedings Of 3604, 28-37 (1999).

62. P. Lasch, M. Boese, and M. Diem, "FT-IR spectroscopic imaging of tissue thin sections," Diagnostic Optical Spectroscopy in Biomedicine 2, 10-16 (2001).

63. B. R. Wood, L. Chiriboga, H. Yee, M. A. Quinn, D. McNaughton, and M. Diem, "Fourier transform infrared (FTIR) spectral mapping of the cervical transformation zone, and dysplastic squamous epithelium," Gynecol Oncol 93, 59-68 (2004).

64. S. Formisano, C. Moscatelli, R. Zarrilli, B. Diieso, R. Acquaviva, S. Obici, G. Palumbo, and R. Dilauro, "PREDICTION OF THE SECONDARY STRUCTURE OF THE CARBOXY-TERMINAL 3RD OF RAT THYROGLOBULIN," Biochemical and Biophysical Research Communications 133, 766-772 (1985).

65. C. M. Rivolta and H. M. Targovnik, "Molecular advances in thyroglobulin disorders," Clinica Chimica Acta 374, 8-24 (2006).

66. M. R. Oboodi, C. Alva, and M. Diem, "Solution-Phase Raman Studies of Alanyl Dipeptides and Various Isotopomers - a Reevaluation of the Amide-lii Vibrational Assignment," Journal of Physical Chemistry 88, 501 505 (1984).

67. S. Yoshida, M. Miyazaki, K. Sakai, M. Takeshita, S. Yuasa, A. Sato, T. Kobayashi, S. Watanabe, and H. Okuyama, "Fourier transform infrared spectroscopic analysis of rat brain microsomal membranes modified by dietary fatty acids: Possible correlation with altered learning behavior," Biospectroscopy 3, 281-290 (1997).

68. J.-D. Lin, "Thyroglobulin and human thyroid cancer," Clinica Chimica Acta 388, (2008).

69. A. L. Lehninger, D. L. Nelson, M. M. Cox, Louis B. Flexner Medical Book Fund., Alumni and Friends Memorial Book Fund., and Rosengarten Family Fund., Lehninger principles of biochemistry, 5th ed. (W.H. Freeman, New York, 2008), p. 1 v. (various pagings).

70. M. J. Spiro, "STUDIES ON PROTEIN PORTION OF THYROGLOBULIN - AMINO ACID COMPOSITIONS AND TERMINAL AMINO ACIDS OF SEVERAL THYROGLOBULINS," Journal of Biological Chemistry 245, 5820-\& (1970). 


\section{PRODUÇÃO CIENTÍFICA DURANTE O DOUTORADO}

\section{Publicações em periódicos Internacionais}

1. GOMES, M ; DEVITO-MORAES, A ; FRANCCI, C ; MORAES, R ; PEREIRA, T ; FROES-SALGADO, N ; YAMAZAKI, L ; SILVA, L ; ZEZELL, D . Temperature Increase at the Light Guide Tip of 15 Contemporary LED Units and Thermal Variation at the Pulpal Floor of Cavities: An Infrared Thermographic Analysis. Operative Dentistry, v. 38, p. 324-333, 2013.

2. Pereira, Thiago Martini ; ZEZELL, D M ; BIRD, BENJAMIN ; MILJKOVIC, MILOS ; DIEM, M. The characterization of normal thyroid tissue by micro-FTIR spectroscopy. Analyst (London. 1877. Print), v. 1, p. 1, 2013.

3. Pereira, Thiago Martini ; M.L.Z DAGLI ; MENNECIER G ; ZEZELL, D.M . Influence of Fixation Products Used in the Histological Processing in the FTIR Spectra of Lung Cells. Journal of Spectroscopy, v. 27, p. 399, 2012.

4. CORREA, P. R. ; PEREIRA, T ; VELOSO, M. N. ; ZEZELL,DM . Development of a communication interface to determinate the thermal diffusivity as a function of temperature by infrared thermography.. $\boldsymbol{Q I R T} \boldsymbol{J}$, v. 11, p. 1-7, 2012.

5. ZEZELL, D ; PEREIRA, TM; MENNECIER G ; BACHMANN L ; GOVONE A.B ; M.L.Z DAGLI . FTIR characterization of animal lung cells: normal and precancerous modified e10 cell line. Progress in Biomedical Optics and Imaging, v. 8427, p. 8427, 2012.

6. KABBACH, WILLIAM ; ZEZELL, D M ; M. C. BANDEA ; PEREIRA, T M ; ANDRADE, M. F. An in vitro Thermal Analysis during Different Lightn Activated Hydrogen Peroxide Bleaching. Laser Physics, v. 20, p. 1833-1837, 2010.

7. BENETTI, C ; Santos $m$; Pereira, Thiago Martini ; ZEZELL, D M . determination and optimization of ATR-FTIR parameters for bone tissue analysis. Revista Brasileira de Pesquisa e Desenvolvimento, v. 12, p. 41-45, 2010.

\section{Publicações em periódicos nacionais}

8. Santos $\mathrm{m}$; ZEZELL, D M ; Pereira, TM ; ALBERO F ; Freitas AZ ; Samad RE ; viera ND Jr ; Valerio M ; GOMES ASL . non-linear index refraction of hap solution using z-scan technique. Revista Brasileira de Pesquisa e Desenvolvimento, v. 12, p. 51-54, 2010.

9. PEREIRA, TM ; ZAMATARO CB ; ZEZELL, D M . thermal diffusivity measurement of enamel and dentin as a function of temperature obtained by 
infrared camera. Revista Brasileira de Pesquisa e Desenvolvimento, v. 12, p. 61-65, 2010.

\section{Capitulo de livros}

ZEZELL, D M ; ANA, P A ; PEREIRA, TM; CORREIA PR ; VELLOSO W JR . Heat Generation and Transfer on Biological Tissues Due to High-Intensity Laser Irradiation. In: arco Aurélio dos Santos Bernardes. (Org.). Developments in Heat Transfer. Rijeka: InTech - Open Access Publisher, 2011, v. 1, p. 227-246.

\section{Resumos em congressos.}

1.

PEREIRA, T ; ZEZELL, D M ; BIRD, B. ; MILJKOVIĆ ; DIEM, M. . The characterization of normal thyroids tissue by micro-FTIR. In: SPEC 2012 Shedding New Light on Disease, 2012, Chiang Mai. abstract, 2012. v. 1. p. 1-1.

2.

PEREIRA, T M; MENNECIER G ; M.L.Z DAGLI ; ZEZELL, D M . influence of fixation products used in the hostological processing in the FTIR Spectra of Lung cell. In: 14th European Conference of biological molecules, 2011, Coimbra. 14th european conference of biological molecules, 2011. v. 1. p. 1-1.

3.

ZEZELL, D M ; ANA, PA ; BENETTI, C ; QUINTO, J. ; Pereira, T M ; GOULART VP . FTIR SPECTROSCOPY MONITORING CHEMICAL CHANGES IN ENAMEL, DENTIN AND BONE DUE TO LASER IRRADIATION. In: 29th Annual Conference of the American-Society-for-Laser-Medicine and Surgery, 2010, Phoenix, AZ,. Lasers in Surgery and Medicine (Print). HOBOKEN, NJ: WILEY-LISS, 2010. p. 47-48.

4.

SANTOS M ; PEREIRA, TM ; ZEZELL, DM ; ALBERO F ; FREITAS AZ ; SAMAD RE ; VIERA ND JR ; GOMES ASL ; VALERIO M . Nonlinear index refraction of HAp solution using Z-scan technique,. In: XXXIII Encontro Nacional de Física da Matéria Condensada, 2010, aguas de lindoia. anais do XXXIII Encontro Nacional de Física da Matéria Condensada. São Paulo: Sociedade Brasileira de Fisica, 2010. v. 1. p. 3-4.

5.

BENETTI, C ; SANTOS M ; PEREIRA, T M ; ZEZELL, DM . Methodology development for ATR-FTIR bone analysis. In: XXXIII Encontro Nacional de Física da Matéria Condensada, 2010, aguas de lindoia. anais do XXXIII Encontro Nacional de Física da Matéria Condensada. São Paulo: Sociedade Brasileira de Fisica, 2010. v. 1. p. 1-1.

6. 
DE VITTO A G ; FRANCCI, C. ; M N GOMES ; PEREIRA, THIAGO MARTINI ; ZEZELL, D M . Thermal response of bovine dentin during LED irradiation.. In: encontro nacional da fisica da materia condensada, 2009, Águas de Lindoia. anais do congresso, 2009.

7.

L MARTINS ; BACHMANN L ; ALBERO F ; PEREIRA, TM ; ZEZELL, D $M$. Evaluation of thermal stability of human dental tissue using Fourier Transform Infrared Spec- troscopy. In: encontro nacional da materia condensada, 2009, Aguas de Lindoia. anais do congresso, 2009.

8.

RABELLO J.S. ; PEREIRA, TM ; MAZZOCCHI VL ; ZEZELL, DM . Dental enamel and synthetic hydroxyapatite heated and irradiated by laser of Er,Cr:YSGG : Characterization by FTIR and XRD.. In: encontro nacional da fisica da materia condensada, 2009, Aguas de Lindoia. anais do congresso, 2009. 


\section{PRINCIPAL ARTIGO PUBLICADO}




\title{
The characterization of normal thyroid tissue by micro-FTIR spectroscopy
}

\author{
Thiago M. Pereira, ${ }^{\text {ab }}$ Denise M. Zezell, ${ }^{* a}$ Benjamin Bird, ${ }^{\text {b }}$ Milos Miljkovićb \\ and Max Diem ${ }^{\mathrm{b}}$
}

In this paper, we report the spectral patterns of normal human thyroid tissue and methodology to interpret hyperspectral imaging data and protein conformational changes observed therein. Raw image datasets were imported into software written in-house in the MATLAB environment and processed to yield pseudo-color images of the tissue sections. All spectra were vector normalized, noise-filtered, and corrected for water-vapour contributions and scattering effects before being subjected to Hierarchical Cluster Analysis (HCA) and correlated with histological structures obtained from images of H\&E-stained parallel tissue sections. We successfully identified a protein structural heterogeneity that can be correlated with the spatially resolved amount of iodine in the thyroglobulin structure of colloids and follicular cells.

Received 9th February 2013 Accepted 14th July 2013

DOI: $10.1039 /$ c3an00296a

www.rsc.org/analyst two steps occur inside the follicular cells while the last two occur in the colloid.

Numerous studies ${ }^{7-10}$ have shown that spectral histopathology (SHP), ${ }^{\mathbf{9}, \mathbf{1 1}, \mathbf{1 2}}$ the combination of infrared spectral imaging, multivariate analysis and information from classical pathology, can detect, diagnose and analyze diseases based on the observation of compositional changes occurring in small tissues that accompany disease. ${ }^{13}$ SHP represents a different approach to the analysis of tissue and cells than classical histopathology that uses visible light and the human eye to detect morphological changes in the tissue. In the present paper, SHP is used to monitor complex biochemical processes in healthy thyroid tissue, rather than detecting or diagnosing disease.

There are several studies ${ }^{\mathbf{1 4 - 1 6}}$ using FTIR to classify and biochemically characterize thyroid tissue. However, these studies were focused primarily on the biochemical differences among normal and abnormal stages of disease. These studies were also not performed using micro-FTIR techniques and hence the accurate biochemical characterization of each thyroid specific cell type was not performed. The complete biochemical characterization of these thyroid tissue types is of great importance since it can reveal a clearer picture of aberrant sequences in early stage thyroid disease that cannot presently be observed by classical histopathology.

Healthy thyroid tissue is an ideal system to explore the biostructural capabilities of SHP. The biochemical processing steps from thyroglobulin to its iodinated state can be detected by SHP and interpreted in terms of known biochemical steps. This report presents a detailed insight into the structural sensitivity of SHP toward subtle conformational changes that occur within the colloids of normal thyroid tissue. 
The complex hormonal action can be disrupted if the gland itself is injured or affected by diseases such as neoplasia. ${ }^{2,17}$ As a consequence the equilibrium inside the thyroid follicle is altered. The gland can produce high amounts of hormone (hyperthyroidism) or low amounts of hormone (hypothyroidism). These abnormal aberrations in hormone production can lead to several serious health problems. Therefore, it is important to develop new methods to characterize the thyroid follicle in order to evaluate the normal and abnormal physiological process.

Fine needle aspiration (FNA) is one of the most common procedures for diagnosis of thyroid disorders. However, this method presents a high rate of false-negative diagnoses (up to $37 \%)^{2}$ and the differentiation among the common thyroid diseases is quite difficult. The low specificity of thyroid FNA can be inadequate positioning of the needle relative to the lesion, which is guided by palpation, or due to the fact that the aspirate may contain no diseased cells or insufficient amount of them, which does not allow a precise diagnosis. Nevertheless, any residual material of the FNA, such as colloids, contains valuable biochemical information of the thyroid condition ${ }^{\mathbf{1 8}}$ that can be analyzed by SHP and give more biochemical information for better diagnosis.

Thus, the characterization of normal thyroid tissue by microFTIR is important since it can report biochemical changes in follicular cells and follicle colloids that may occur before current histological and cytological methods can observe them. The report presented here concentrates on normal thyroid tissue and its biochemical composition.

\section{Materials and methods}

\section{Sample preparation}

The thyroid tissue microarray (TMA, BiomaxUS, TH804) used in this study contained 80 different patient tissue cores that measure $c a .1 .5 \mathrm{~mm}$ in diameter. The paraffin-embedded tissue sections were microtomed at $5 \mu \mathrm{m}$ thickness and mounted on slides by the supplier according to our request as described below. One section of each sample was mounted on a glass microscope slide and hematoxylin and eosin (H\&E) stained. Two sequential sections were mounted on infrared reflective substrates (Kevley Technologies, Chesterland, $\mathrm{OH}$ ).

The first H\&E stained section was used to localize the anatomical features, and to correlate HCA images that were constructed via FTIR analysis on the second unstained and deparaffinized section. The tissue section on the infrared reflective slide was de-paraffinized and dried before data acquisition. Although only imaging results from one tissue core are reported (Fig. 1), the spectral patterns to be discussed were observed for all normal thyroid tissue cores in the TMA.

\section{Data acquisition}

Infrared spectral hypercubes were acquired in transflection mode using an FTIR imaging system (Spectrum 1/Spotlight 400, Perkin Elmer, Shelton, CT) that incorporates a 16 element focal plane array (FPA) detector system. The size of each HgCdTe detector element is $25 \mu \mathrm{m} \times 25 \mu \mathrm{m}$, and the detector is cooled by liquid nitrogen. Infrared maps were acquired with an image magnification of 4 ; thus the pixel size covered by each detector was $6.25 \mu \mathrm{m} \times 6.25 \mu \mathrm{m}$. The images are collected by moving the sample through the focal point of the infrared microscope.

Infrared micro-spectral images were recorded in transflection (transmission/reflection) mode with a pixel size of $6.25 \mu \mathrm{m} \times 6.25 \mu \mathrm{m}$, a spectral resolution of $4 \mathrm{~cm}^{-1}$ and the coaddition of 2 interferograms before Norton-Beer apodization and Fourier transformation. An appropriate background spectrum was collected outside the sample area by the co-addition of 120 interferograms.

The entire instrument and microscope were purged with dry air to keep the relative humidity constant and below $5 \%$ to eliminate water vapor contributions to the FTIR spectra.

\section{Data processing and analysis}

After elimination of spectra collected from areas where no tissue exists or displays excess noise, the hyperspectral imaging data sets were composed of $c a .13000$ spectra, each containing 1625 spectral intensity values between 750 and $4000 \mathrm{~cm}^{-1}$. The datasets were imported into software written in-house in the MATLAB environment. Data pre-processing included the restriction of the wavenumber range between 778 and $1800 \mathrm{~cm}^{-1}$, imposition of selection criteria to avoid pixels not covered by tissue and/or those that displayed excessively strong scattering effects (Amide I peak position $<1620 \mathrm{~cm}^{-1}$ ). All spectra were vector normalized and converted to second derivatives using a Savitzky-Golay smoothing filter (11-point), vector normalised and phase corrected. ${ }^{19}$

Spectral datasets were subsequently converted to pseudocolor images using hierarchical cluster analysis (HCA), which clusters patterns in a dataset based on their spectral similarity. For this purpose the Euclidean distance was used to define the spectral similarity and Ward's algorithm was used for clustering. This process creates pseudo-color images that reproduce stained images very well. Further analysis of spectral data, pre-sorted by HCA, is used to discuss the biochemical characteristics of anatomical structures of normal thyroid tissue.

\section{Hormone measurement}

The FTIR spectra of triiodothyronine (T3) and thyroxine (T4) were acquired microscopically in order to identify the contribution of the thyroid hormones to the FTIR spectra in the colloids of normal thyroid patients. The hormones were obtained commercially from Sigma-Aldrich, and were dissolved in distilled water. A drop of solution was spotted onto low-e microscope slides and dried for 24 hours before measurement.

The FTIR measurements were collected in transflection mode using an FTIR imaging system (Spectrum 1/Spotlight 400, Perkin Elmer, Shelton, CT) using the $100 \mu \mathrm{m}$ diameter single element HgCdTe detector. The spectrum from each hormone was acquired using a $4 \mathrm{~cm}^{-1}$ spectral resolution, the co-addition of 1024 interferograms, an aperture of $100 \mu \mathrm{m} \times 100 \mu \mathrm{m}$, and between $700 \mathrm{~cm}^{-1}$ and $4000 \mathrm{~cm}^{-1}$. 


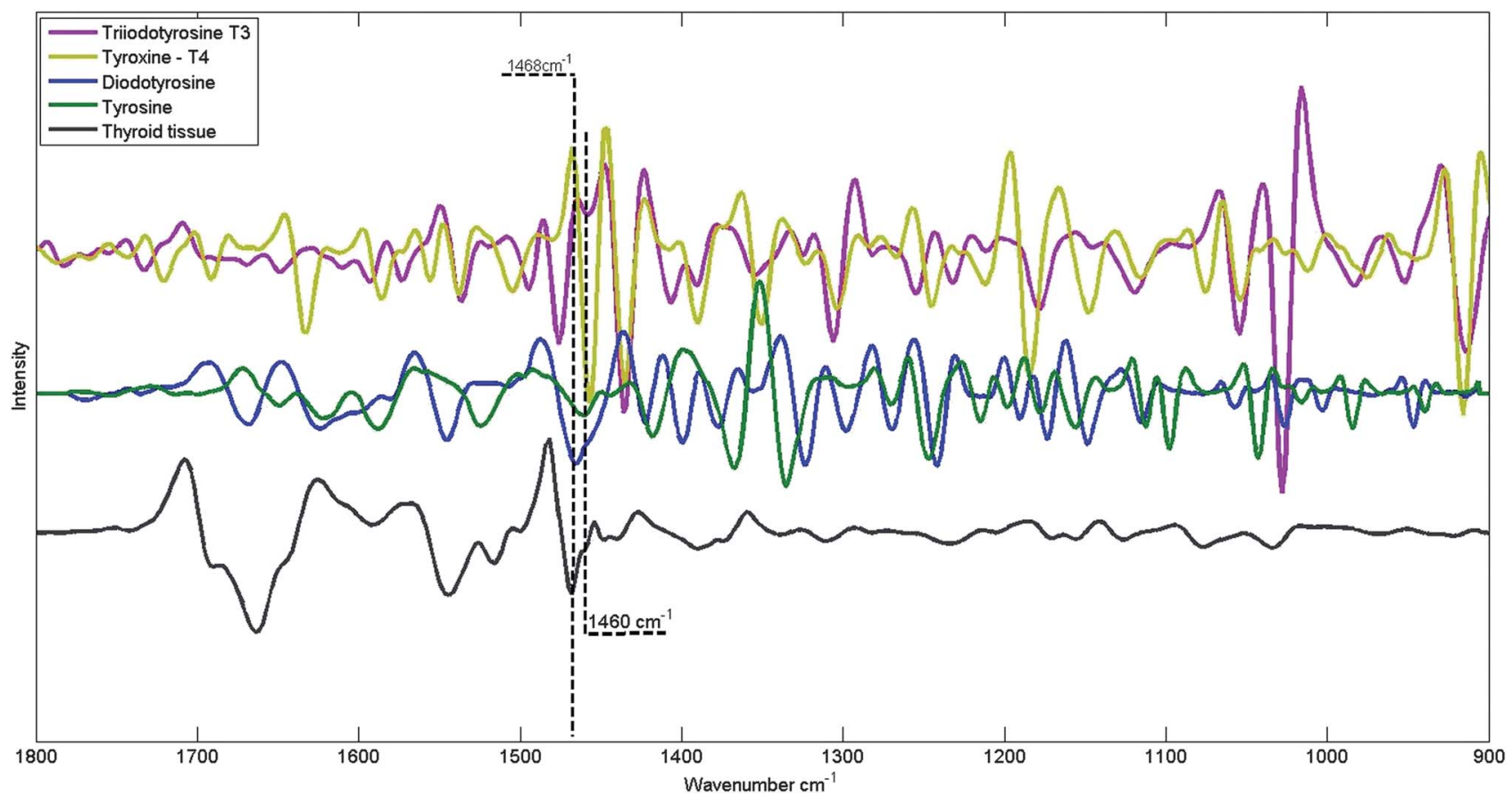

Fig. 1 Second derivative of FTIR spectra of hormones triiodothyronine (T3), thyroxine (T4), diiodotyrosine $\mathrm{e}^{20}\left(1468 \mathrm{~cm}^{-1}\right)$, tyrosine $\mathrm{e}^{20}$ and thyroid tissue.

\section{Results and discussion}

\section{Hormones and their precursors}

Fig. 1 shows the FTIR spectra of the hormones triiodothyronine (T3), thyroxine (T4), diiodotyrosine and healthy thyroid tissue in the second derivative format.

Fig. 1 shows the 2nd derivative FTIR spectra of the pure thyroid hormones T3 and T4. These spectra exhibit strong peaks at 916, 1630, 14601190,1476 , and $1458 \mathrm{~cm}^{-1}$ respectively. We conversely observe a strong peak at $1468 \mathrm{~cm}^{-1}$ for diiodotyrosine $^{20}$ (blue trace). A normal thyroid tissue spectrum is shown for direct comparison (gray trace). While there are several strong peaks related to thyroid hormones and diiodotyrosine in the spectral region $900-1800 \mathrm{~cm}^{-1}$, the most prominent correlation of the hormone and/or its precursors with the thyroid tissue spectrum is the peak located at $1468 \mathrm{~cm}^{-1}$ and its low wavenumber shoulder at $c a .1460 \mathrm{~cm}^{-1}$.

Fig. 2 shows the triiodothyronine (T3) and thyroxine (T4) molecules that are formed from two phenol groups.

An investigation ${ }^{21}$ that utilized density functional theory calculations for thyroid hormones concluded that the spectral band located at $1458 \mathrm{~cm}^{-1}$ can be directly correlated with an aromatic ring vibration when one iodine atom is attached to the $\beta$ phenol ring, and is only observed in the T3 hormone. The $\beta$ phenol moiety of the T3 molecule is also formed from monoiodotyrosine (MIT) and thus this vibration is also related to MIT.

We conclude that the peak at $1468 \mathrm{~cm}^{-1}$ observed in our results is related to the amount of diiodotyrosine (DIT) and the shape of this peak is quite similar to that of normal thyroid tissue. The shoulder $\left(1460 \mathrm{~cm}^{-1}\right)$ is related to MIT.

DIT and MIT are hormone precursors and are formed in the colloids when the phenol group ${ }^{1}$ of the tyrosine amino acid from the thyroglobulin molecule is iodinated at position 3 and/ or 5 of the aromatic ring. We believe we do not observe any distinct peaks associated with the thyroid hormone in tissue spectra since the amount of DIT and MIT is approximately 6 times larger than thyroid hormones in the phenol residual sites of thyroglobulin. ${ }^{22}$ We found the peak at $1468 \mathrm{~cm}^{-1}$ and a shoulder at $1460 \mathrm{~cm}^{-1}$ in all mean spectra from the normal thyroid tissue and they never shifted, but showed differences in their intensity profile.
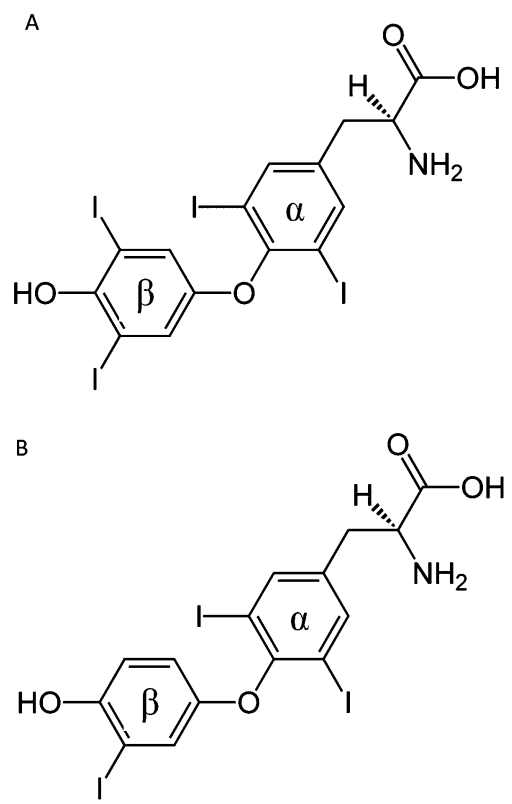

Fig. 2 Structure of the thyroid hormone triiodothyronine (T3) and thyroxine (T4). 
This peak $\left(1468 \mathrm{~cm}^{-1}\right)$ and its low wavenumber shoulder $\left(1460 \mathrm{~cm}^{-1}\right)$ show the amount of iodine linked to the thyroglobulin molecule. When consulting literature ${ }^{22-25}$ addressing quantitative iodine measurement in the thyroid, we observed that the investigation that was performed used elementary quantitative analysis and thus did not distinguish whether or not iodine is attached to the thyroglobulin molecule. To the best of our knowledge, our investigation is the first to report the semi-quantitative spatially resolved measurement of iodine content linked to thyroglobulin.

\section{Thyroid tissue}

Fig. 3 shows spectral images, constructed via HCA (Panels A and B), a univariate plot of the intensity at $1468 \mathrm{~cm}^{-1}$ (Panel C) and a visual image of the parallel stained tissue section (Panel D).

The nine-cluster image in Fig. 3A (cluster image constructed from the 900-1800 $\mathrm{cm}^{-1}$ spectral range) reveals the follicular cells as a red colored cluster, and the colloid represented by green, pink and cyan colored clusters. The chemical composition in the colloid areas of different colors is quite different, as will be discussed below. Most likely, the red cluster in Fig. 3A is not due to follicular cells only, but it seems that pixels of follicular cells and the innermost layer of the colloid are mixed. This observation is not attributed to scattering effects that are often observed for small, cellular structures, since the cells are embedded in the glycoproteins of the colloid, and thus are not exposed to large changes in refractive index that can give rise to these confounding effects. Rather, we believe that the width of the red areas reflects the similarity between the glycoprotein produced by the follicular cells and that stored in the innermost layers in the colloid.

As was found in earlier work on lymph node SHP, ${ }^{13}$ when selecting a specific spectral region without amide contribution, biochemical differences can be emphasized for three reasons.
First, the spectra were corrected for dispersive line shapes by a phase correction algorithm that has been demonstrated to remove scattering effects satisfactorily. ${ }^{26}$ Second, the observed heterogeneity of the protein spectra is enormous (see Fig. 4); thus, by cutting the spectral range to exclude most of the protein heterogeneity, only small differences between spectra of pure follicular cells are observed and thus the colloid directly surrounding them can be emphasized. Third, the follicular cells are embedded in the colloid and therefore, their refractive index is matched with their surroundings. Nevertheless, the follicular cells are best resolved in the $900-1358 \mathrm{~cm}^{-1}$ range but their position is not markedly different from that indicated by the entire spectral range.

Panel B of Fig. 3 depicts a nine-cluster image constructed from the $900-1350 \mathrm{~cm}^{-1}$ spectral range. This image shows a better definition of areas of follicular cells (in red), and also of the onion shell-like structure of some colloids. The colloid marked by the white arrow in Fig. 3B, for example, shows different layers in the visible as well as in the HCA images, but these differences are better defined in Panel 3B. This colloid, for example, is made up of 3 clusters while others are composed of one cluster only. At this point, we can interpret the different colloid spectral properties (see below), but do not have any explanation about the biological meaning of these differences.

Fig. 3C shows an intensity image constructed using the spectral band located at $1468 \mathrm{~cm}^{-1}$, since this peak can be directly associated with iodine in the thyroglobulin structure. Lighter grey areas of colloids represent lower content of iodinated thyroglobulin. Using this image we can further observe that the amount of iodine has a strong relationship with colloid clusters (grey, dark green and cyan). To the best of our knowledge, this is the first report in the literature that shows a microscopic image of the iodine content linked to thyroglobulin. This result is important since in many thyroid disorders,
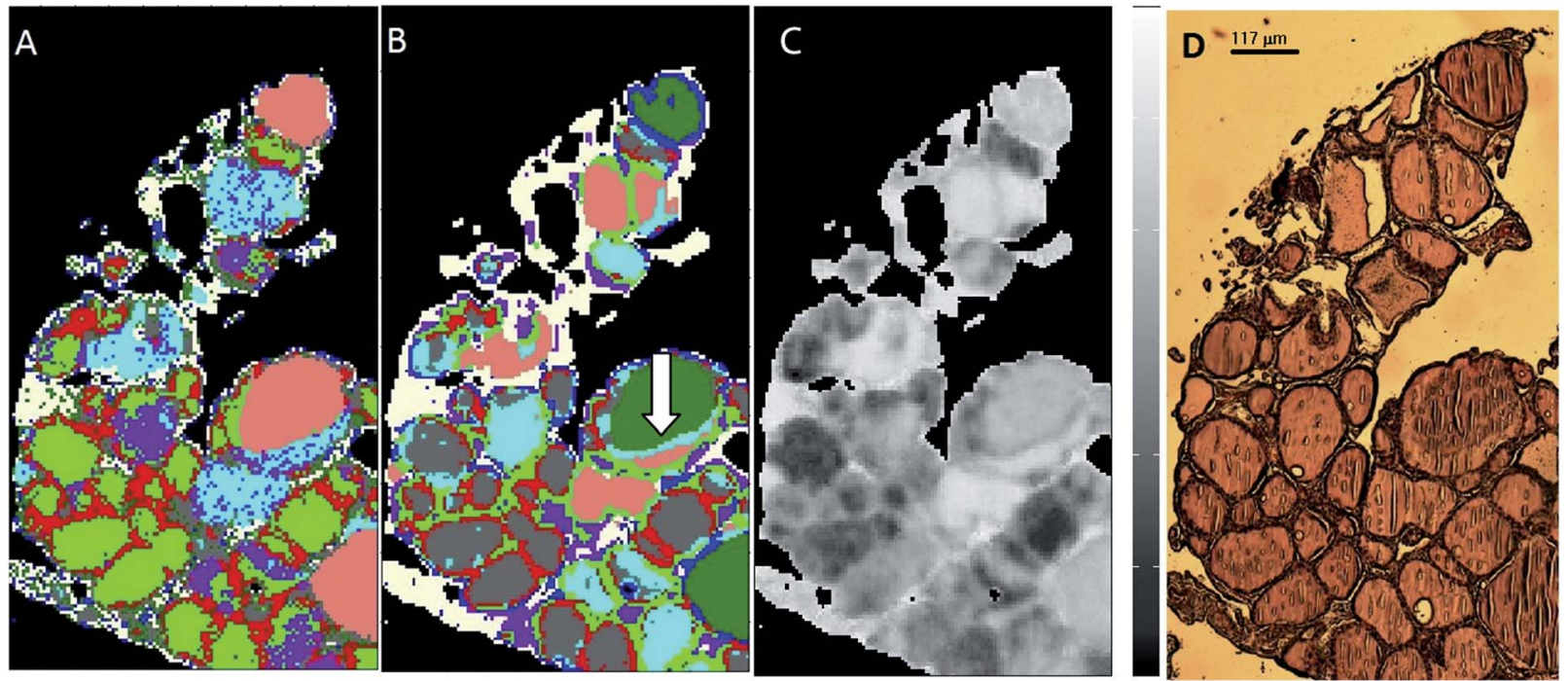

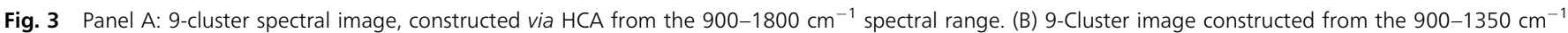

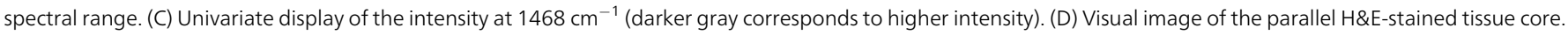




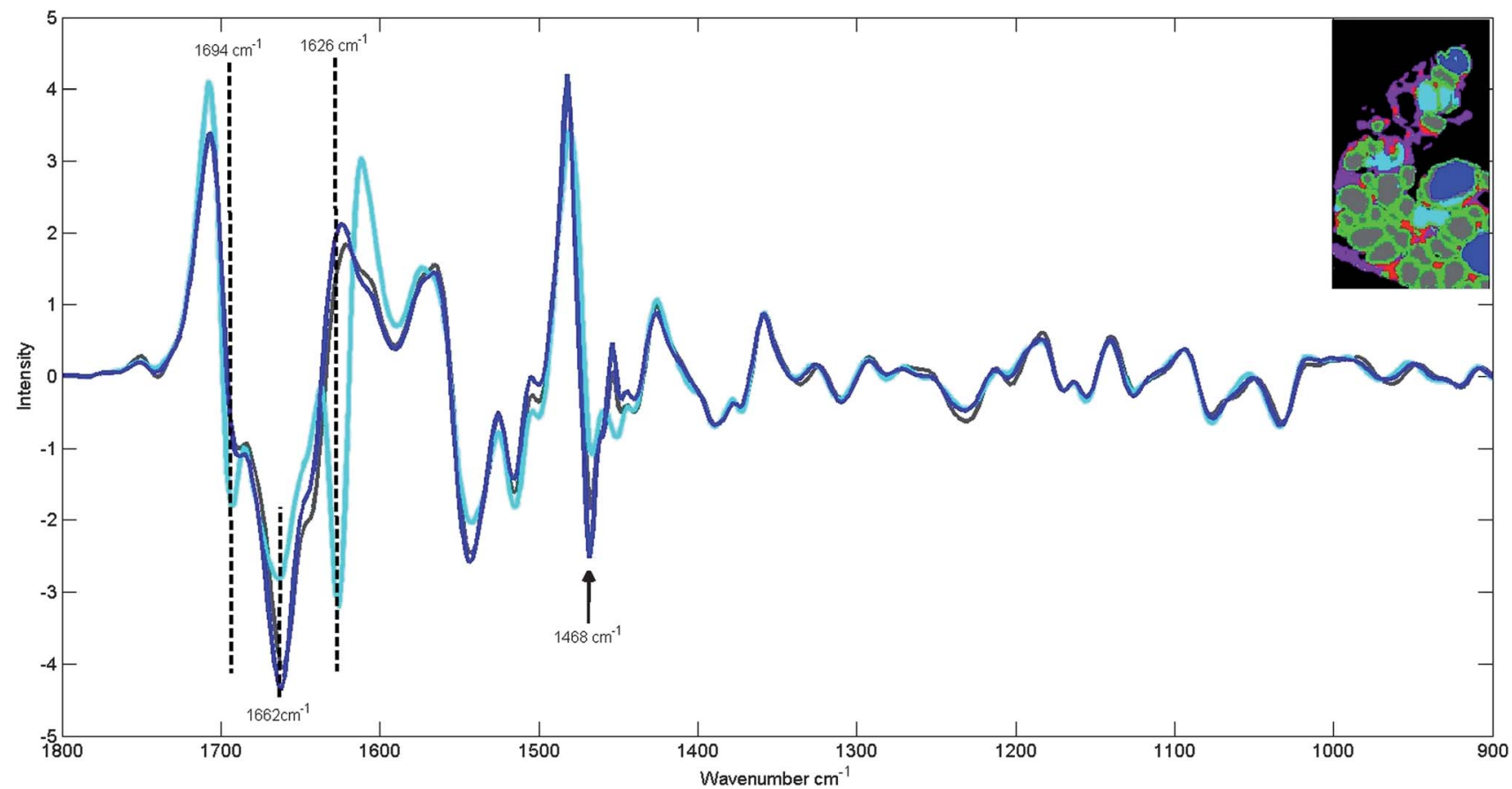

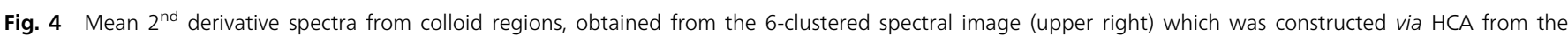
900-1350 $\mathrm{cm}^{-1}$ spectral range. Colors in the second derivative spectra correspond to the same color of the cluster at the upper right figure.

such as goiter, the amount of iodine plays a key role in the early development of these diseases.

We also observed very large protein heterogeneity in the colloids of the thyroid that came as quite a surprise at first, and requires a more detailed understanding of the biochemical processes and protein structural changes within the colloid. Furthermore, thyroid disorders such as goiter and papillary carcinoma occur in follicular cells, but also influence the properties of the thyroglobulin proteins. A detailed understanding of the protein spectral changes can shed light on the

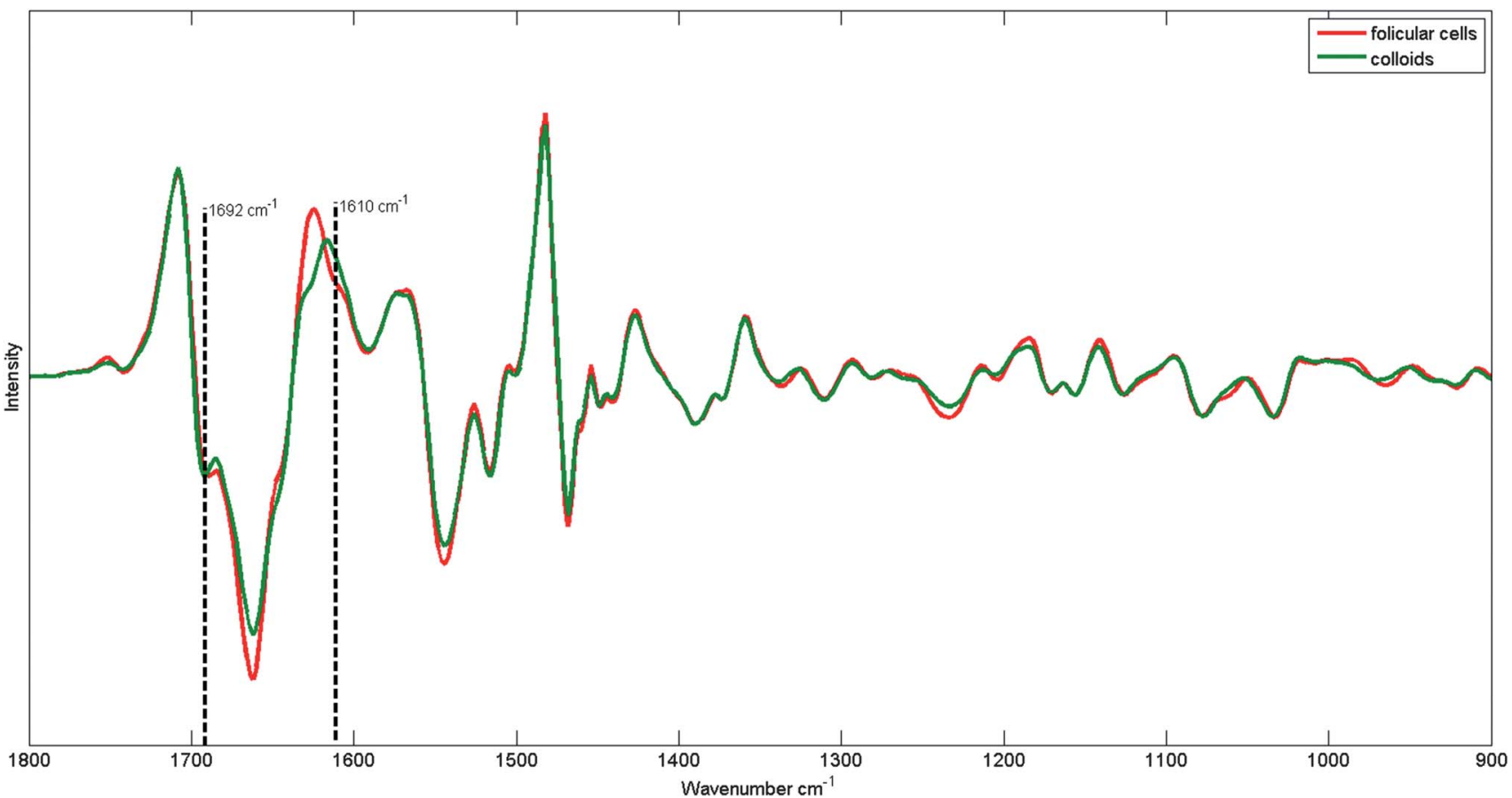

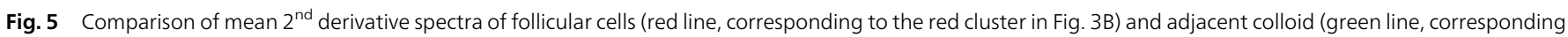
to the dark green, grey and cyan colloid clusters of Fig. 3B). 
physiological process inside the follicular cells because synthesis and glycosylation of thyroglobulin occur inside these cells.

Fig. 4 shows the $2^{\text {nd }}$ derivative mean cluster spectra of the colloid regions. The biggest differences between these spectra are found in the amide I region. The grey and dark blue (pink, dark green and white clusters in Fig. 3B) traces are mostly due to $\alpha$-helical proteins, while the cyan trace (grey and cyan clusters in Fig. 3B) in Fig. 4 exhibits typical $\beta$-sheet structure markers at $1694 \mathrm{~cm}^{-1}$ and $1628 \mathrm{~cm}^{-1}$. These spectral patterns suggest that the colloid proteins have two different conformations: $\alpha$-helix and $\beta$-sheet.

Inspection of the spectral traces in Fig. 4 reveals that spectral differences in the amide I region present direct relationship with the peak at $1468 \mathrm{~cm}^{-1}$. This fact is evidence for the iodization process, and possibly the linkage of the second aromatic ring to the $\beta$-tyrosine residue.

It has been shown ${ }^{27}$ that the thyroglobulin from humans has two distinct conformations: one is highly structured (high alpha-helix content), which contains the hormonogenic (iodine content) sites, while the other is less structured.

Thyroglobulin, which has tyrosine-rich proteins, is produced by follicular cells and is stored in the colloid. In the colloid, both positions one and/or two that are adjacent to the $\mathrm{OH}$ functional group in tyrosine are iodinated and form monoiodotyrosine (MIT) and diiodotyrosine (DIT) respectively. Subsequently, another iodinated tyrosine is linked to form triiodothyronine (MIT and DIT) or thyroxine (DIT and DIT). ${ }^{1}$ Thus, the iodinated thyroglobulin re-enters the follicular cells where the hormones $\mathrm{T} 3$ and $\mathrm{T} 4$ are split from the protein backbone.

We conclude that the cyan cluster in Fig. $3 \mathrm{~B}$ is due to the non-iodinated form of thyroglobulin shown in lighter gray in Panel 3C, which has a $\beta$-sheet conformation, while the grey and blue clusters in Fig. 3B are due to areas of high amounts of iodine, namely the iodinated form of thyroglobulin that has an $\alpha$-helical conformation. The spectral signatures of the other thyroid hormone, triiodothyronine T3 are not as evident in the spectra of the colloid, and we conclude that its concentration is less than that of T4.

We do observe small intensity differences and peak shifts in the amide III region (1200-1400 $\left.\mathrm{cm}^{-1}\right)$. This region is known to be sensitive to protein conformation as well, and particularly sensitive to the side chains and glycosylation ${ }^{28}$ of the peptide backbone. However, since the changes in amide III patterns are concomitant with those in the amide I region, we cannot conclude whether there are any changes in thyroglobulin glycosylation in the colloids of normal patients.

Finally, we compare in Fig. 5 the spectra of follicular cells with those of colloid regions in direct contact with these cells. The follicular cells (blue trace, Fig. 5) display spectra quite similar to those of other glandular cells, although they exhibit slightly more prominent $\beta$-sheet signatures $\left(1692 \mathrm{~cm}^{-1}\right)$. The collection of these spectra is quite difficult since these cells occur in a monolayer of cells $c a .10 \mu \mathrm{m}$ thick.

The green trace in Fig. 5 shows the mean spectra from all colloid regions in the dataset. When compared to the mean follicular cell spectrum they appear quite similar, including the shape of the amide I band. Therefore, the mean spectrum from follicular cells is heavily dominated by the contribution of thyroglobulin. In the spectra of the follicular cells, a shoulder at $1610 \mathrm{~cm}^{-1}$ is observed that is associated with the amino acid tyrosine. ${ }^{29}$ The amount of tyrosine in the follicular cells is high because the transcription of thyroglobulin requires a high amount of this amino acid. ${ }^{30}$

\section{Conclusions}

In this report, we present the spectral characterization of normal thyroid tissue as well as the FTIR spectra of thyroid hormones. The data processing methods applied in this paper enabled the acquisition and subsequent analysis of small follicular cells of thyroid tissue. This methodology will be applied in future studies in abnormal thyroid tissue. We show that SHP can be used to identify the amount of iodinated thyroglobulin present within the thyroid tissue.

\section{Acknowledgements}

Support of this work from CEPID/FAPESP 05/51689-2; Instituto Nacional de Fotônica/CNPq 573916/2008-0; CAPES/9036-11-3, CNPq 555621/2009-0 and $308277 / 2009-0$ is gratefully acknowledged.

\section{References}

1 A. C. G. a. J. E. Hall, Textbook of medical physiology, Elsevier Saunders, Philadelphia, 2006.

2 C. S. B. Teixeira, R. A. Bitar, H. S. Martinho, A. B. O. Santos, M. A. V. Kulcsar, C. U. M. Friguglietti, R. B. da Costa, E. A. L. Arisawa and A. A. Martin, Analyst, 2009, 134, 23612370 .

3 V. K. R. S. Cotran, T. Collins and S. L. Robbins, pathologic basis of disease, Saunders, philadelphia, 1999.

4 L. C. U. Junqueira, J. Carneiro and A. N. Contopoulos, in A Concise medical library for practitioner and student, Lange Medical Publications, Los Altos, Calif., 1975, p. v.

5 D. Kirsten, Neonatal Netw. J. Neonatal. Nurs., 2000, 19, 11-26. 6 C. Yarrington and E. N. Pearce, J. Thyroid Res., 2011, 2011, 934104.

7 B. Bird, M. Miljkovic, M. J. Romeo, J. Smith, N. Stone, M. W. George and M. Diem, BMC Clin. Pathol., 2008, 8, 8.

8 B. Bird, K. Bedrossian, N. Laver, M. Miljkovic, M. J. Romeo and M. Diem, Analyst, 2009, 134, 1067-1076.

9 J. M. Schubert, A. I. Mazur, B. Bird, M. Miljkovic and M. Diem, J. Biophotonics, 2010, 3, 588-596.

10 T. Pereira, M. Dagli, G. Mennecier and D. Zezell, Spectroscopy, 2012, 27, 399-402.

11 M. Diem, M. Miljkovic, B. Bird, T. Chernenko, J. Schubert, E. Marcsisin, A. Mazur, E. Kingston, E. Zuser, K. Papamarkakis and N. Laver, Spectroscopy, 2012, 27, 463-496.

12 S. Boydston-White, M. Romeo, T. Chernenko, A. Regina, M. Miljkovic and M. Diem, Biochim. Biophys. Acta, Biomembr., 2006, 1758, 908-914. 
13 B. Bird, M. Romeo, N. Laver and M. Diem, J. Biophotonics, 2009, 2, 37-46.

14 Y. Liu, Y. Xu, Y. Zhang, D. Wang, D. Xiu, Z. Xu, X. Zhou, J. Wu and X. Ling, Br. J. Surg., 2011, 98, 380-384.

15 X. Zhang, Y. Xu, Y. Zhang, L. Wang, C. Hou, X. Zhou, X. Ling and Z. Xu, J. Surg. Res., 2011, 171, 650-656.

16 Y. Q. Liu, Y. Z. Xu, Q. G. Sun, X. Q. Zhang, Z. Xu, Y. F. Zhang, J. G. Wu, X. S. Zhou and X. F. Ling, Zhonghua Zhongliu Zazhi, 2009, 31, 908-910.

17 C. S. B. Teixeira, R. A. Bitar, A. B. O. Santos, M. A. V. Kulcsar, C. U. M. Friguglietti, H. S. Martinho, R. B. da Costa and A. A. Martin, Evaluation of thyroid tissue by Raman spectroscopy, San Francisco, CA, 2010.

18 C. P. Schultz, K. Z. Liu, E. A. Salamon, K. T. Riese and H. H. Mantsch, J. Mol. Struct., 1999, 481, 369-377.

19 M. Miljkovic, B. Bird and M. Diem, Analyst, 2012, 137, 39543964.

20 NIST- Standard Reference Data Program, 3,5-Diiodo-Ltyrosine. http://webbook.nist.gov/cgi/cbook.cgi?ID=300-390, accessed on 10 July 2013.
21 R. M. S. Alvarez, R. N. Farias and P. Hildebrandt, J. Raman Spectrosc., 2004, 35, 947-955.

22 K. Sorimachi and N. Ui, Biochim. Biophys. Acta, 1974, 342, 3040.

23 J. Handl, W. Kuhn and R. D. Hesch, J. Endocrinol. Invest., 1984, 7, 97-101.

24 M. Hansson, G. Berg and M. Isaksson, X-Ray Spectrom., 2008, 37, 37-41.

25 M. Hansson, T. Grunditz, M. Isaksson, S. Jansson, J. Lausmaa, J. Molne and G. Berg, Thyroid, 2008, 18, 12151220.

26 B. Bird, M. S. Miljkovic, S. Remiszewski, A. Akalin, M. Kon and M. Diem, Lab. Invest., 2012, 92, 1358-1373.

27 S. Formisano, C. Moscatelli, R. Zarrilli, B. Diieso, R. Acquaviva, S. Obici, G. Palumbo and R. Dilauro, Biochem. Biophys. Res. Commun., 1985, 133, 766-772.

28 A. Barth, Biochim. Biophys. Acta, Bioenerg., 2007, 1767, 10731101.

29 A. Barth, Prog. Biophys. Mol. Biol., 2000, 74, 141-173.

30 D. Kirsten, Neonatal Netw. J. Neonatal. Nurs., 2000, 19, 11-26. 